\title{
LEVANTAMENTO E ANÁLISE FAUNISTICA DE INSETOS COLETADOS EM CULTURA DE CACAU NA REGIĀO DE ALTAMIRA - PARÁ
}

\author{
CARLOS RENATO LEAL BICELLI
}

Orientador: Prof.. Dr. SINVAL SILVEIRA NETO

\begin{abstract}
Dissertação apresentada à -Escola Superior de Agricultura "Luiz de Queiroz", da Universidade de São Paulo, para obtenção do título de Mestre em Ciências Biológicas, Área: de Concentração: Entomologia.
\end{abstract}

PIR A CICABA

Estado de São Paulo :- Brasil

Setembro - 1983 
i i .

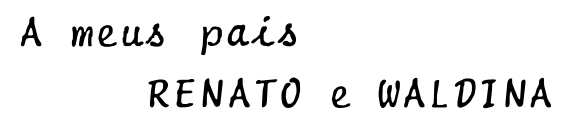

A meus pais

RENATO \& WALDINA
A minha tia WANDA
A minha esposa
I LSE
A meus filhos
RENATA, BRUNO \& BRENO

DEDICO. 
iij.

\section{AGRADECIMENTOS}

o Autor é sinceramente grato a todos que, direta ou indiretamente, colaboraram para a realização deste trabalho, especialmente:

A Comissão Executiva do Plano da Lavoura Cacaueira (CEPLAC), pela oportunidade de aperfeiçoamento concedida;

Ao Dr. Sinval Silveira Neto, Professor Titular do Departamento de Entomologia da Escola Superior de Agricultura "Luiz de Queiroz", USP, pela segura e valiosa orientação, amizade e estímulos recebidos;

Ao Corpo docente do Departamento de Entomologia, ESALQ/USP, na pessoa de seu chefe, Prof. Dr. Octávio Nakano, pela amizade e ensinamentos;

Aos Drs Ubirajara R. Martins, do Museu de Zoologia da USP; Sérgio Vanin, do Departamento de Zoologia da USP; Jocélia Grazia, do Departamento de Zoologia da UFRGS e José Cândido de Melo Carvalho, do Museu Nacional do Rio de Janeiro, pela colaboração prestada na identificação dos insetos;

Ao Amigo e colega Engo Agrọ Francisco Ivaldo Oliveira Melo, da EPACE e à Dra. Marinéria de Lara Haddad da EMBRAPA pela orientação e sugestões na anālise estatística.

Ao Dr. Evōneo Berti Filho, Professor Livre Docente do Departamento de Entomologia da. Escola Superior de Agricul tura "Luiz de Queiroz", USP, pela versão do resumo em inglès. 
Aos DrṢ João de Jesus da Silva Garcia, Antonio Carlos de Barros Mendes e Ruth Maria Cordeiro Scerne, pela colabo ração prestada no levantamento dos insetos e dados fenológicos;

Ao Amigo e colega Engọ Agrọ João Aurēlio Soares Viana, da EMATER-BA, pela revisão do texto.

Ao Pessoal da CEPLAC/Estação Experimental de Altamira pelo auxílio na coleta dos insetos.

A EMBRAPA/UEPAE/Altamira pelo fornecimento dos dados meteorológicos. 


\section{INDICE}

Pāgina

RESUMO

$x \vee \boldsymbol{j}$

SUMMARY

$x v i \mathrm{i}$

1. INTRODUÇAO $\ldots \ldots \ldots \ldots \ldots \ldots \ldots \ldots \ldots \ldots \ldots \ldots \ldots \ldots \ldots \ldots \ldots$

2. REVISATO DE LITERATURA $\ldots \ldots \ldots \ldots \ldots \ldots \ldots \ldots \ldots \ldots$

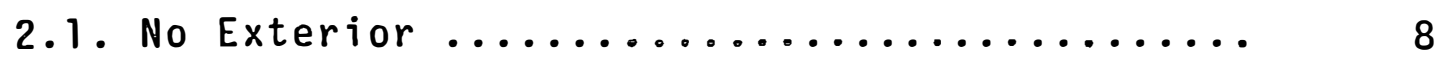

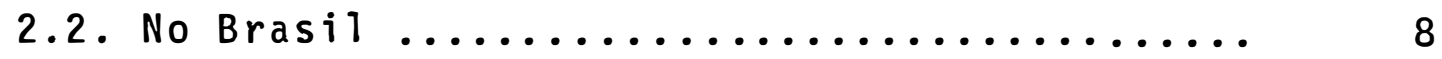

2.2.1. Na região Amazōnica ........... 8

2.2.2. Outras regiões ............... 11

3. MATERIAIS E METOdOS ....................... 14

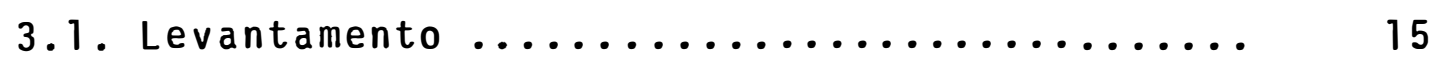

3.1.1. Amostragem ................................ 15

3.1.2. Identificação das espécies ........ 16

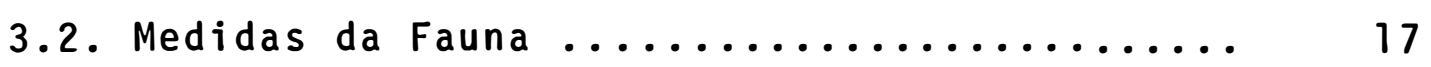

3.2.1. Frequência ................. 17

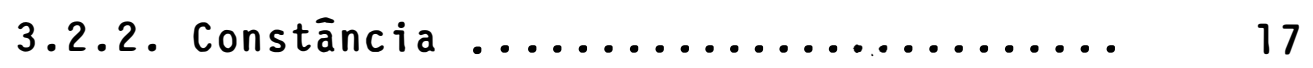

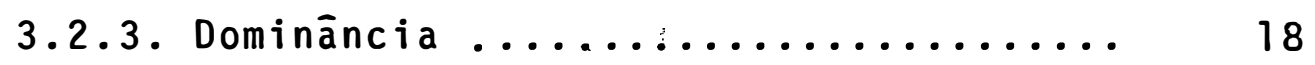

3.2.4. Abundāncia .................. 19

3.2.5. Indice de Diversidade ........... 20

3.2.6. Indice de similaridade ............ 20

3.2.7. Porcentagem de similaridade ........ 21

3.3. Flutuação populacional ............... 22

4. RESULTADOS E DISCUSSÃO .................... 24

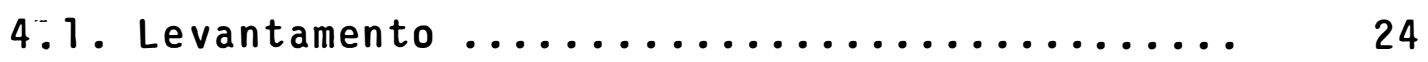

4.2. Medidas da fauna ................. 46

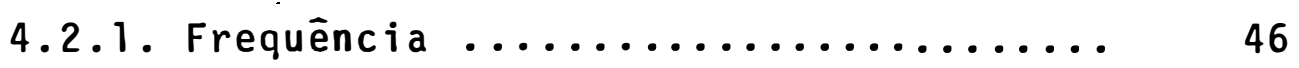

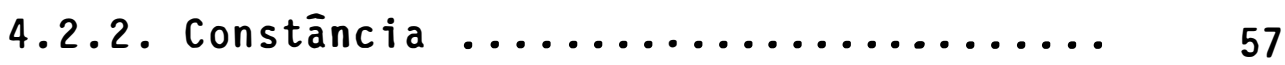

4.2.3. Dominância .................. 65

4.2.4. Abundāncia ................... 66 
vi.

Pāgina

4.2.5. Indice de diversidade .......... 73

4.2.6: Indice de similaridade .......... 74

4.2.7. Porcentagem de similaridade ....... 77

4.3. Flutuação populacional $\ldots \ldots \ldots \ldots \ldots \ldots \ldots$.

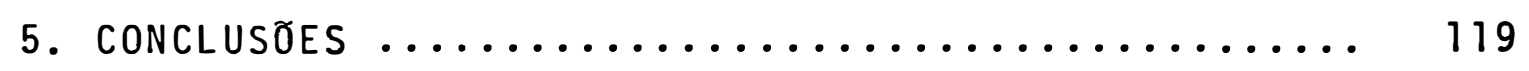

6. Literatura CitAdA .................... 121 
vi i .

\section{LISTA DE TABELAS}

Tabela no

Pāgina

01 Totais mensais do nūmero de indivíduos das espécies de insetos coletadas em ca caueiro na região de Altamira, Parā, Brasil, no período de setembro de 1978 a agosto de $1981 \ldots \ldots \ldots \ldots \ldots \ldots$

02 Totais mensais do nūmero de indivíduos das espécies de insetos coletadas em cá caueiro na região de Altamira, Parā, Brasil, no período de setembro de 1979 a agosto de $1980 \ldots \ldots \ldots \ldots \ldots$

03 Totais mensais do nūmero de indivíduos das espécies de insetos coletadas em ca caueiro na região de Altamira, Parā, Brasil, no período de setembro de 1980 a agosto de $1981 \ldots \ldots \ldots \ldots \ldots \ldots$

04 Número total de insetos coletados em cacaueiro na região de Altamira, Pará, Brasil no período de setembro de 1978 a agosto de $1981 \ldots \ldots \ldots \ldots \ldots \ldots$

05 Frequência (\%) das espécies coletadas em cacaueiro na região de Altamira, Pa rá, Brasil, no período de setembro de 1978 a agosto de $1981 \ldots \ldots \ldots \ldots \ldots$

Porcentagem de ocorrēncia das ordens es tudadas com relação ao nūmero de famílias, espécies e indivíduos coletados em cacaueiro na região de Altamira, $\mathrm{Pa}$ rá, Brasil, no período de setembro de 1978 a agosto de $1981 \ldots \ldots \ldots \ldots \ldots \ldots$ 

cacaueiro na região de Altamira, Pará, Brasil, no período de setembro de 1978 a agosto de $1981 \ldots \ldots \ldots \ldots \ldots \ldots$

08

Número e porcentagem de espécies constan tes, acessórios e acidentais, coletadas em cacaual, no período de setembro de 1978 a agosto de 1981, Altamira, Pará,

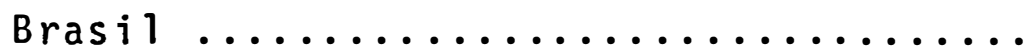

Domināncia e abundāncia das espécies coletadas em cacaueiro na região de Altami ra, Parā, Brasil, no período de setembro de 1978 a agosto de $1981 \ldots \ldots \ldots \ldots \ldots$

Número e porcentagem de espécies dominantes coletadas em cacaueiro, no período de setembro de 1978 a agosto de 1981.

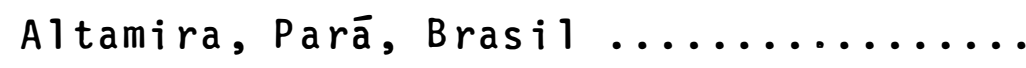

11 Nūmero de espécies (S), nūmero de indivíduos (N) e índice de diversidade $(\alpha)$ da entomofauna em cacaual, no perĩodo de setembro de 1978 a agosto de 1981. A] tamira, Parā, Brasil ................

Porcentagem de similaridade (\%) entre- os anos de amostragens de insetos em cacaual, no período de setembro de 1978 a agosto de 1981, Altamira, Pará ......... 
Relação das espēcies predominantes, nos 3 anos de amostragens e respectivos ín dices faunísticos. Altamira, Parā, Bra sil (setembro/1978 a agosto/1981) ....

14 Nūmero médio mensal de indivíduos das espécies predominantes nos 3 anos de amostragens. Altamira, Parā, Brasillse

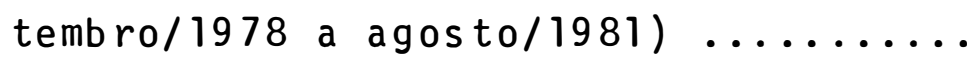

Dados climáticos médios de temperatú ra $(O C)$, umidade relativa (\%) e precip $\underline{i}$ tação pluvial (mm) no km $101 \mathrm{da}$ BR 230. Altamira, Parā, Brasil (Setembro/

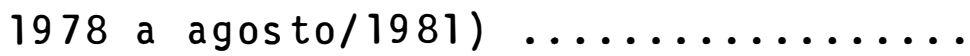

16 Dados fenolōgicos médios de produção (frutos/ārvore), lançamentos (folhas / rama), floração (flores/m2) do cacaue $\underline{i}$ ro na região de Altamira, Parā, Brasil (setembro/1978 a agosto/8981) ....

17 Valores do teste " $F$ " e do coeficiente de determinação $\left(R^{2}\right)$ das diferentes va riāveis, nas equações de regressão para explicação da variação populäcjonal de Colaspis sp. na região de Altamira Parā, Brasil (setembro de 1978 a agos-

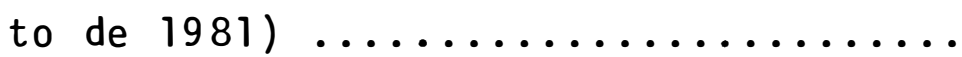


Valores do teste "F" e do coeficiente de determinação $\left(R^{2}\right)$ das diferentes va riāveis, nas equações de regressão para explicação da variação populacional de Noriaia sp. na região de Altamira, Parā, Brasil (setembro de 1978 a agos-

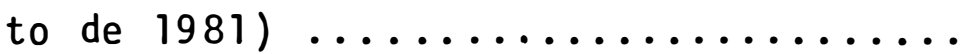

Valores do teste "F" e do coeficiente de determinação $\left(R^{2}\right)$ das diferentes va riāveis, nas equações de regressão para explicação da variação populacional de Eccoptopsis sp. na região de Altami ra, Parā, Brasil (setembro de 1978 a

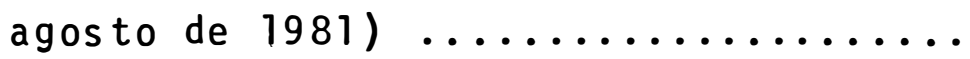

Valores do teste "F" e do coeficiente de determinação $\left(R^{2}\right)$ das diferentes va riāveis, nas equações de regressão para explicação da variação populacional de Rhabdopterus sp. na região de Altamira, Parā, Brasil (setembro de 1978 a

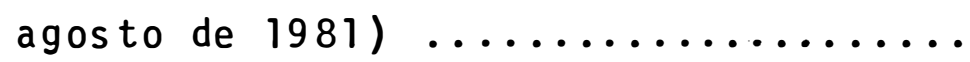

21 Valores do teste "F" e do coeficiente de determinação $\left(R^{2}\right)$ das diferentes va riáveis, nas equações de regressão para explicação da variação populacional de Antiteuchus tripterus (Fabr., 1787): na região de Altamira, Pará, Brasil (setembro de 1978 a agosto de 1981) .... 
Valores do teste "F" e do coeficiente de determinação $\left(R^{2}\right)$ das diferentes va riāveis, nas equações de regressão para explicação da variação populacional de Antitypona spp. na região de Altami ra, Pará, Brasil (setembro de 1978 a

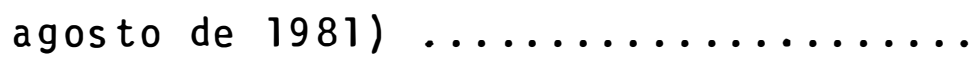

Valores do teste "F" e do coeficiente de determinação $\left(R^{2}\right)$ das diferentes va riāveis, nas equações de regressão para explicação da variação populacional de Clastoptera ochrospila Jacobi, na região de Altamira, Parā, Brasil (setembro de 1978 a agosto de 1981) .....

Valores do teste "F" e do coeficiente de determinação $\left(R^{2}\right)$ das diferentes va riāveis, nas equações de regressão para explicação da variação populacional de Hylax sp. na região de Altamira, Pará, Brasil (setembro de 1978 a agos-

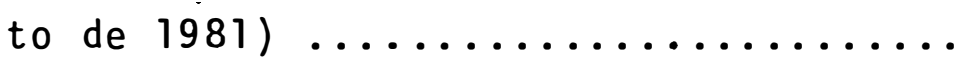

25 Valores do teste "F" e do coeficiente de determinação $\left(R^{2}\right)$ das diferentes va riāveis, nas equações de regressão para explicação da variação populacional de Platycarenus umbractulatus Fabr., 1803 na região de Altamira, Pará, Brasil (setembro de 1978 a agosto de 1981) 
Valores do teste "F" e do coeficiente de determinação $\left(R^{2}\right)$ das diferentes va riāveis, nas equações de regressão para explicação da variação populacional de Compsus sp. na região de Altamira, Parā, Brasil (setembro de 1978 a agos-

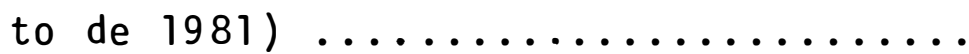

110

Valores do teste "F" e do coeficiente de determinação $\left(R^{2}\right)$ das diferentes va riāveis, nas equações de regressão para explicação da variação populacional de Acinocoris lunaris (Gmelin) na região de Altamira, Pará, Brasil (setembro de 1978 a agosto de 1981) .......

Valores do teste "F" e do coeficiente de determinação $\left(R^{2}\right)$ das diferentes va riāveis, nas equações de regressão para explicação da variação populacional de Amastris elevata Funkhouser na região de Altamira, Pará, Brasi? (setembro de 1978 a agosto de 1981) ........

Valores do teste "F" e do coeficiente de determinação $\left(R^{2}\right)$ das diferentes va riáveis, nas equações de regressão para explicação da variação populacional de Epormenis unimaculata (Fennah) na região de Altamira, Parā, Brasil (setembro de 1978 a agosto de 1981) ..... 
$x i i j$

\section{LISTA DE FIGURAS}

Figura no

Pāgina

01

Frequiência das famílias da ordem Coleopte ra, coletadas em cacaueiro no período de setembro de 1978 a agosto de 1981. Altami ra, Parā, Brasil .................

02

Freqüência das famílias da ordem Hemiptera coletadas em cacaueiro no período de setembro de 1978 a agosto de 1981. Altami

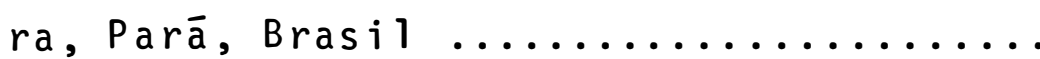

03 Frequiência das famīlias da ordem Homop̣te ra coletadas em cacaueiro no período de setembro de 1978 a agosto de $1981 \ldots \ldots$

04 Frequiéncia das famílias de insetos coleta das em cacaueiro no período de setembro de 1978 a agosto de 1981. Altamira, Pará,

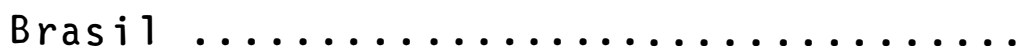

05 Classificação dos anos de amostragens quan to ao indice de similaridade (\%) ....... 75

06 Flutuação populacional mēdia de Colaspis sp. correlacionada com dados climáticos e fenolōgicos do cacaueiro. Altamira, Pará, Brasil (setembro de 1978 a agosto de 1981)

Flutuação populacional mēdia de Noriaia sp. correlacionada com dados climáticos e fenológicos do cacaueiro. Altamira, Pará, Brasil (setembro.de 1978 a agosto de 1981 . 
Flutuação populacional média de Eccoptopsis sp. correlacionada com dados climáticos e fenológicos do cacaueiro. Altamira, Pará, Brasil (setembro de 1978 a agosto de 1981).

Flutuação populacional média de Rhabdopte rus sp., correlacionada com dados climáticos e fenológicos do cacaueiro. Altamira, Pará, Brasil (setembro de 1978 a agosto

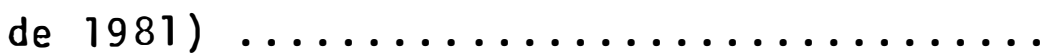

10 Flutuação populacional média de Antiteuchus tripterus (Fabr., 1787), correlaciona da com dados climáticos e fenológicos do cacaueiro. Altamira, Pará, Brasil (setem-

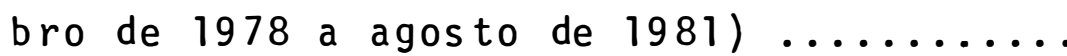

11 Flutuação populacional média de Antitypona spp., correlacionada com dajos climāticos e fenológicos do cacaueiro. Altamira, Pará, Brasil (setembro de 1978 a agosto

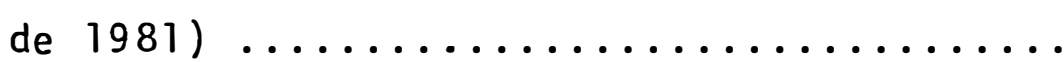

12 Flutuação populacional média de Clastoṕtera ochrospila Jacobi, correlacionada com dados climáticos e fenológicos do cacaueiro, Altamira, Parā, Brasil (setembro de

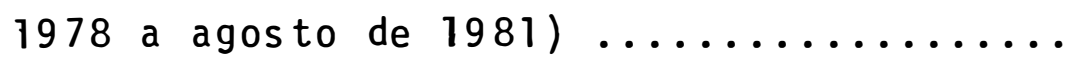

13 Flutuação populacional média de Hylax sp., correlacionada com dados climáticos e fenológicos do cacaueiro. Altamira, Pará, Brasil (setembro de 1978 a agosto de 1981) 
Flutuação populacional média de Platycare nus umbractulatus Fabr., 1803, correlacio nada com dados climáticos e fenológicos do cacaueiro. Altamira, Parā, Brasil (setembro de 1978 a agosto de 1981) .......

15 Flutuação populacional média de compsus sp. correlacionada com dados climāticos e fenológicos do cacaueiro. Altamira, Pará, Brasil (setembro de 1978 a agosto de 1981)

16 Flutuação populacional média de Acinocoris lunaris (Gmelin), correlacionada com dados climáticos e fenológicos do cacaueiro. Altamira, Parā, Brasil (setembro de 1978 a agosto de 1981) $\ldots \ldots \ldots \ldots \ldots \ldots$

17 Flutuação populacional média de Amastris elevata Funkhouser, correlacionada com da dos climāticos e fenológicos do cacaueiro Altamira, Pará, Brasil (setembro de 1978

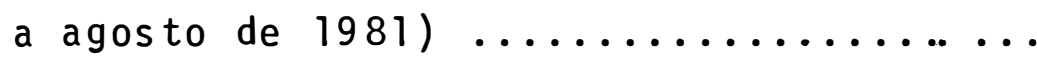

18 Flutuação populacional média de Epormenis unimaculata (Fennah), correlacionada com dados climáticos e fenológicos do cacaueiro. Altamira, Parā, Brasil (setembro de

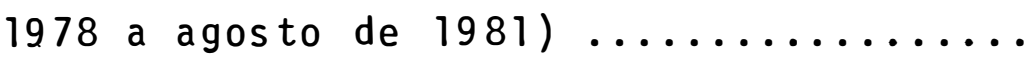




\section{LEVANTAMENTO E ANALISE FAUNISTICA DE INSETOS COLETADOS} EM CULTURA DE CACAU NA REGIAO DE ALTAMIRA-PARA

Autor: CARLOS LEAL BICELLI

Orientador: Prof. Dr. SINVAL SILVEIRA NETO

\section{RESUMO}

No presente trabalho, efetuou-se por meio detra tamento de choque com BHC 12\% (Knock-down), um levantamento e estudo faunistico dos insetos das Ordens Coleoptera, Hemipte ra e Homoptera coletadas em cacaueiro na região de Altamira, Estado do Pará, no período de setembro/1978 a agosto / 1981. Foram estudados os parâmetros faunísticos de freqléncia, cons tāncia, domināncia, diversidade, similaridade e porcentagem de similaridade, bem como a flutuação populacional das espécies predominantes, correlacionando-as com os fatores meteoro lógicos e fatores fenológicos do cacaueiro. Foram capturados 20.033 indivíduos pertencentes a 92 espēcies, das quais 73 são dominantes. Constataram-se 10 espécies muito abundantes, 12 comuns, 10 dispersas e 60 raras. Observou-se também, que de $\underline{s}$ tas espécies, 13 são constantes, 20 acessṓrias e 59 acidentais. 0 indice de diversidade foi de 9,2. Verificou-se a maior similaridade entre o 20 (1979/80 e $39(1980 / 81)$ ano de 
amostragem, com indice de $6,5 \%$ o que se confirma pela porcenta gem de similaridade de $86,58 \%$ entre os referidos anos. 0 estu do da flutuação populacional das espécies predominantes: Colaspis sp., Noriaia sp., Eccoptopsis sp., Rhabdopterus sp., Antitypona spp., Hylax sp., Compsus sp. (Coleoptera). Antiteuchus tripterus (Fabr., 1787), Platycarenus umbractulatus Fabr., 1803, Acinocoris lunaris (Gmelin) (Hemiptera), clastoptera ochrospila Jacobi, Amastris elevata Funkhouser, Epormenis unimaculata (Fennah) (Homoptera), mostrou que cerca de $60 \%$ delas estiveram correlacionadas com fatores fenológicos do cacaueiro, do que com os fatores meteorológicos. 
$x v i i j$.

SURVEY AND FAUNAL ANALYSIS OF INSECTS COLLECTED IN COCCOA CROPS IN THE REGION OF ALTAMIRA STATE OF PARA, BRAZIL

Author: CARLOS RENATO LEAL BICELLI

Adviser: Prof. Dr. SINVAL SILVEIRA NETO

\section{SUPMARY}

This paper deals with a survey and a faunal study of insects of the Ordens Coleoptera, Hemiptera and Homoptera collected in coccoa crops in the region of Altamira, State of Parā, Brazil, from September 1978 to August 1981. The insects were collected by means of a knock-down treatment with BHC $12 \%$. The following faunistic parameters were studied: frequency, constancy, dominance, abundance, diversity, similarity, and percentage of similarity, as well as the population fluctuation of the predominant species. These parameters were then correlated to the meteorological factors and to the phenological factors of the coccoa treee. The total of 20,033 individuals collected included 92 species from which 73 were dominant. Also, it was observed 10 species as very abundant, 12 common, 10 disperse and 60 rare. By other hand of these, 13 species were constant, 20 accessory and 59 accidental. The index of diversity was 9.2 The higher similarity was observed 
$x i x$.

between the second year $(1979 / 80)$ and the third year (1980/ 1981) of sampling, with an index of $6.5 \%$ wich as confirmed by the percentage of similarity between those years. The predominant species were: Colaspis sp.,. Noriaia sp., Eccoptopsis sp., Rhabdopterus sp., Antitypona spp., Hylax sp., Compsus sp. (Coleoptera), Antiteuchus tripterus (Fabr., 1787), Platycarenus umbractulatus Fabr., 1803, Acinocoris lunaris (Gmelin) (Hemiptera), Clastoptera ochrospila Jacobi, Amastris elevata Funkhouser, Epornemis unimaculata (Homoptera). The study of the population fluctuation on these species have indicated that about $60 \%$ of them were correlated to the phenological factors of the coccoa tree. 


\section{INTRODUÇAO}

Com o advento em 1976 do Programa de Expansão da Cacauicultura Nacional - PROCACAU (1978) - novos polos de desenvolvimento vem surgindo, sendo o cacaueiro amplamente cultivado na região Amazōnica e cuja meta inicial é a implantação de 160 mil hectares atē 1985, o que proporcionará uma pró dução de 192 mil toneladas de cacau em 1995. A.tualmente, os cacauais na Amazōnia ocupam uma ārea de 7.2 mil hectares: (1), sendo um dos principais polos o da Transamazōnica (Altamira), com uma previsão de cultivo de 40 mil hectares até 1985.

Evidenciam-se portanto, os problemas entomológicos neste novo Agroecossistema em substituição às florestas primitivas, com o surgimento de insetos, que em determinadas condições, atingem altos níveis populacionais, o que pode aca $\underline{r}$ retar sérias conseqüēncias à produção da cultura.

A necessidade de se conhecer parte da entomofau na cacaueira na região de Altamira e a potencialidade das es(1) Fonte: CEPLAC/DEPEA/Coordenadoria de Extensão. 
pécies de estabelecerem-se como pragas, objetivou a realização do presente estudo, cujos, resultados poderão fornecer subsídios que possibilitarão a elaboração de programas mais eficientes de controle das pragas na referida região. 


\title{
2. REVISAO DE LITERATURA
}

\author{
2.1. NO EXTERIOR
}

A literatura mundial registra diversos trabaIhos relacionados com o estudo de populações de insetos associados à cultura do cacaueiro.

Uma das primeiras referēncias é de URICH (1911), em Trinidad, realizando estudos sobre a população do tripes de cacaueiro, Heliothrips rubrocinctus Giard e cujas observações mostraram que nas estações chuvosas os danos causados às folhas do cacaueiro eram maiores do que nas estações secas, quando o inseto migrava para hospedeiros intermediārios.

No Suriname, REYNE (1921) constatou que o tripes (Selenothrips rubrocinctus Giard) é mais abundante na es tação seca, cuja população decresce lentamente ou permanece em equilíbrio até o final da pequena estação seca. 0 mais bai xo nível é atingido durante a grande estação chuvosa. Não hou 
ve correlação entre a população do tripes no campo e a variação de temperatura, como também com a época de maior ocorrēncia de folhas novas.

Atravēs de observações dos fatores que influen ciavam o ciclo anual de Sahlbergella singularis Hagl. e Distantiella theobromae (Dist.) em Ghana, WILLIAMS (1954) determinou os períodos de māxima e mínima infestação destas pragas, de modo a fornecer subsídios para o controle das mesmas.

Estudos realizados na Costa do Marfim por LAVABRE et alii (1962 e 1963), sobre a evolução regional e estacional de mirídeos do cacaueiro, permitiram ajustar os tratamentos com inseticidas de acordo com as regiões, condições de cultivo e de clima.

Na Costa Rica, MORALES et alii (1963) estudaram as populações dos hemípteros Monalonion spp. e dos homōpteros Amastris elevata Fabr. e Clastoptera globosa Fabr., determinando as interrelações existente entre as flutuações destas pragas e as variações climāticas, a fim de estabelecer eficientes métodos de controle.

ENTWISTLE (1964) estudando a flutuação anual de mirídeos, pragas do cacaueiro na Nigéria, verificou que o pico populacional de $S$. singularis apresentava variações no decorrer dos anos, sem determinar no entanto, as causas destas variações.

Estudos sobre as variações estacionais das populações de $S$. singularis e $D$. theobramae foram desenvolvidos 
por GIBBS et alii. (1968), em Ghana, utilizando diversos métodos de amostragens como: "choque" (Knock-down) com piretro, armadilha de luz ultra-violeta, contagens diretas em cacaueiros infestados e observações da presença ou ausēncia de cada espécie nas partes da planta acessíveis ao observador. Concluíram os autores, que o crescimento destas populações acompanha a maturação do fruto, dependendo diretamente do progres so da colheita principal em fins de julho ou agosto, para atin gir o pico em setembro ou outubro. Após a colheita, os insetos migram para os ramos, onde permanecem em nítveis elevados, decrescendo muito em janeiro e fevereiro, que é a época mais seca do ano.

Utilizando os mesmos métodos de amostragens, LESTON \& GIBBS (1969) e GIBBS \& LESTON (1970) obtiveram dados relativos às variações estacionais de diversas espécies de in setos, em cacaual sob floresta semidecídua no 0este africano.

Na revisão efetuada por LESTON (1970), sobre os problemas entomológicos do cacaueiro na África, constam diversas citações sobre estudos fenológicos de insetos e cujos resultados tornaram possível o uso de produtos químicos com maior eficiēncia no controle das pragas.

Em campos experimentais de cacau, na República de Camarões, BRUNEAU de MIRE (1970) realizou observações durante quatro anos sobre a ecologia e o ciclo anual do mirídeo s. singularis. Após descrever os vārios tipos de variações populacionais e analisar os fatores que estariam deter- 
minando as fases sucessivas do ciclo anual destes insetos, 0 autor chamou a atenção para o fato de que, a diminuição do crescimento populacional não resulta das condições climāticas, mas ē provocada por fatores biōticos. Mostra também que a presença de frutos em fase de maturação, geralmente interpretada como um fator propício ao crescimento populacional, tem, pelo contrário, um efeito desfavorável.

Na Nova Guiné, ROOM e SMITH (1975) estudaram a distribuição e abundāncia de insetos nocivos ao cacaueiro. Os resultados evidenciaram que o gorgulho Pantorhytes szentivanyi foi o mais importante e abundante, causando prejuízos permanentes ao cacaueiro.

ROOM (1975) utilizando dois métodos de amostra gens, "choque" (Knock-down) com piretro e coleta manual, estü dou a distribuição relativa de formigas em plantações de cacau na Nova Guiné. 0 autor observou que na copa do cacaueiro, as espécies dominantes Anoplolepis longipes e Technomyrmex albipes eram abundantes, Oecophylla smaragdina moderadamente abundante e Crematogaster sp. escassa. No solo, as dominantes Brachyponera croceicornis, Pheidole megacephala, Odontoma chus simillimus e Rhytidoponera araneoides eram moderadamente abundantes em adição aos tipos comumente dominantes da copa.

As relações entre a morte descendente do cacaueiro e as infestações de Monalonion annulipes Sig., foram estudadas por VILLACORTA (1977), na Costa Rica, em āreas sombreadas e sem sombra, cujos resultados mostraram que esta pra ga ocorre em maior nūmero nas āreas sem sombreamento. Os maio 
res picos populacionais observados nas duas āreas foram nos meses de outubro e novembro. Concluiu o autor que o sombreamento é importante na prevenção contra a morte descendente do cacaueiro, observando que em āreas com sombreamento deficiente, ocorre uma relação positiva entre o ataque destes mirídeos aos brotos terminais das plantas e a intensidade de morte descendente das mesmas.

Em Ghana, OWOSU-MANU (1977), usando diferentes métodos de amostragem, realizou estudos sobre a distribuição e abundāncia do pentatomídeo Bathycoelia thalassina, cuja população māxima foi estimada em 5.500 indivíduos por hectare no período de setembro a novembro. Observou o autor, que a abun dāncia desta praga acompanha as épocas de colheita, aumentando em nūmero à medida que há formação de frutos, de modo que atinge o seu pico populacional em outubro-novembro e praticamente desaparecendo em dezembro-janeiro, final do período de colheita.

BIGGER (1981) realizou estudos sobre a abundān cia de seis espécies de coccídeos e pseudococcídeos vetores da doença do "broto inchado" do cacaueiro em Ghana. Observou o autor, que Planococcides njalensis (Laing) ocorria em densidades mais altas em árvores infestadas do que as outras espécies, enquanto que Planococcus citri (Risso), apesar de me nos abundante, apresentava uma melhor distribuição na ārea, com um maior número de ārvores infestadas. A probabilidade de se encontrar $P$. citri foi de $0,87 \%$ contra $0,23 \%$ para $P$. 
njalensis, sugerindo esses resultados, que a primeira espécie deveria ser mais importante na propagação da doença do que prọ vaveimente tem sido suposto.

2.2. NO BRASIL.

2.2.1. Na região Amazōnica

Na Amazónia Brasileira, um dos primeiros regis tros da ocorréncia de insetos nocivos ao cacaueiro, foi feito por CALDEIRA e VIEIRA (1938), no Estado do Pará, onde mencionam a presença do fulgorídeo Tragopa auriculata (0liv.) e das formigas Dolichoderus attelaboides Fabr., D. bidens L. e D. bispinosus L., causando danos em cacaueiros.

SEFER (1961) citou as espécies Acromyrimex coro natus. (Fabr.), Atta cephalotes(L.), A. sexdens (L.), Azteca chartifex (Forel), A. paraensis (Roger), Selenothrips rubrocinctus (Giard) e Tragopa auriculata (01iv.), como pragas do cacaueiró na Amazōnia.

A saūva e a formiga de enxerto A. paraensis bondari são também mencionada por CONDURO (1966) como pragas do cacaueiro.

SILVA e COSTA (1973) registram em Beléma ocorréncia do curculionídeo Plectrophorus incertus Voss, causando sérios danos às folhagens do cacaueiro.

No Amazonas, NASCIMENTO et alii (1975) citaram 
a ocorrēncia de pragas como Nodonota sp., Colaspis sp., Monalonion sp., formigas Solenopsis spp., Azteca spp., Acromyrmex sp. e cupins.

Em Rondōnia, VENTOCILLA (1975) constatou a pre sença de diversas pragas como serradores, coleobrocas e formi gas doceiras em trofobiose com insetos sugadores, tais como membracídeos Horiola sp.. Também foi observada a formiga caçarema Azteca chartifex spiriti Fore1. 0 autor observou danos causados por Monalonion sp.. Foram constatados ainda, ou tros insetos como Oiketicus kirbyi (Lands-Guild), percevejos, homopteros e lagartas "mede palmo".

SORIA e CRUZ (1977) relacionaram cerca de 25 espécies de insetos causando danos ao cacaueiro em Rondónia. No Pará, COSTA (1977) citou a ocorrēncia de da nos provocados por diversas espécies de crisomelídeos como Maecolaspis ornata (Germ.), Taimbezinha theobromae (Bryant), Colaspis aeruginosa (Germ.), além do curculionídeo Plectropho rus incertus Voss., mirídeos do gēnero Monalonion, formigas, cupins e membracídeos, causando danos ao cacaueiro.

MENDES. (1979) registrou pela primeira vez a ocorrência da cigarrinha clastoptera sp. em Rondōnia, Amazonas e Pará, atacando almofadas florais e pedūnculo de frutos novos do cacaueiro.

Recentemente, MENDES et alii. (1979), relacionaram as principais espécies nocivas ao cacaueiro na Amazónía, fornecendo dados bionómicos das mesmas e respectivos métodos 
de controle. Evidenciam-se o Selenothrips rubrocinctus (Giard.), Xylosandrus compactus (Eichh.) e Steirastoma breve Sulzer co mo as de maior nocividade para a cultura.

os estudos sobre a população de insetos nocivos do cacaueiro, iniciaram-se com o trabalho de GARCIA e SIL VEIRA NETO (1980) realizando o levantamento e estudando os ín dices faunísticos, em duas regiões cacaueiras no Estado do Pa rā. A fauna da região Bragantina mostrou ser mais numerosa e diversificada que a fauna da região Guajarina. 0 autor deter minou a flutuação populacional de Antiteuchus spp., Costalimaita ferruginea. Ephyraea sp., Plectrophorus incertus da região Bragantina e Antiteuchus spp., Ephyraea sp. e Macropygium reticulare da região Guajarina, verificando não haver correla ção significativa entre as flutuações populacionais e os fato res climáticos e fenológicos do cacaueiro.

MENDES e ROSARIO (1980) realizaram estudos fau nísticos de insetos associados ao cacaueiro em Rondōnia e Ama zonas. Os autores observaram que a fauna de Rondōnia é mais numerosa e diversificada que a do Amazonas, cujo coeficiente de similaridade de $14,5 \%$ evidencia uma não semelhança em termos de-espécies entre as duas regiões.

Em Rondōnia, MENDES e GARCIA (1981) desenvolve ram estudos determinando a época de maior ocorrēncia dos crisomelídeos M. ornata (Germar), Metachroma sp., dos curculioní deos Pandeleiteius bisseriatus (Kirsch) e uma espécie não identificada da tribo Barynotini. Os autores observaram que 
os maiores picos populacionais de M. ornata (Germar), Metachroma sp. e $P$. bisseriatus (Kirsch) ocorreram nos meses de junho e julho, enquanto que para o curculionídeo da tribo Barynotini ocorreu no mês de março. A precipitação pluviométrị ca foi o fator de maior influéncia na população das espécies, apresentando uma correlação negativa com o nūmero de indivíduos, exceto para o curculionídeo da tribo Barynotini. Observaram também, que o lançamento de folhas novas nao teve influēncia na população das espécies estudadas.

\subsubsection{Outras regiões.}

Um dos primeiros estudos de comunidades de insetos associados ao cacaueiro foi o de VENTOCILLA (1967), na Bahia, que utilizando armadilhas de luz negra, determinou a flutuação populacional do coleoptero Amphix discoidea (Fabr.), o qual se alimenta do fungo Phytophthora palmivora causador da podridão do fruto do cacaueiro.

Posteriormente, SILVA et alii. (1969) empregaram a armadilha de luz negra para estudar a periodicidade de vōo de insetos noturnos e elaboraram a curva de flutuação da mariposa Arsenura armida (Cramer), cuja lagarta alimenta-se das folhas do cacaueiro.

VENTOCILLA (1970), estudando a flutuação de Empoasca sp., observou que a mesma atinge nīveis máximos no período de janeiro a maio, sendo as maiores infestações em plantações desprovidas de sombra. 
No Espírito Santo, ABREU (1971) realizou estudos sobre a fenologia de coleopteros pragas do cacaueiro, estabelecendo. as curvas de flutuação do crisomelídeo Maecolaspis ornata (Germ.) e dos curculionídeos Lordops aurosa Germ., Naupactus bondari Marsh., Naupactus sp. e Lasiopus cilipes (Sahlb.). Os lançamentos mostraram correlações positivas altamente significativas com a população de M. ornata dois meses apōs a sua ocorrēncia, enquanto que para $L$. aurosa as cor relações foram positivas e significativas ao nível de $5 \%$ de probabilidade de um e dois meses após a sua ocorréncia. No ca so de N. bondari, a correlação foi positiva e significativa no mesmo més. Finalmente, para a população total representada pe 10 somatório das coletas das cinco espécies, as anālises mostraram correlações positivas no mesmo mès, um més depois e, mais significativamente, dois meses após o seu evento. Baseado nestes resultados, o autor concluiu que os períodos mais apropriados para os tratamentos com inseticidas devem corres ponder ao início dos lançamentos, quando as populações destas pragas se encontram no seu nível mais baixo.

Estudando a dinâmica populacional de Selenothrips rubrocinctus (Giard.) em cacaueiros, no Espírito Santo, SMITH (1973) encontrou correlações positivas entre o nível da população com a frutificação até dois meses após o evento. Não houve correlação positiva com o lançamento de folhas novas até quatro meses após a sua ocorrência. A precipitação pluviomé- 
trica teve influéncia negativa no aumento populacional, ocorrendo tambēm uma correlação negativa com a temperatura até quinze dias após a sua manifestação, entretanto, teve influ éncia positiva na população do tripes, trés a quatro meses de pois. Baseado nestes resultados, o autor recomendou que as medidas de controle deveriam efetivar-se no início dos períodos de frutificação, após o aparecimento dos primeiros sintomas de ferrugem. 
14.

\section{MATERIAIS E METODOS}

Os trabalhos foram desenvolvidos em propriedades localizadas entre os km. 30 e 120 da rodovia Transamazōni ca (BR-230), no trecho Altamira/Itaituba no estado do Pará, que è a ārea de maior representatividade da cultura de cacau na região.

De acordo com PEREIRA e RODRIGUES (1971) a area apresenta um clima do tipo AW da classificação de Koppen (clima tropical com temperatura média mensal sempre superior a 180C). O total anual das chuvas é de $1.689 \mathrm{~mm}$, com um regị me pluviométrico caracterizado por chuvas de verão-outono cujo período concentra $89 \%$ do total anual, definindo duas esta çoes: uma bastante chuvosa (Dezembro a Maio) e outra menos chuvosa (Junho a Novembro). A temperatura média anual é de 260C, com as médias das máximas e mīnimas de $30,80 \mathrm{C}$ e $21,10 \mathrm{C}$ respectivamente.

Do ponto de vista físico, a área é caracteriza da por solos férteis de origem basāltica do tipo Terra Roxa 
Estruturada Eutrófica, com relevo variando de plano a forteon dulado (FALESI, 1972). A vegetação caracteriza-se por apre sentar, além da predominante Floresta Tropical Omida, uma grande diversidade de cultivos como cana-de-açúcar, cacau, ca fé, pastagens, pimenta-do-reino, etc.

\subsection{LEVANTAMENTO}

\subsubsection{Amostragem}

Foram selecionadas 12 propriedades com um mínimo de 20 hectares de cacaueiros (idade acima de 5 anos) cada uma. Em cada propriedade realizaram-se amostragens quinze nais da população de insetos de 10 cacaueiros escolhidos ao acaso.

0 método de amostragem empregado foi o de "cho que" (Knock-down) com BHC $12 \%$, em regime de rotatividade, con forme utilizado na Africa por LAVABRE (1963) e preconizadopor SOUTHWOOD (1971). Também utilizado no Brasil por ABREU (1971) no Espīrito Santo, GARCIA (1979) no Parā e MENDES e GARCIA (1981) em Rondōnia e descrito a seguir:

Usando-se polvilhadeira costal motorizada, 0 produto foi aplicado às primeiras horas da manhã (6:00 às 8:00 h.). Os insetos atingidos eram coletados em lençōis de nylon de $4 \times 4 \mathrm{~m}^{2}$, previamente estendidos ao redor de cada cacaueiro a ser amostrado. Decorridas 6 horas da realização do 
tratamento, recolhiam-se os insetos, acondicionando-os em fras $\cos$ contendo álcool $70 \%$, para separação, contagem e identifí cação em laboratório.

\subsubsection{Identificação das espécies}

0 presente trabalho foi desenvolvido somente com as ordens Coleoptera, Hemiptera e Homoptera, devido ao fá to de concentrarem a maioria das espécies nocivas ao cacaueiro, como também pela eficiēncia do método usado na coleta de insetos destes grupos.

No grupo dos coleópteros, parte foi identifica da pelos Drs. Theodore J. Spilman, Donald R. Whitehead e Richard E. White, pertencentes ao Beltsville Agricultural Research Center, E.U.A.; pelos Drs. Ubirajara R. Martins do Museu de Zoologia da Universidade de São Paulo e Sérgio Vaniñ do Departamento de Biologia do Instituto de Biocienncias da USP.

Os hemípteros e homópteros foram identificados pela Dra. Jocélia Grazia do Departamento de Zoologia da UFRGS, o Dr. José Cándido de Melo Carvalho do Museu Nacional do Rio de Janeiro e Dr. Jon L. Herring do Beltsville Agricultural Re search Center.

Algumas espécies foram identificadas pelo autor por comparação com exemplares pertencentes ao Museu Paraen se Emilio Goeldi, principalmente os crisomelídeos, como também do Departamento de Entomologia da ESALQ/USP. 
Todos os insetos coletados estão conservados no museu da Divisão de Entomologia da CEPLAC/Departamento Especial da Amazōnia, em Belēm.

\subsection{MEDIDAS DA FAUNA}

Das amostragens realizadas durante o período de 1978/81, foram selecionadas entre as espécies identificadas,

aquelas que apresentaram um total mínimo de trēs indivíduos co letados, sendo estudados os seguintes parāmetros:

\subsubsection{Freqüēncia}

A freqüência foi calculada pela participação percentual de cada espécie, em nūmero de indivíduos com relação ao total coletado.

\subsubsection{Constāncia}

Calculada através da fórmula:

$$
C=\frac{P}{N} * 100 \quad C=\frac{P}{N} \times 100
$$

onde:

$$
\begin{aligned}
& \mathbf{C}=\text { porcentagem de constāncia; } \\
& \mathbf{P}=\text { número de coletas contendo a espécie; } \\
& \mathbf{N}=\text { número total de coletas efetuadas. }
\end{aligned}
$$


Em função das porcentagens obtidas, as espēcies foram separadas em categorias, segundo a classificação de Bodenheimer (1965), citado por SILVEIRA NETO et alii. (1976):

Espécies constantes $(w)$ : presentes em mais de $50 \%$ das coletas;

Espēcies acessōrias (y): presentes em 25-50\% das coletas;

Espécies acidentais $(z)$ : presentes em menos de $25 \%$ das coletas.

3.2.3. Domināncia

Calculada pelo método de Kato et alii. (1952), citado por LAROCA e MIELKE (1975), utilizando as seguintes equações:

$$
\begin{aligned}
& L S=\frac{n_{1} F_{0}}{n_{2}+n_{1} F_{0}} \times 100 \\
& L I=1-\frac{n_{2} F_{0}}{n_{1}+n_{2} F_{0}} \times 100
\end{aligned}
$$

onde:

$$
\begin{aligned}
& \text { LS }=1 \text { limite superior } \\
& L I=1 i m i t e \text { inferior } \\
& n_{1}=2(K+1) \\
& n_{2}=2(N-K+1) \\
& N=\text { nūmero total de indivíduos capturados; } \\
& K=\text { nūmero de indivíduos de cada espécie }
\end{aligned}
$$


$F_{0}=$ valor obtido através da tabela de distribuição de $F$, ao nível de $5 \%$ de probabilidade, com graus de liberda de de $n_{1}$ e $n_{2}$.

Para a determinação da domināncia, comparou-se os Limites Inferiores com o Limite Superior para $K=0$, sendo consideradas espécies dominantes aquelas que apresentaram LI maior que LS, quando $K=0$.

\subsubsection{Abundāncia}

A abundāncia das espécies foi calculada empregando-se uma medida de dispersão usada por SILVEIRA NETO et alii (1976), através do cálculo do desvio padrão, erro padrão da média e intervalo de confiança (IC) para "t" a $5 \%$ e $7 \%$ de probabilidade utilizando-se a distribuição de "t". Estabeleceu-se as seguintes classes de abundāncia com os respectivos limites:

Raro $(r)$ : numero de indivíduos menor que o limite inferior do IC a $1 \%$ de probabilidade;

Disperso (d): nūmero de indivíduos situado entre os 1 imi tes inferiores do IC a $5 \%$ e $1 \%$;

Comum (c): nūmero de indivíduos situado dentro do IC a $5 \%$;

Abundante (a): número de indivíduos situado entre os limites superiores do IC a $5 \%$ e. $1 \%$;

Muito Abundante $(m)$ : nūmero de indivíduos maior que o limite superior do IC a $1 \%$. 


\subsubsection{Indice de diversidade.}

Calculou-se a diversidade da fauna, através da equação proposta por MARGALEF (1951):

$$
\alpha=\frac{S-1}{\log _{e} N}
$$

onde:

$$
\begin{aligned}
& S=\text { nümero de espécies; } \\
& N=\text { nūmero de indivíduos } .
\end{aligned}
$$

Esse indice foi calculado para cada ano de observação.

\subsubsection{Indice de similaridade}

Calculou-se este índice através do método proposto por Mountford (1962), citado por SILVEIRA NETO et alii (1976), em que:

$$
I_{1}=\frac{2 j}{2 a b-(a+b) j}
$$

onde:

$I_{1}=$ indice de similaridade entre dois anos;

$\mathrm{a}=$ número de espécies coletadas no ano $\mathrm{A}$;

b = número de espécies coletadas no ano B;

$j$ = número de espécies coletadas em ambos os anos. 
Para comparação entre os vārios anos de amos tragens, atravēs do îndice de similaridade ( $I_{l}$ ) calculado para comparações de anos 2 a 2 , preencheu-se um diagrama de tre liça, utilizando-se em seguida, a fórmula geral, para comparação entre $A_{1}, A_{2}, \ldots, A_{m}$ e $B_{1}, B_{2}, \ldots, B_{n}$ dada por:

$$
I_{z}=\frac{1}{m n} \quad \sum_{i=1}^{m} \sum_{j=1}^{n} I_{1}(A i, B j)
$$

onde:

$I_{z}=$ indice de similaridade entre vārios anos $A$ e $B=$ anos de amostragens.

De posse dos novos índices, calculados atravēs da confecção de treliças, até completa separação dos anos, ob teve-se a classificação final, demonstrada por um grāfico de discriminação.

\subsubsection{Porcentagem de similaridade}

Foi estudada a semelhança entre as comunidades representadas pelos três anos de observações, baseando-se em SOUTHWOOD (1971), em que:

$$
S=\Sigma(a+b+\ldots+n)
$$

sendo:

$S=$ porcentagem de similaridade; 
$a$ = menor porcentagem da espécie a observada no confronto de dois anos;

$b=$ menor porcentagem da espécie $\underline{b}$ observada no confronto de dois anos;

$n=$ menor porcentagem da espécie $\underline{n}$ observada no confronto de dois anos.

\subsection{FLUTUAÇAO POPULACIONAL}

Para o estudo da flutuação populacional foram selecionadas as espécies caracterizadas como predominantes no Agroecossistema cacaueiro, cujo critērio de seleção é baseado nos parāmetros de freqüéncia, constāncia, domināncia e abun dância, utilizando-se para tanto, as médias mensais do nūmero de insetos coletados nos trēs anos de amostragens.

Os dados de Umidade Relativa $\left(x_{1}\right)$, Precipitação pluvial $\left(X_{2}\right)$ e Temperatura $\left(X_{3}\right)$, registrados no posto meteorológico da Estação Experimental da EMBRAPA/UEPAE/Altamira, localizada no km 101 da Rodovia Transamazónica durante o período de realização das amostragens, foram correlacionados com a população das espēcies predominantes $(Y)$, através de anāli ses de regressão linear mūltipla (Stepwise), visando-se a ve rificação de possíveis influencias dos referidos fatores sosobre o comportamento populacional destas espécies de insetos. As mesmas anālises foram utilizadas para ten tar identificar correlações dos fatores fenológicos Lançamen 
to de folhas (Brotação) $\left(X_{4}\right)$, Produção $\left(X_{5}\right)$ e Floração $\left(X_{6}\right)$ do cacaueiro, com a flutuação populacional das espécies jā referidas.

A anālise destes dados foi realizada pelo computador do Centro de Energia Nuclear na Agricultura (CENA)/ USP, cuja programação foi efetuada pelo Engo Agrọ Carlos Hen rique Mattiolli da EMBRAPA. 
24 .

\title{
4. RESULTADOS E DISCUSSÃO
}

\author{
4.1. LEVANTAMENTO
}

Os resultados das amostragens de insetos reali zadas no período de setembro de 1978 a agosto de 1981 , estão contidos nas tabelas 1, 2, 3 e 4 apresentando 0 nümero de insetos coletados mensalmente e separados por ordem alfabética, com a seguinte seqüēncia: nome da ordem, famīlia e espécie .

Nas amostragens realizadas nestes trēs anos, foram capturadas 463 espēcies de insetos, num total de 23.261 indivíduos. 


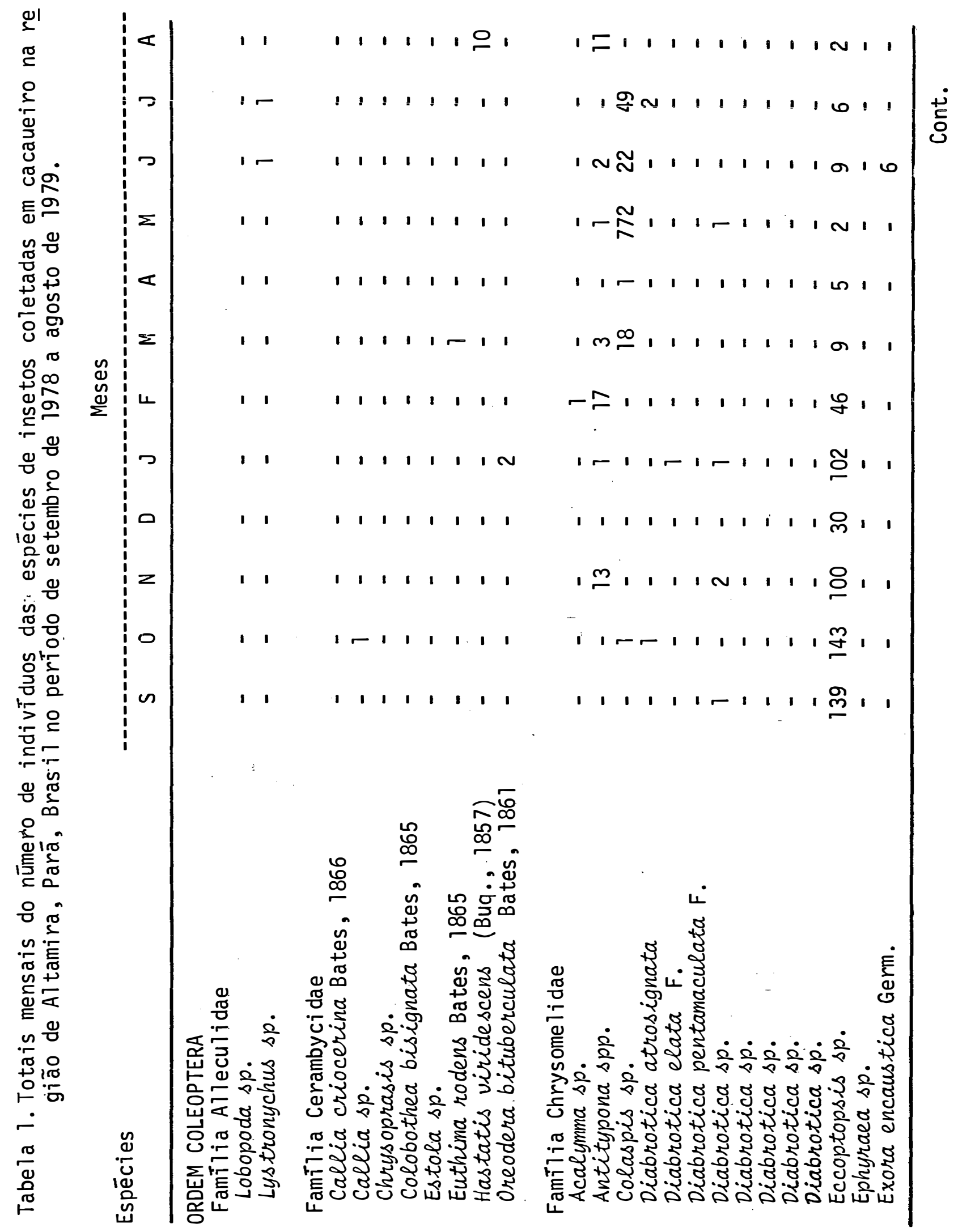




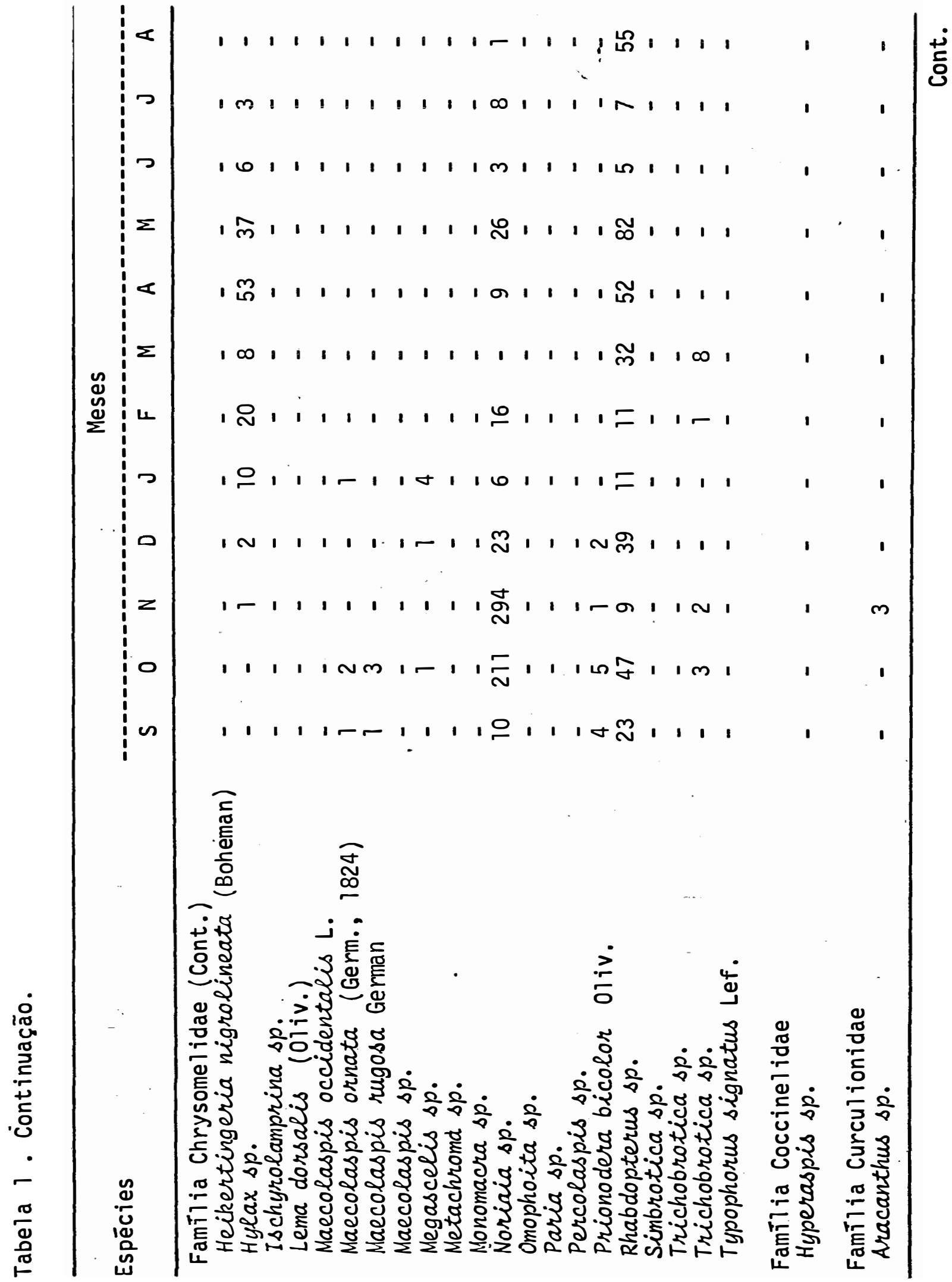




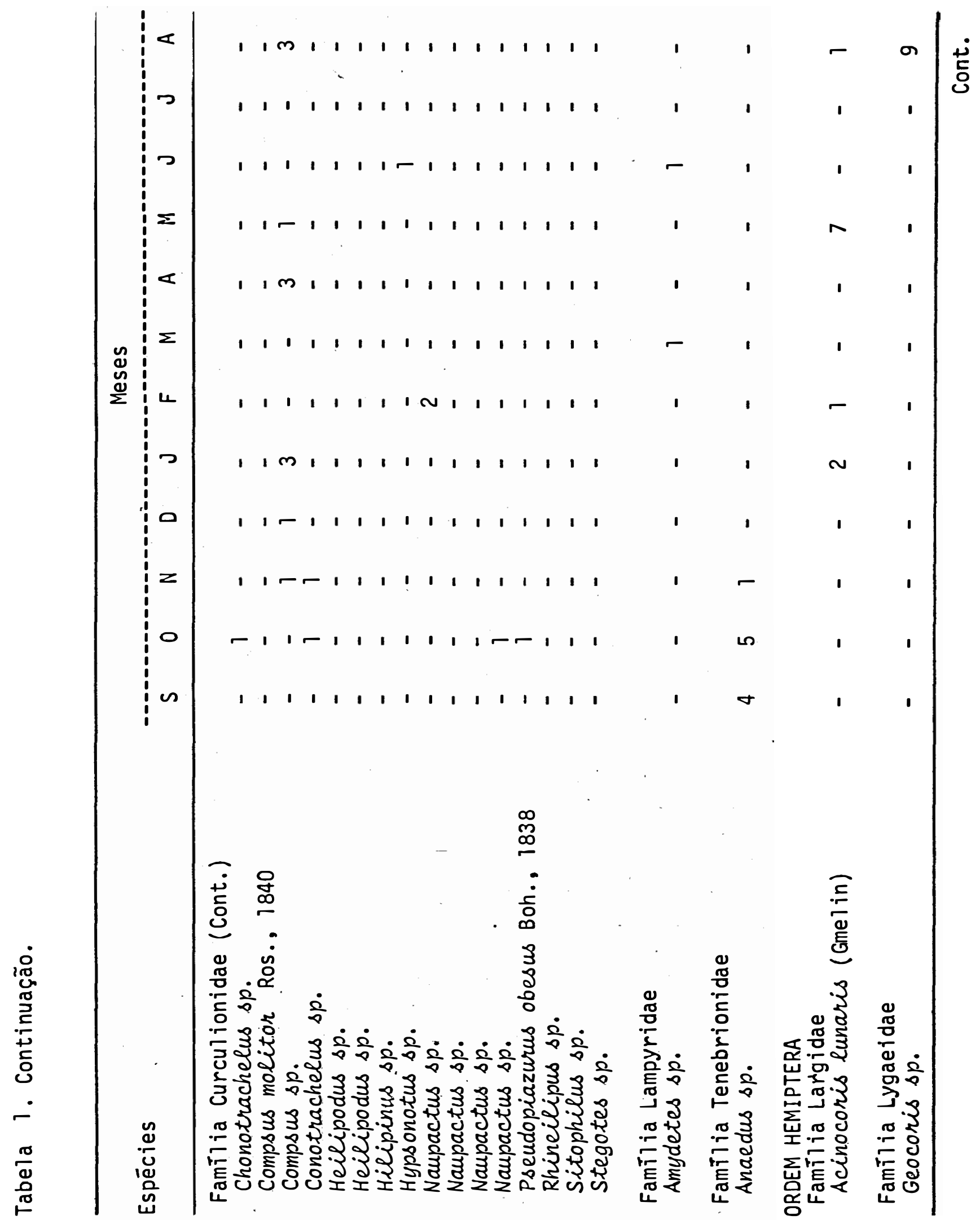




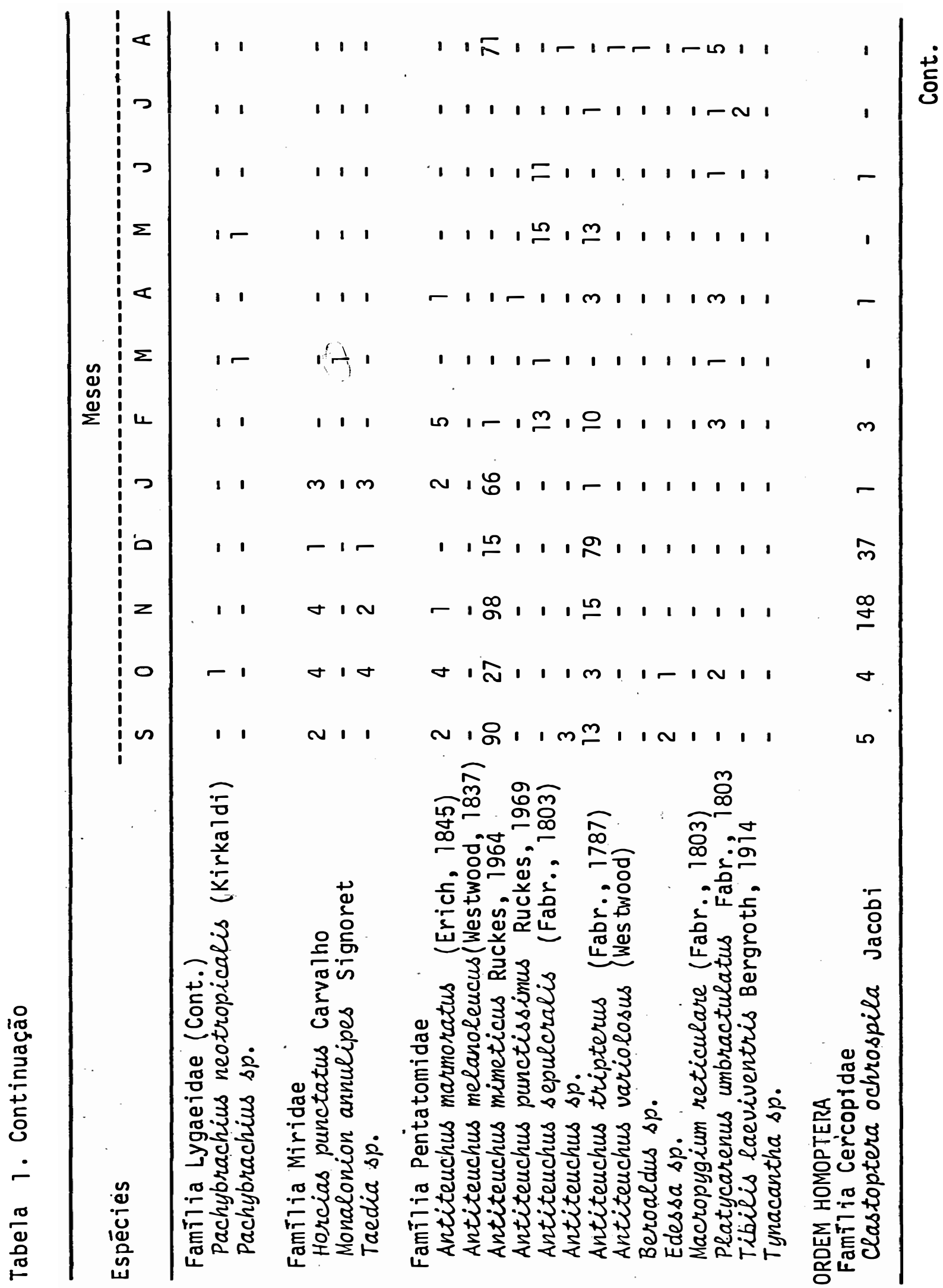




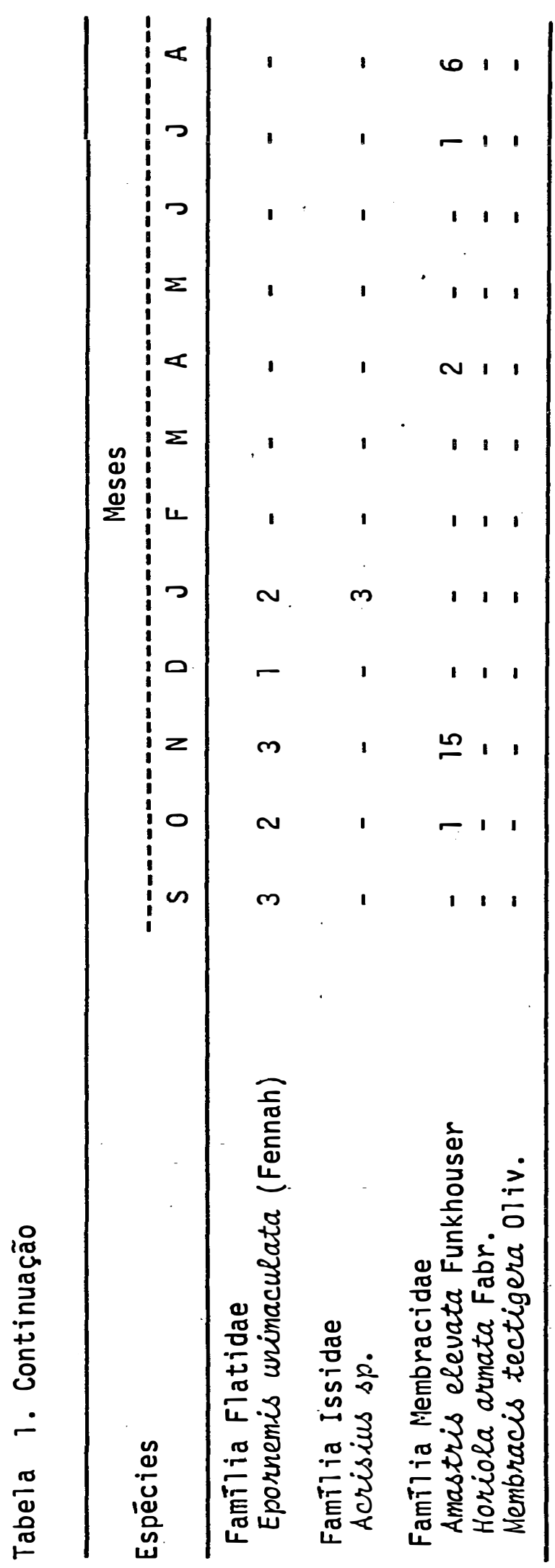


30.

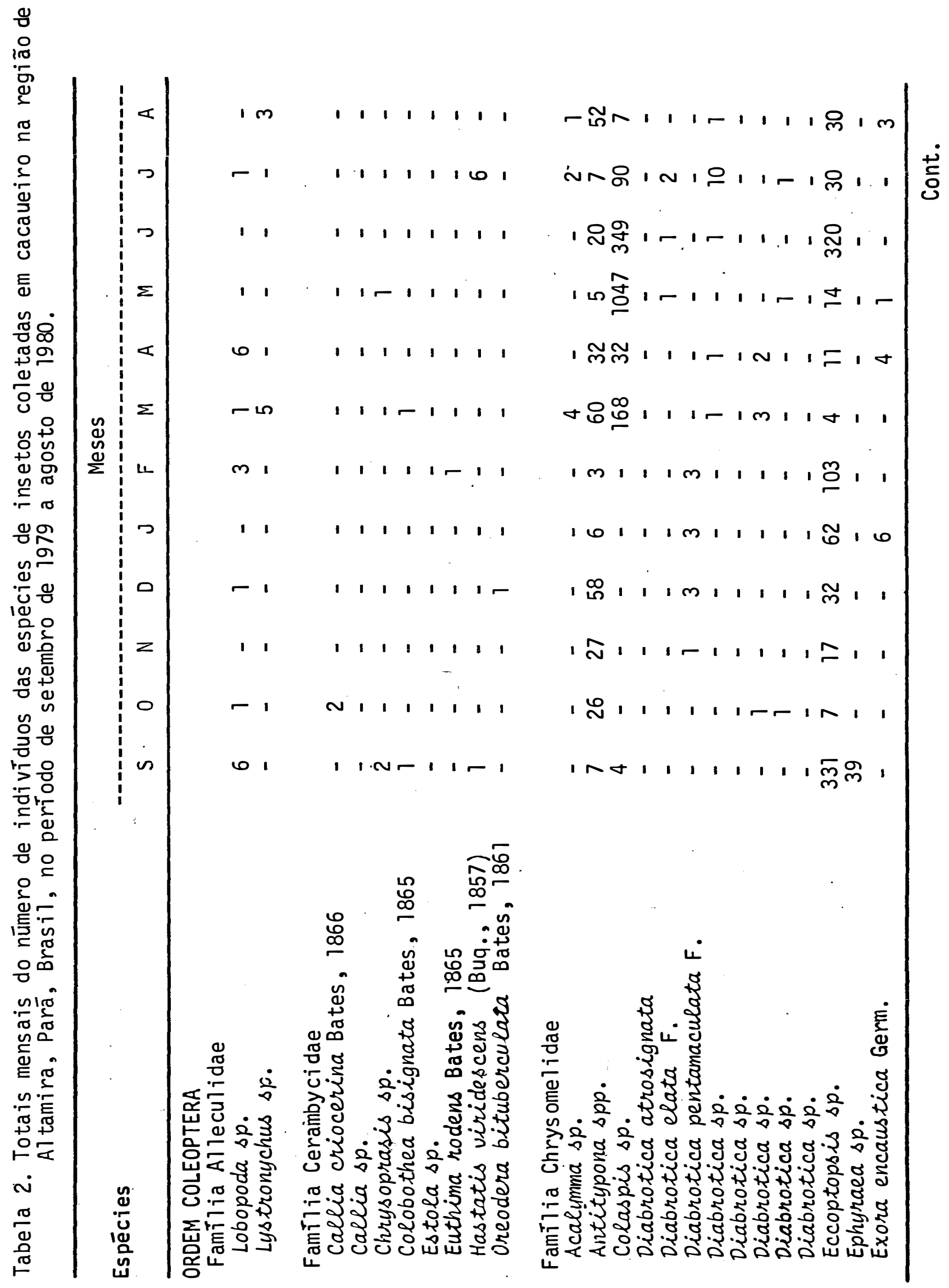




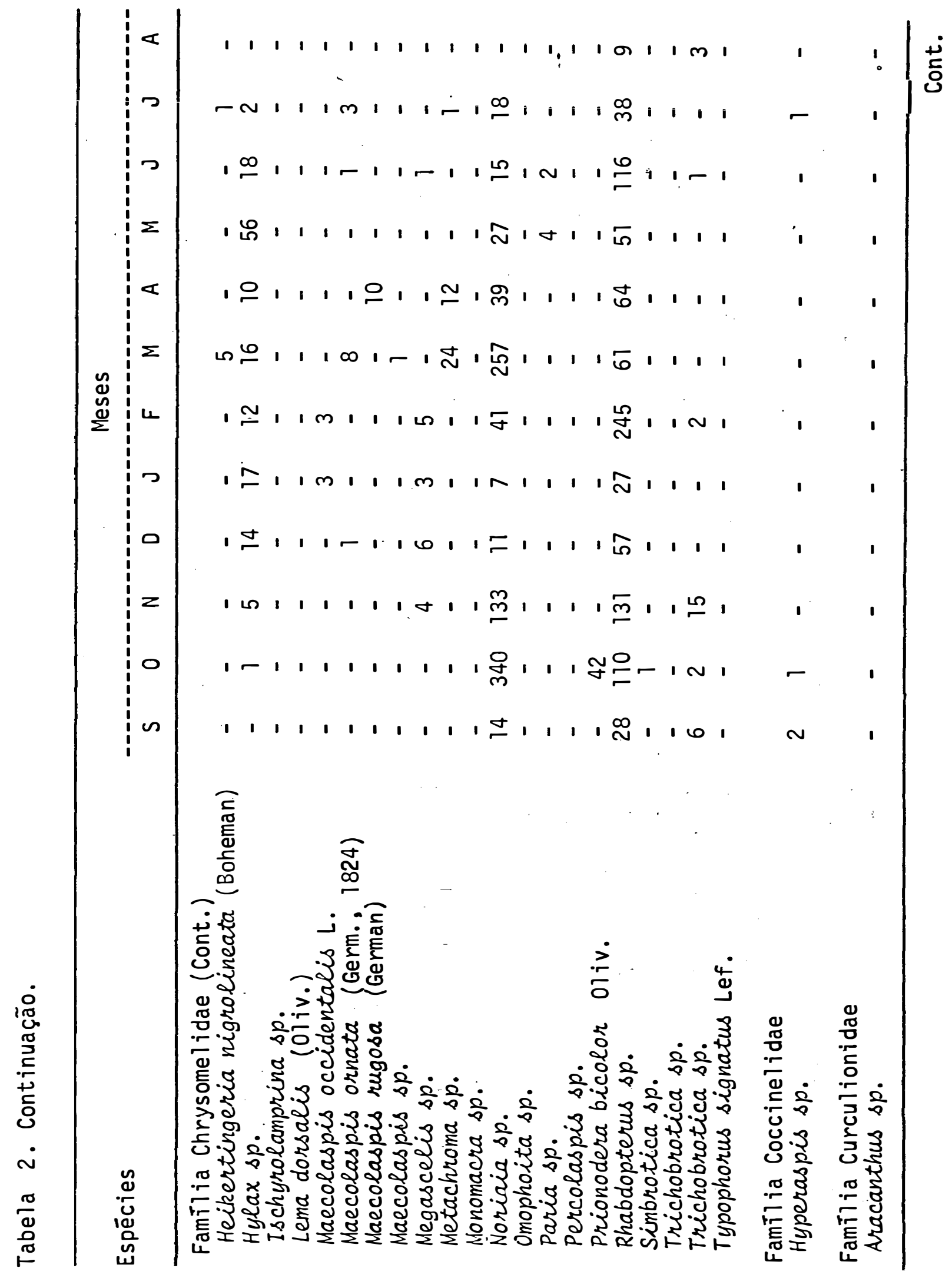




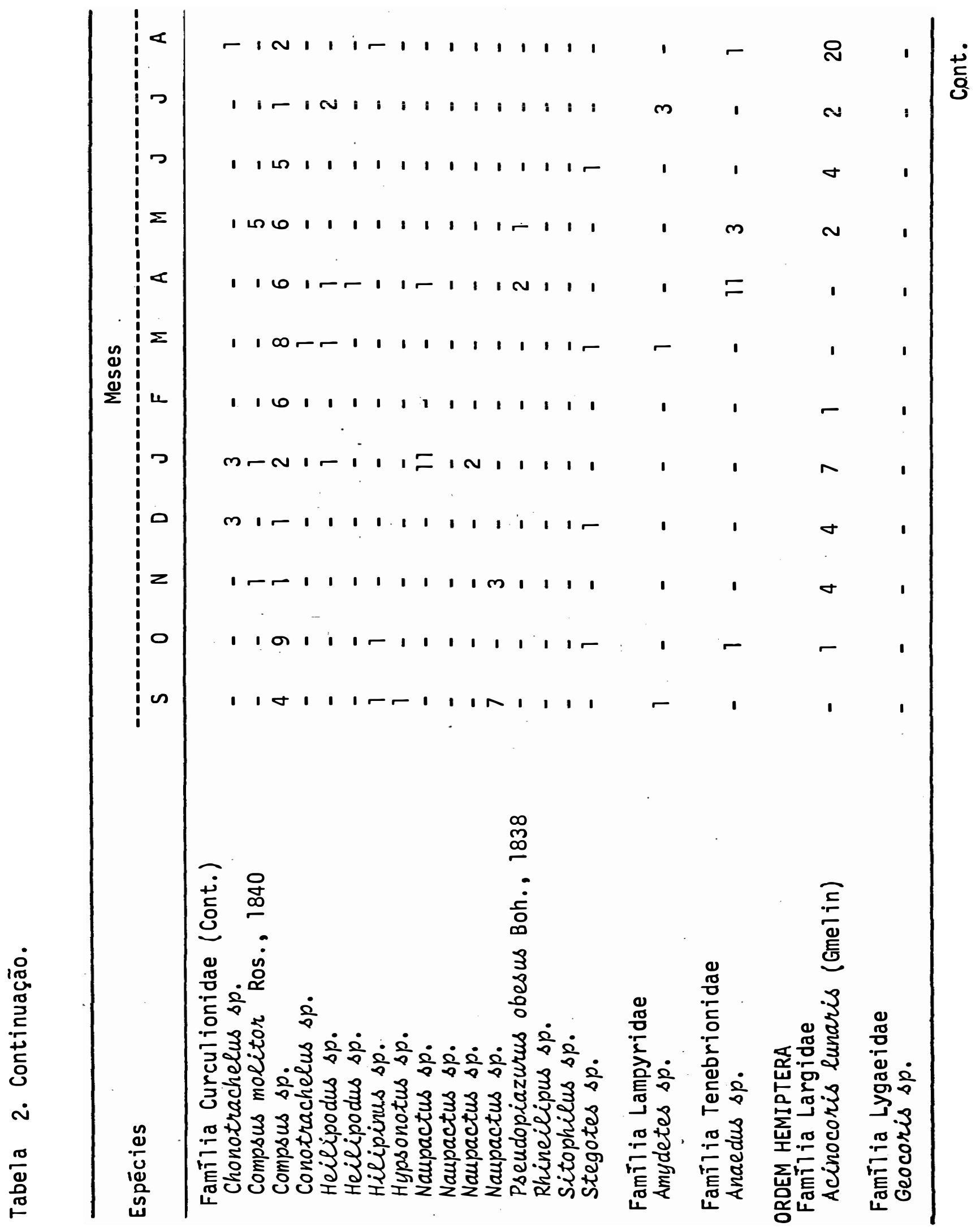




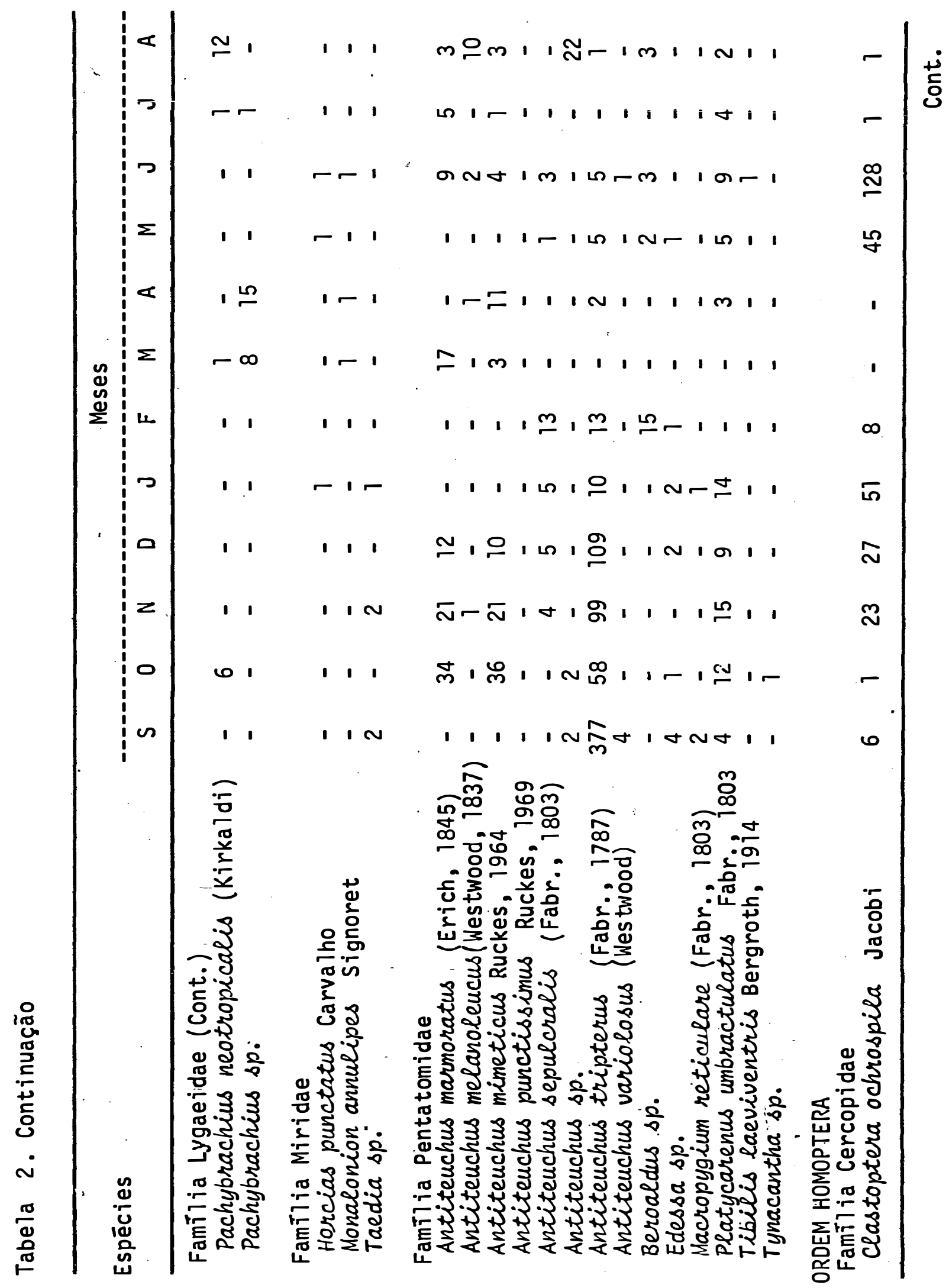




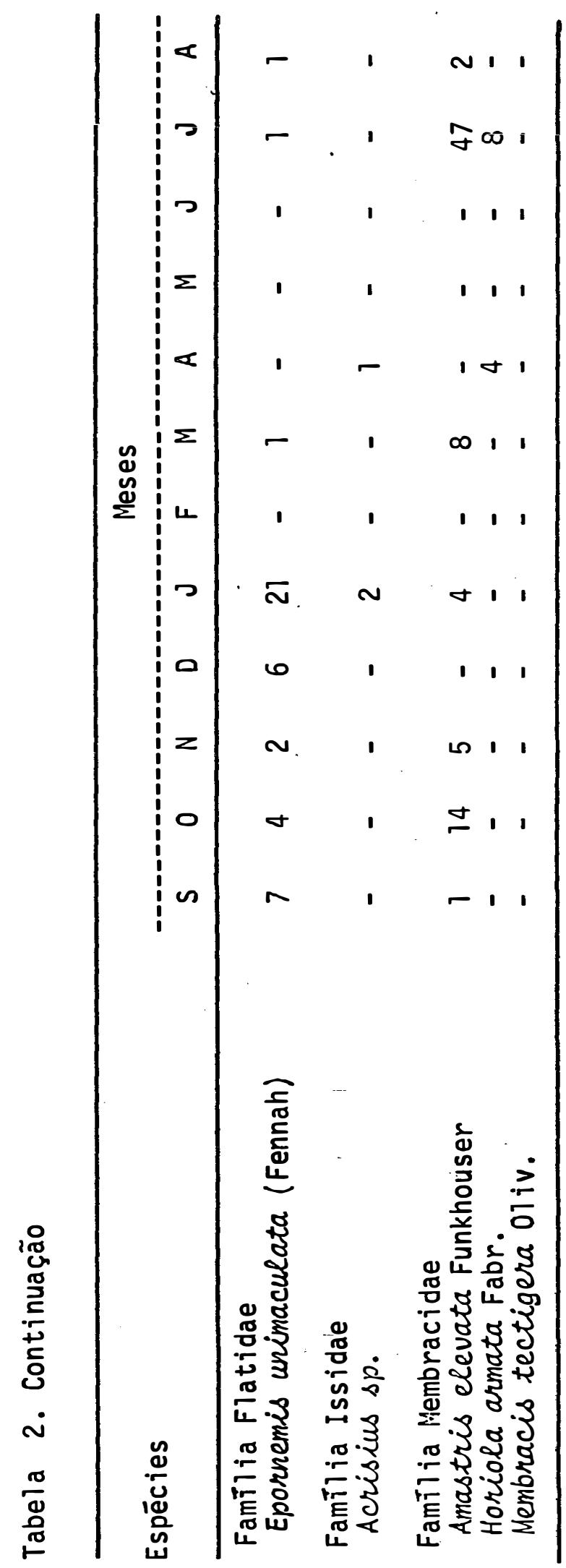




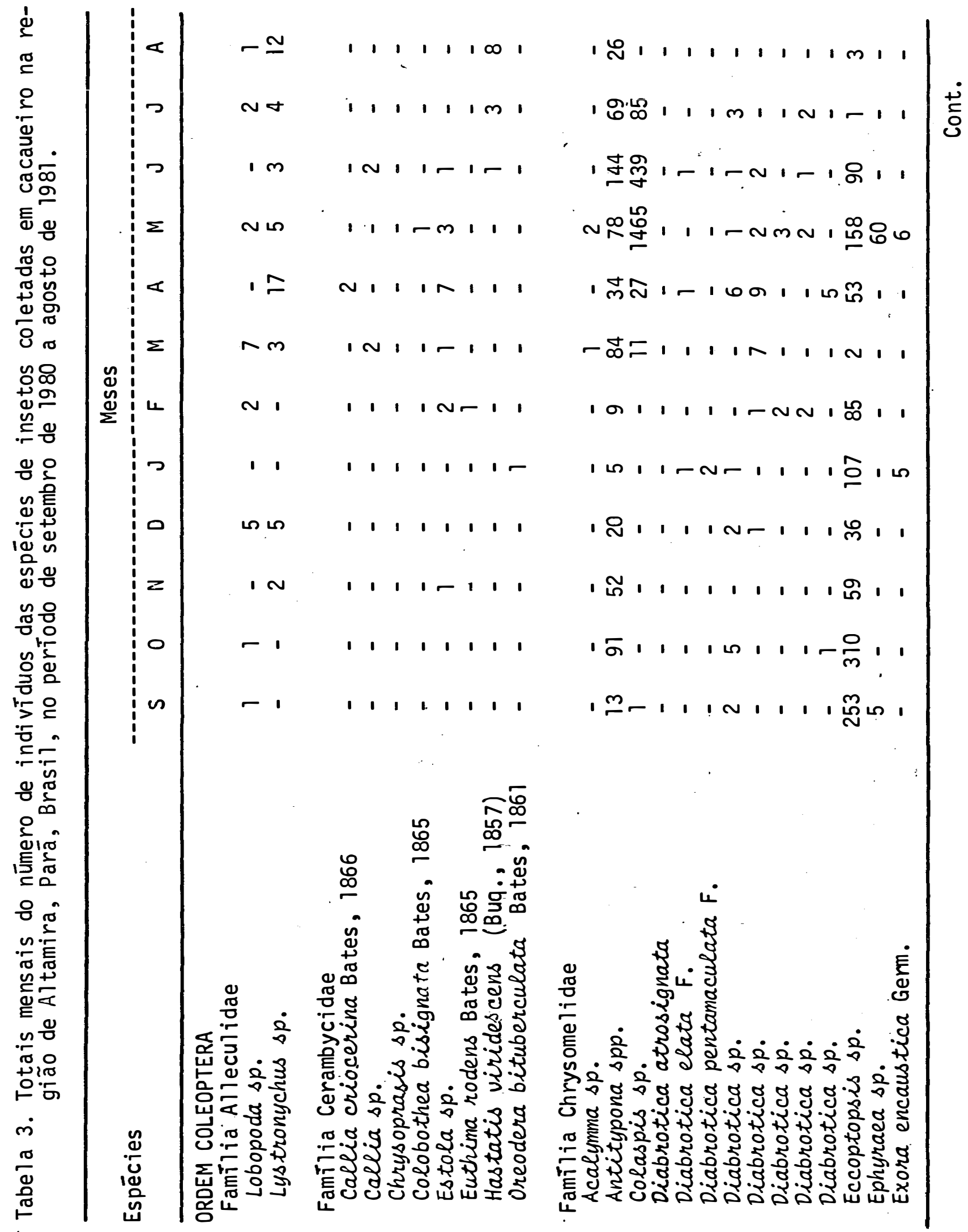




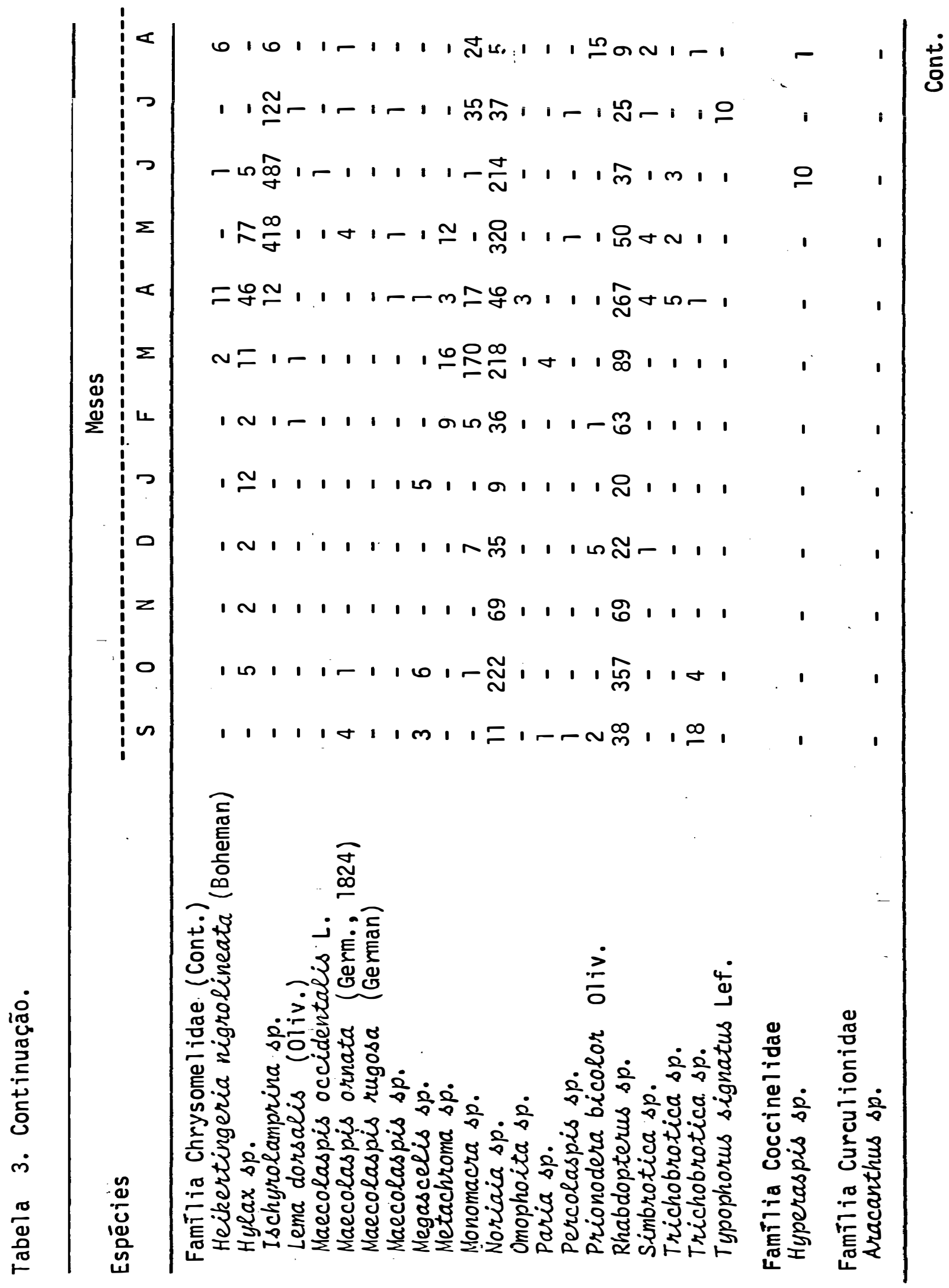




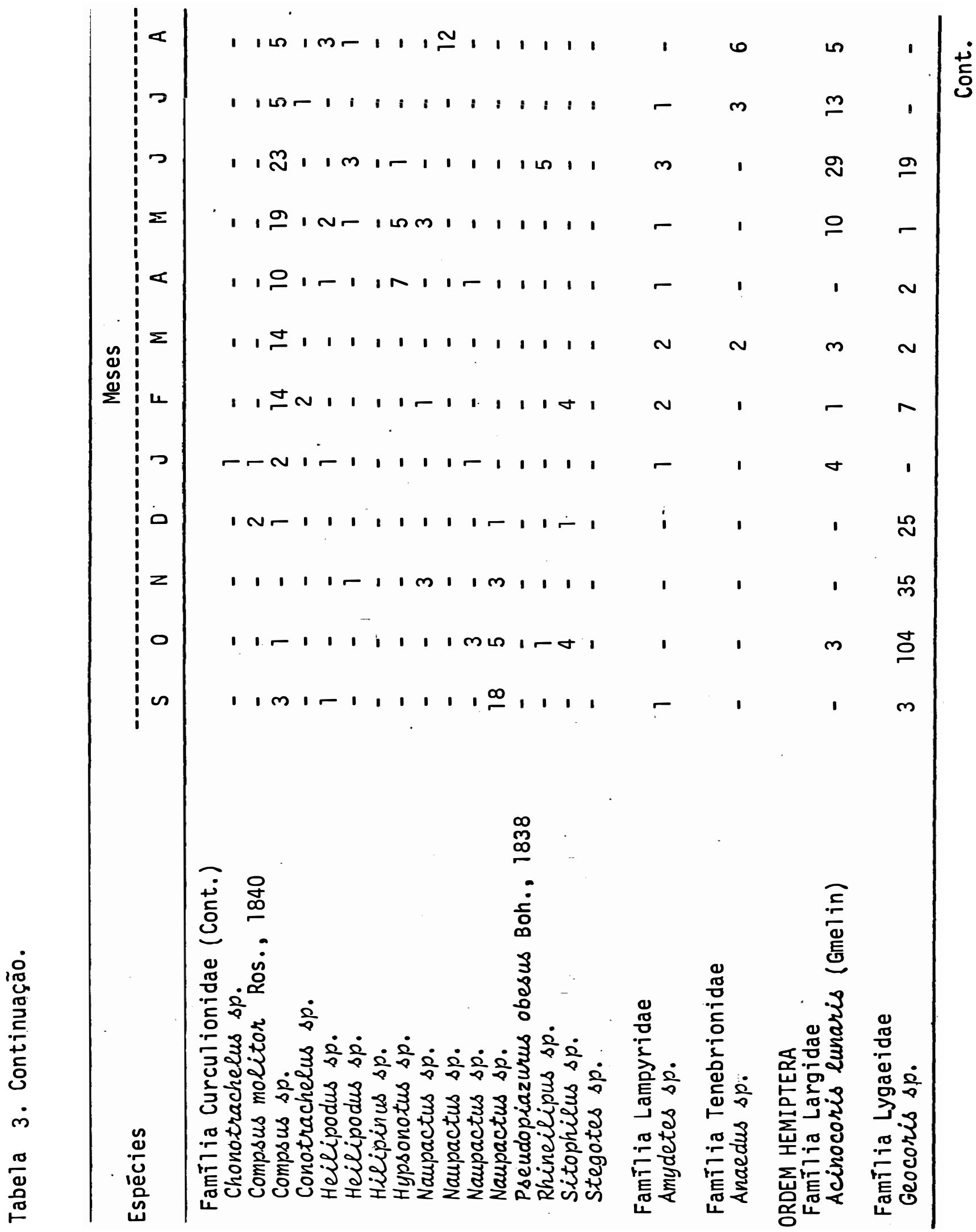




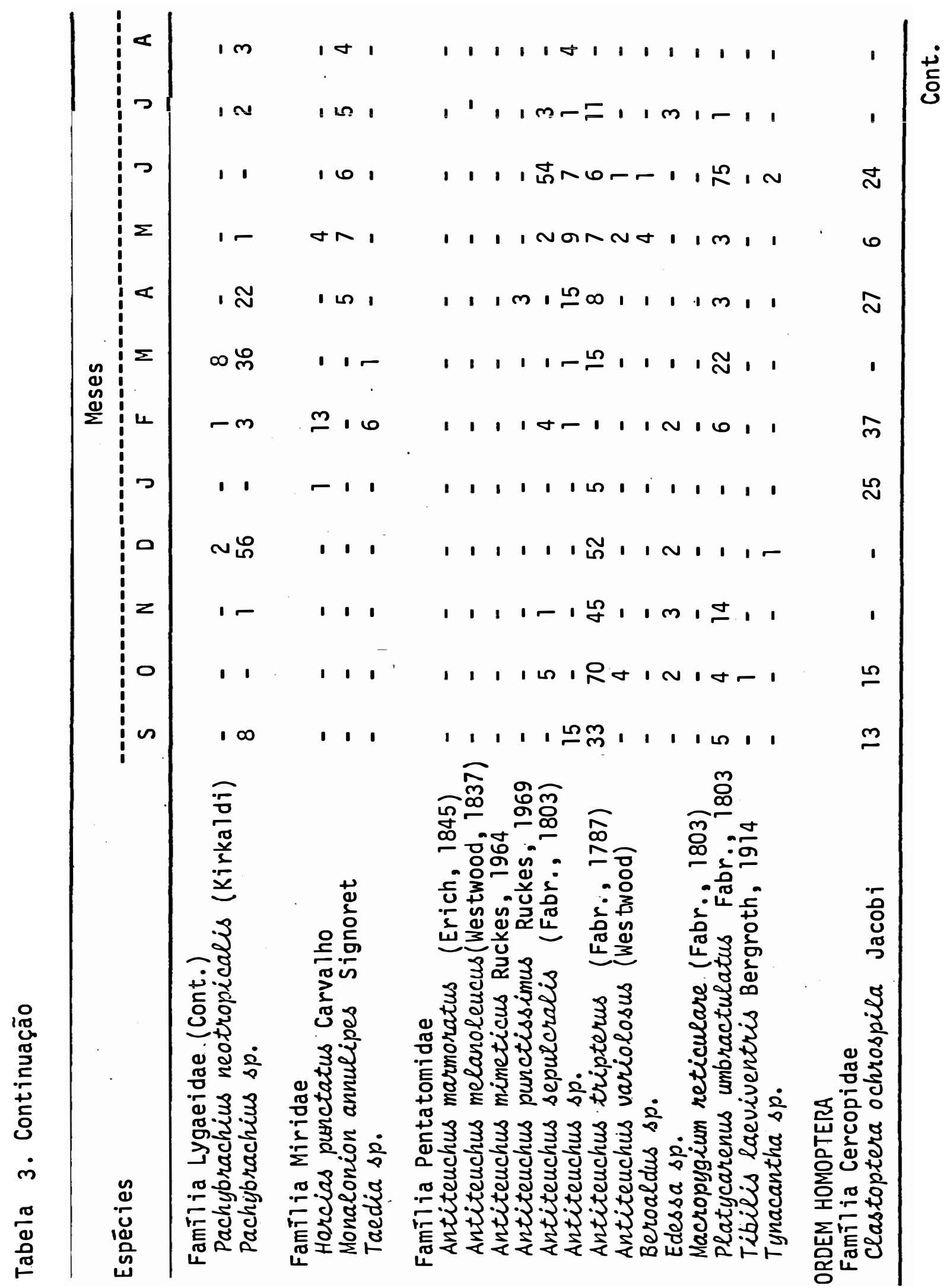




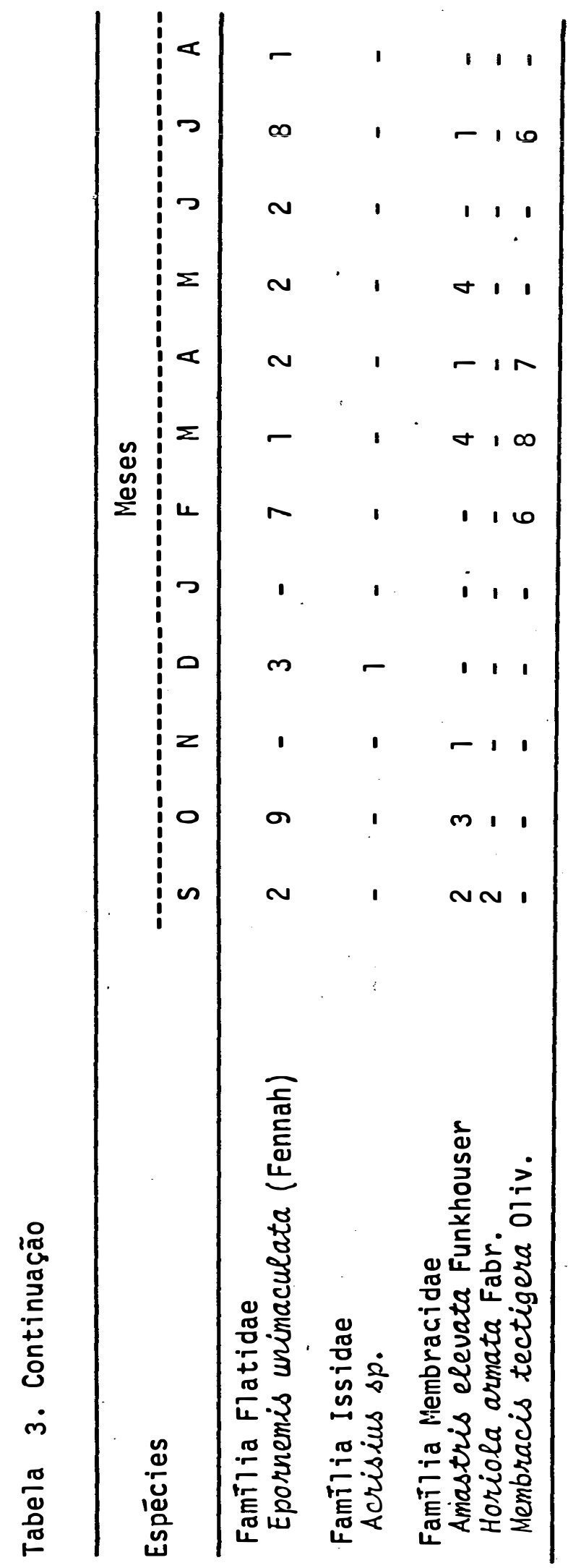




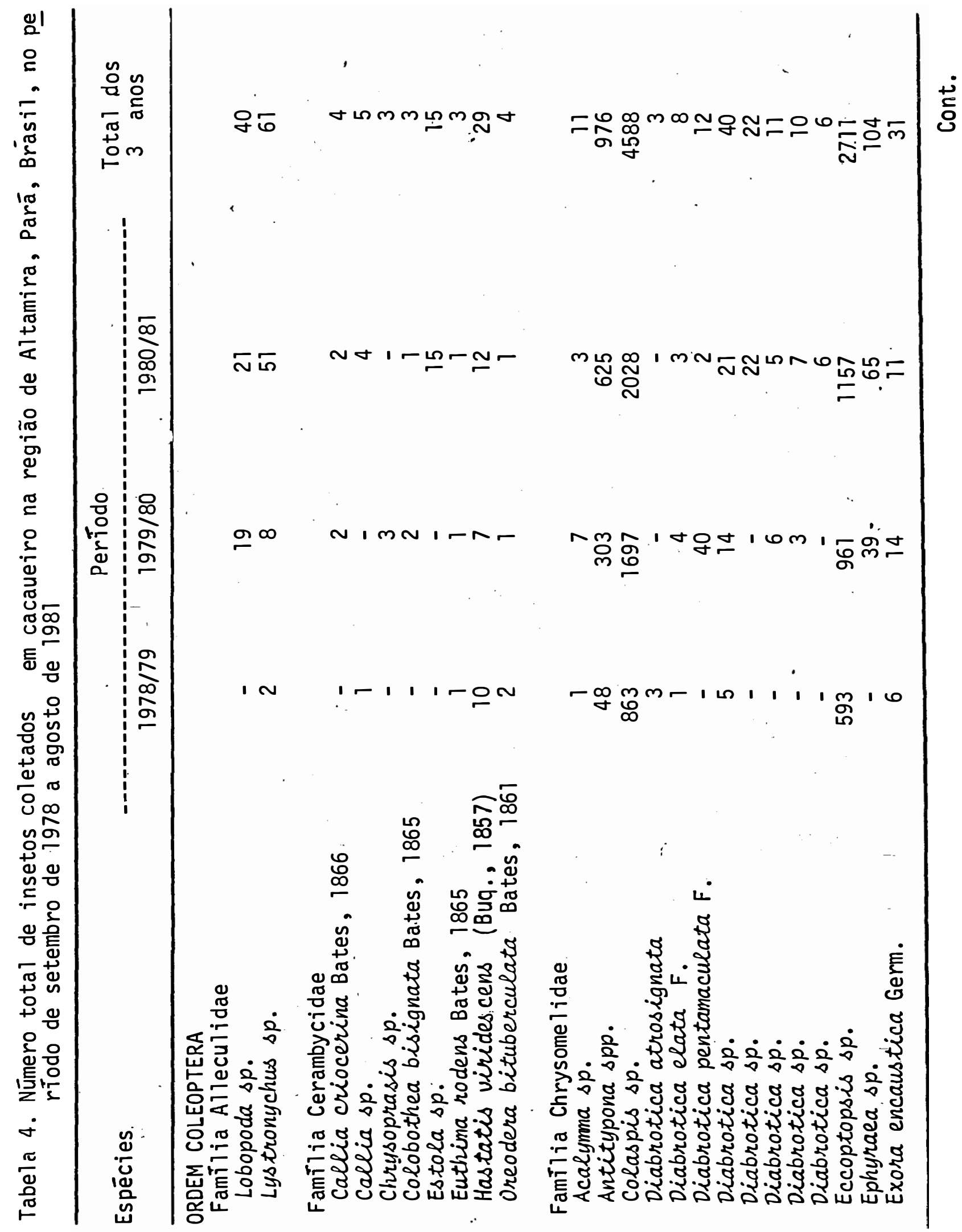




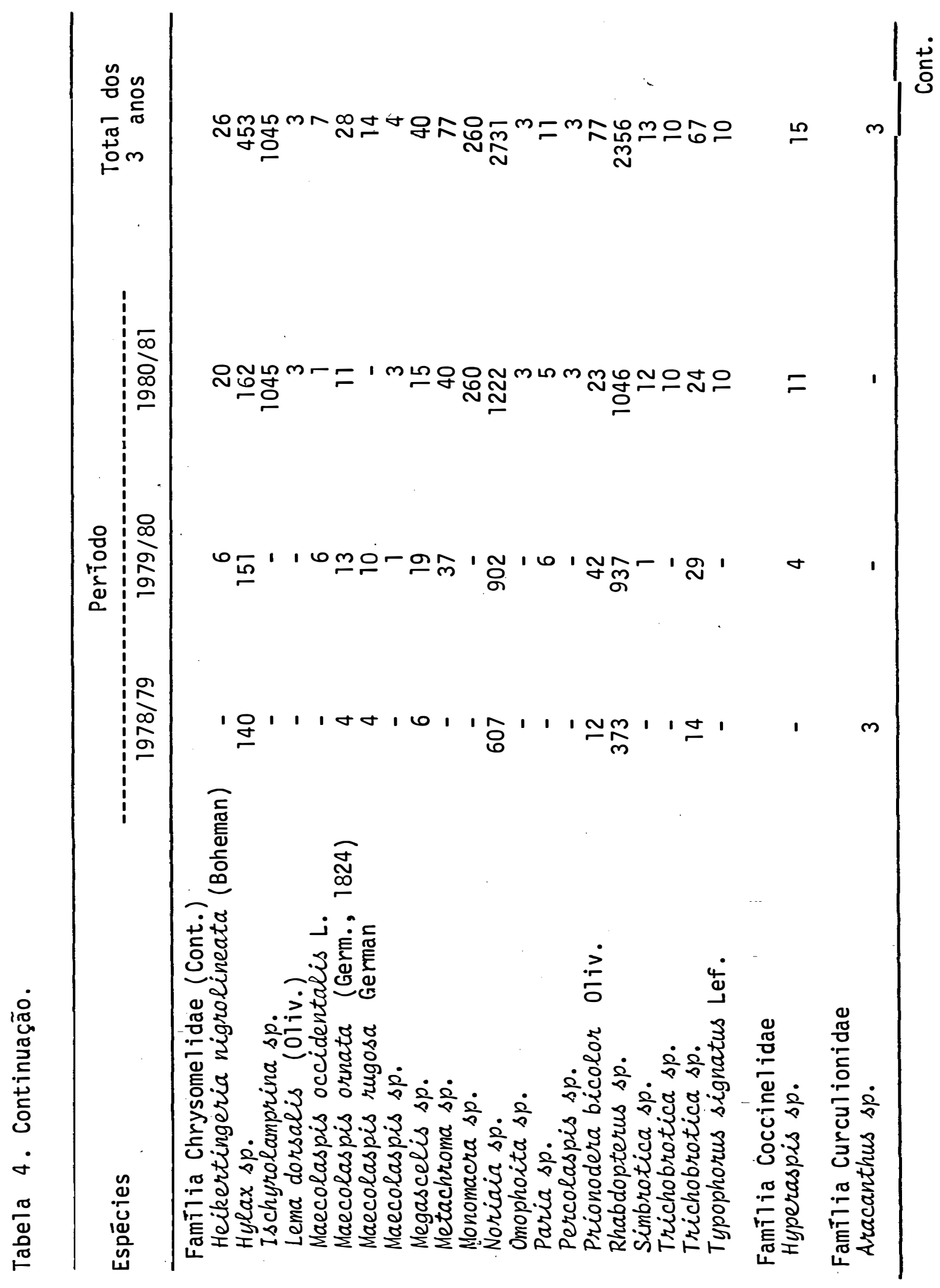


42.

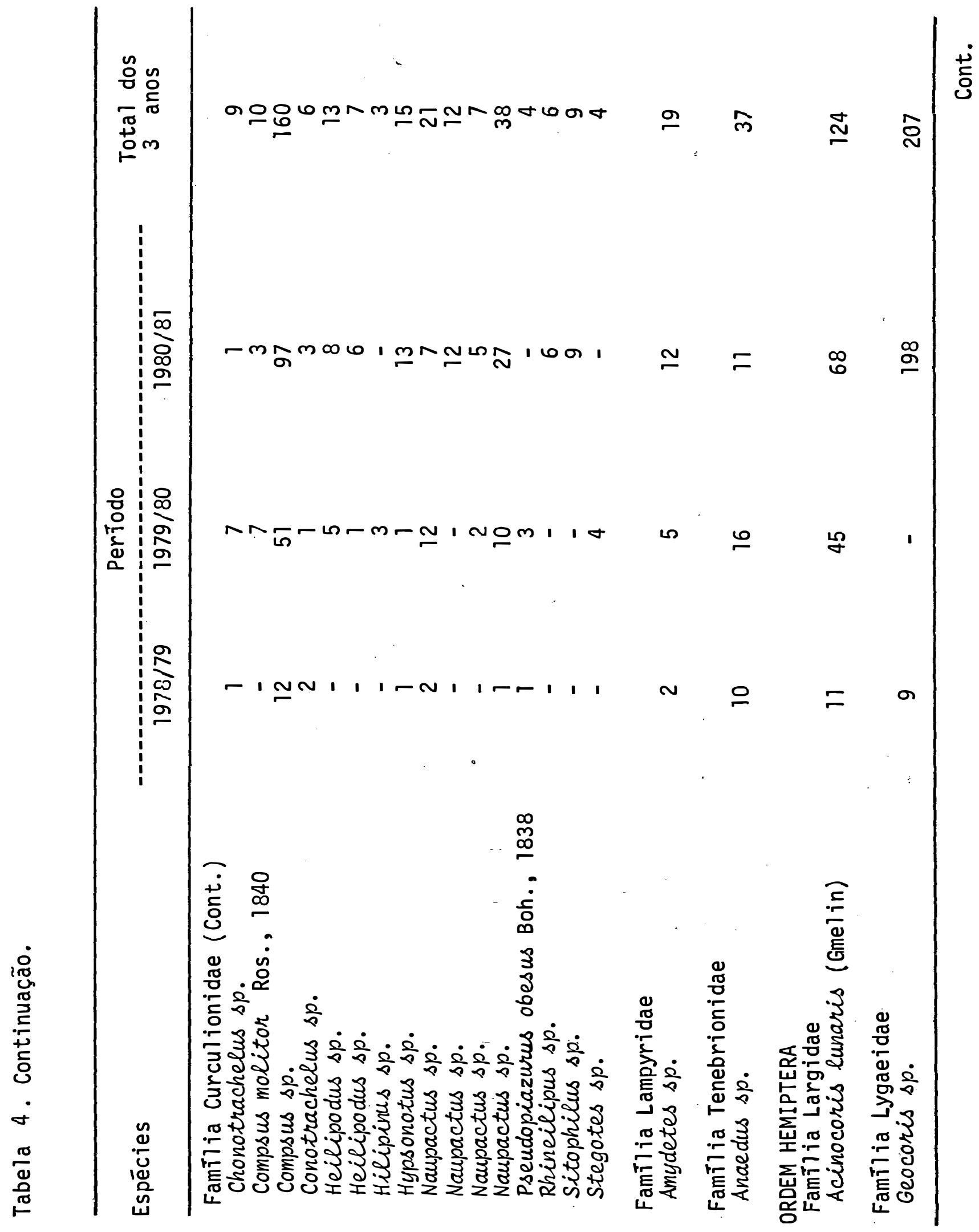


43.

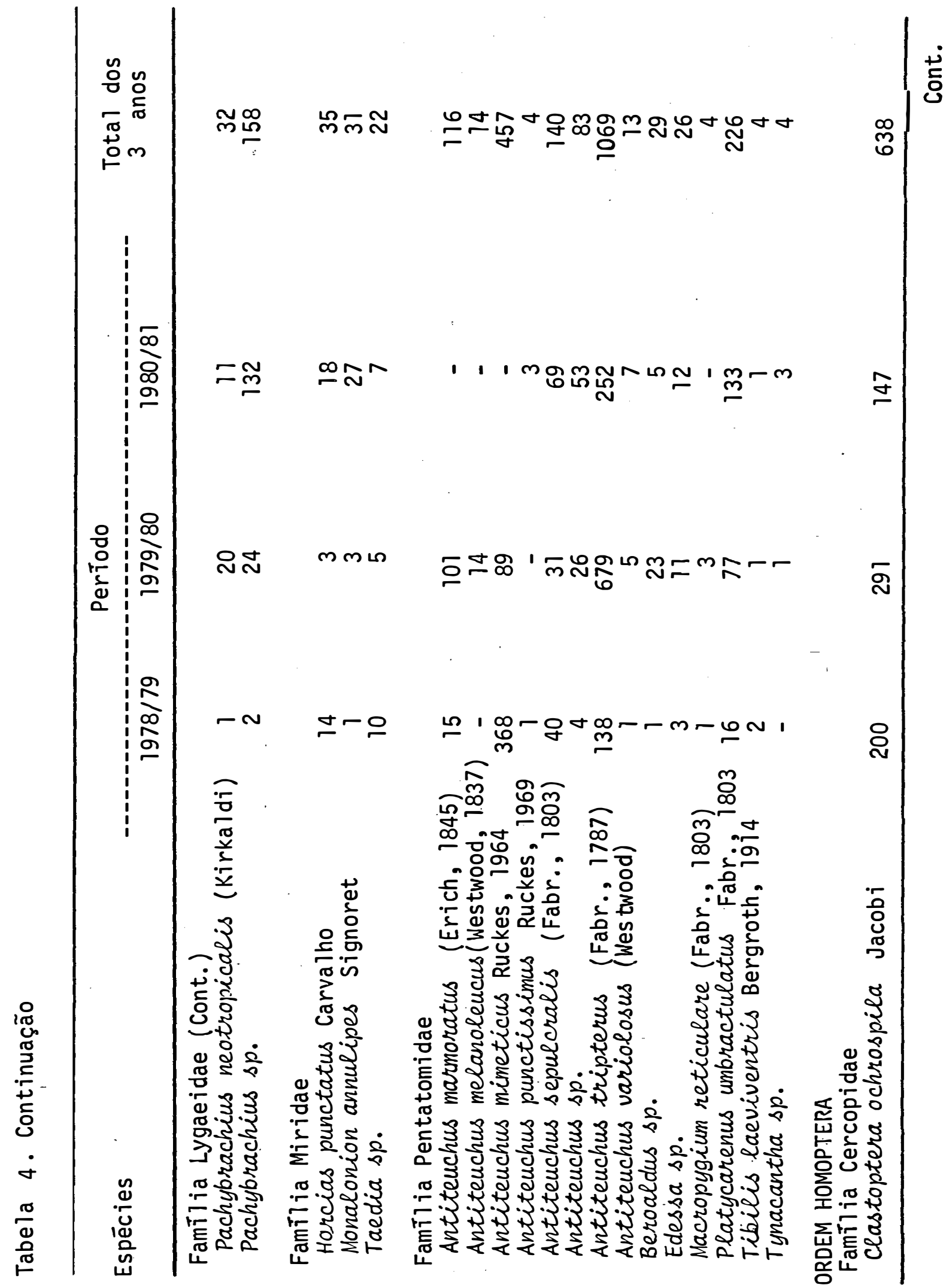


44.

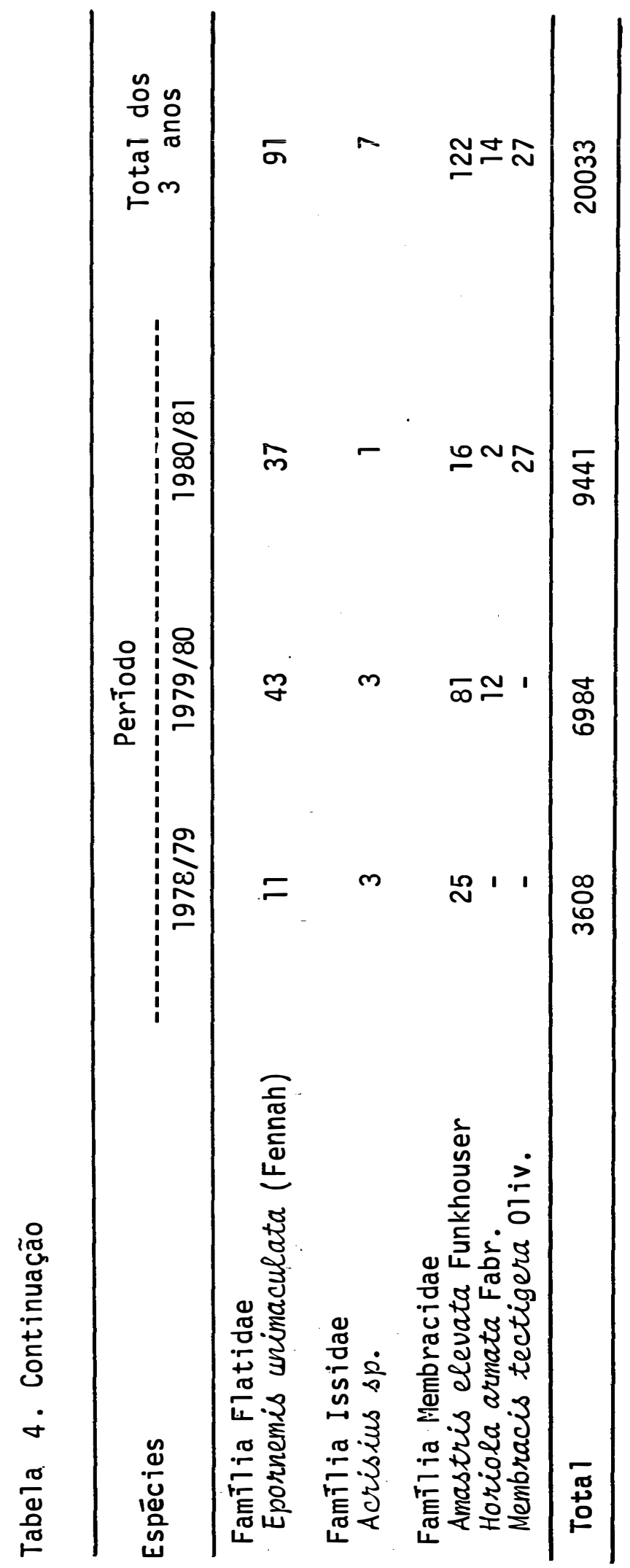


Entretanto, dentre as espécies que foram possíveis de serem identificadas, selecionaram-se 92 para o presente estudo, com um total de 20.033 indivíduos coletados, que representam $86 \%$ do total geral coletado no período de 1978/ 81. Foram capturados 3.608 indivíduos no período de 1978/79, 6.984 em 1979/80 e 9.441 em 1980/81, distribuídos entre as or dens Coleoptera, Hemiptera e Homoptera.

Observaram-se que ocorreu um aumento muito acen tuado no número de indivíduos capturados entre o primeiro e ūltimo anos de amostragens (Tabela 4).

A ordem Coleoptera foi a que mais destacou-se, apresentando 65 espécies, com um total de 16.336 indivíduos capturados e distribuídos em 7 famílias, sendo que somente da famīịa Chrysomelidae foram capturadas 35 espécies, com 15.771 indivíduos. Nessa família evidenciaram-se as espécies colaspis sp. com 4.588 indivíduos capturados, seguida de Noriaia sp. com 2.731 indivíduos, Eccoptopsis sp. com 2.711 indivíduos e Rhabdopterus sp. com 2.356 indivíduos. A presença de altas populações destas espécies, demonstra a sua adaptabilidade à cultura do cacaueiro.

Em seguida vem a ordem Hemiptera com 2.1 espécies e 2.798 indivíduos, sendo 2.189 da família Pentatomidae, com 14 espécies. Dentro desta família, observa-se que Antiteuchus tripterus (Fabr., 1787) e Platycarenus umbractulatus Fabr., 1803 foram as espécies que mais se destacaram. 
Finalmente, a ordem Homoptera com 6 espécies e 899 indivíduos, sendo Cercopidae a principal família com 638 indivíduos e com somente a espécie clastoptera ochrospila Jacobi.

Muitas destas espécies estudadas são também de ocorréncia em outras regiões da Amazónia Brasileira, como pode ser observado pelos trabalhos desenvolvidos por GARCIA e SILVEIRA Neto (1980), no Estado do Parā e MENDES e ROSARIO (1980), nos Estados de Rondónia e Amazonas.

\subsection{MEDIDAS DA FAUNA}

\subsubsection{Freqüēncia}

Constam da Tabela 5 as frequiēncias das espécies coletadas em cacaual, durante o período das amonstragens, cuja variação foi de 0,01 a $22,9 \%$.

Colaspis sp. apresentou a mais alta freqüēncia $(22,9 \%)$, muito superior às apresentadas por Noriaia sp. $(13,63 \%)$, Eccoptopsis sp. $(13,53 \%)$ e Rhabdopterus sp. $(11,76 \%)$. Das espécies restantes, nove delas mostraram freqüéncias entre 1 a $10 \%$ e as demais com valores inferiores a $1 \%$. 


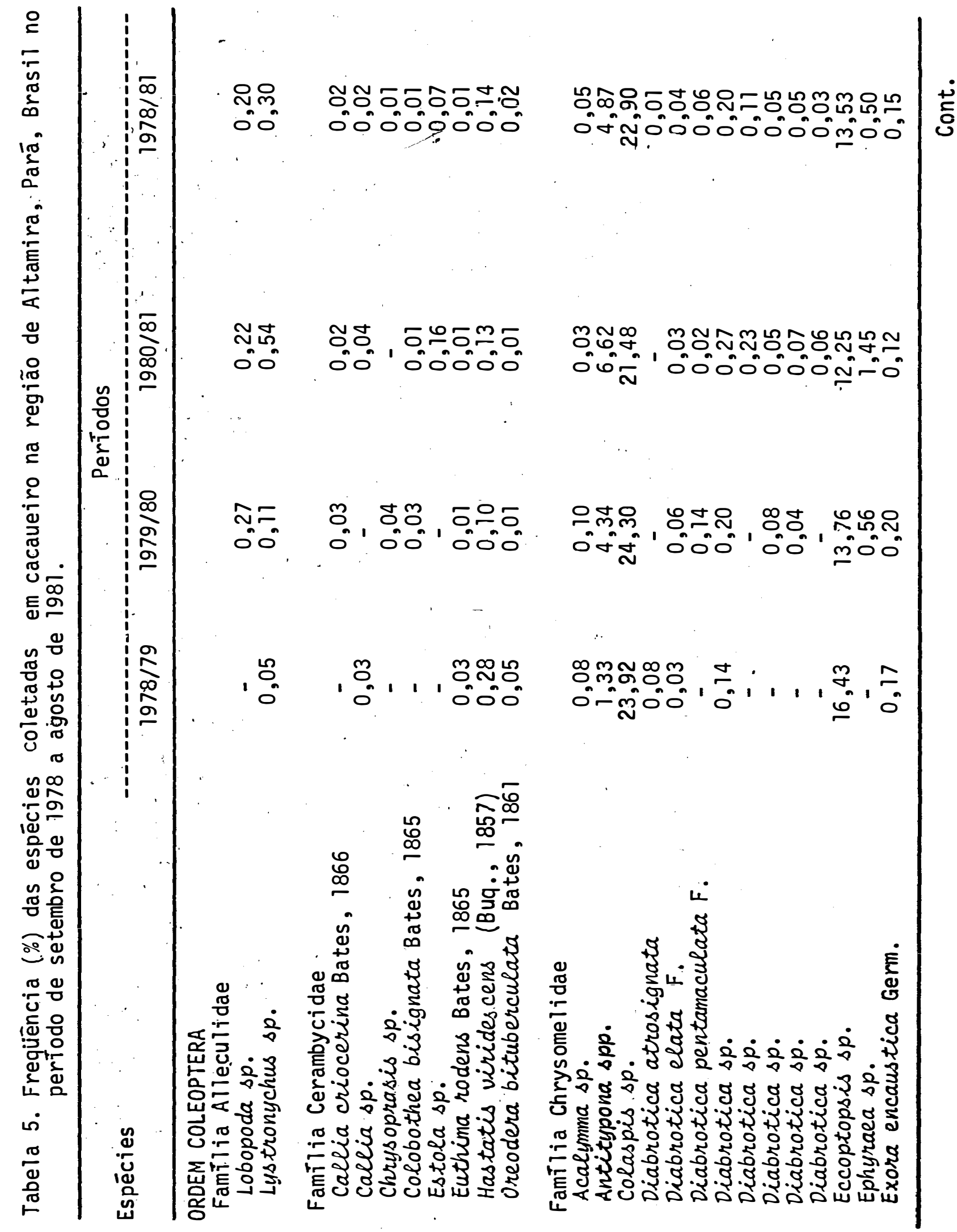




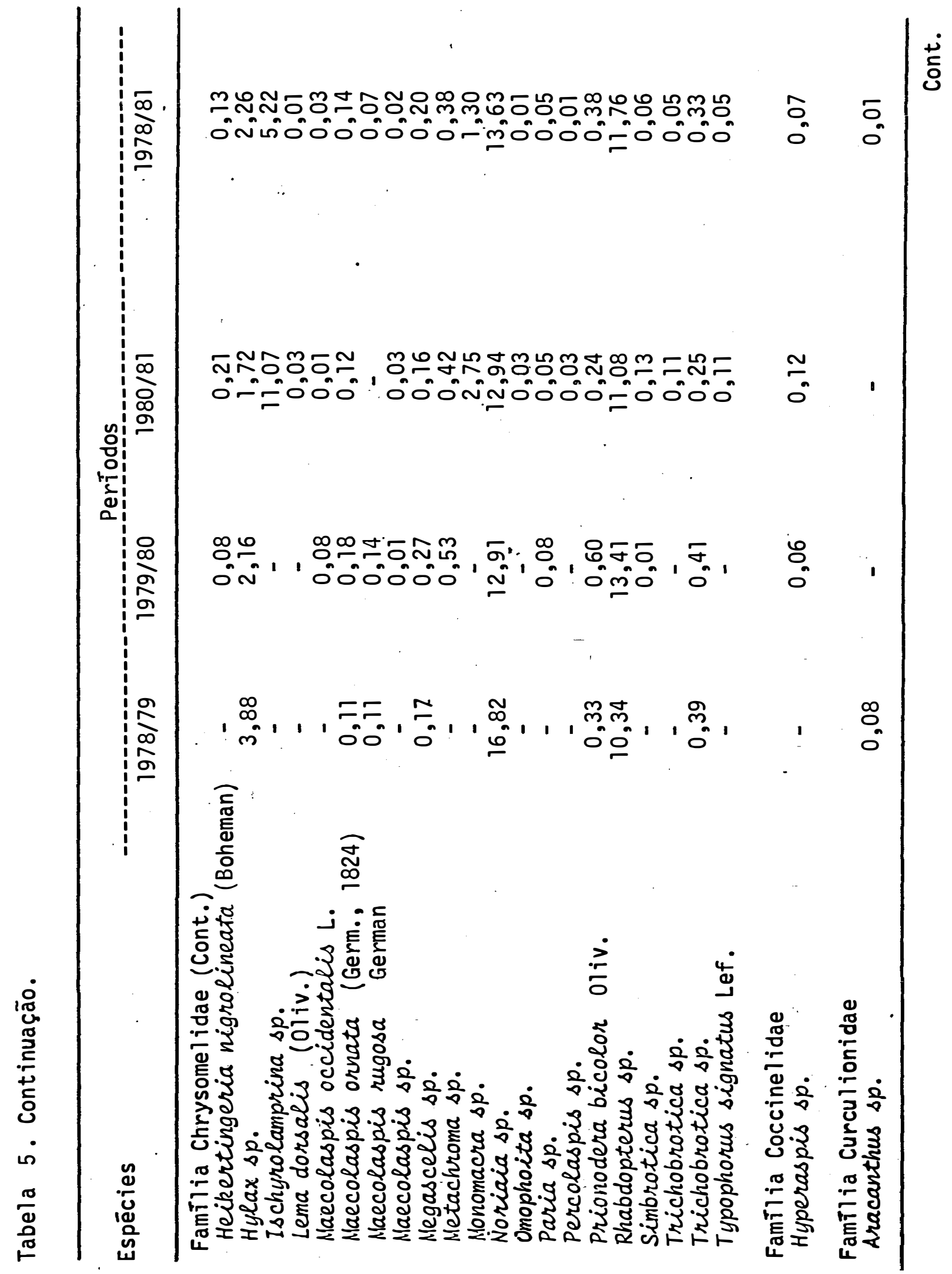




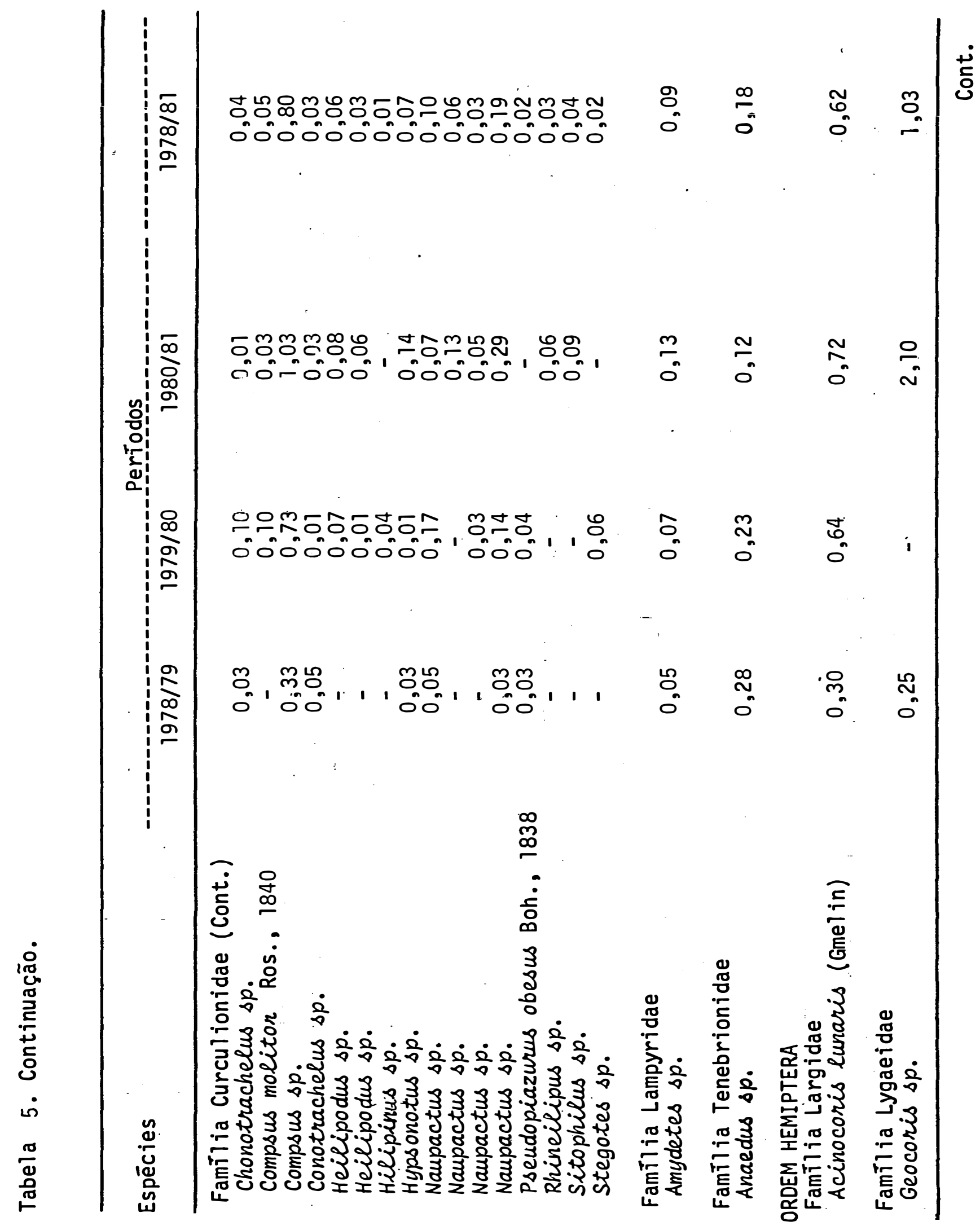




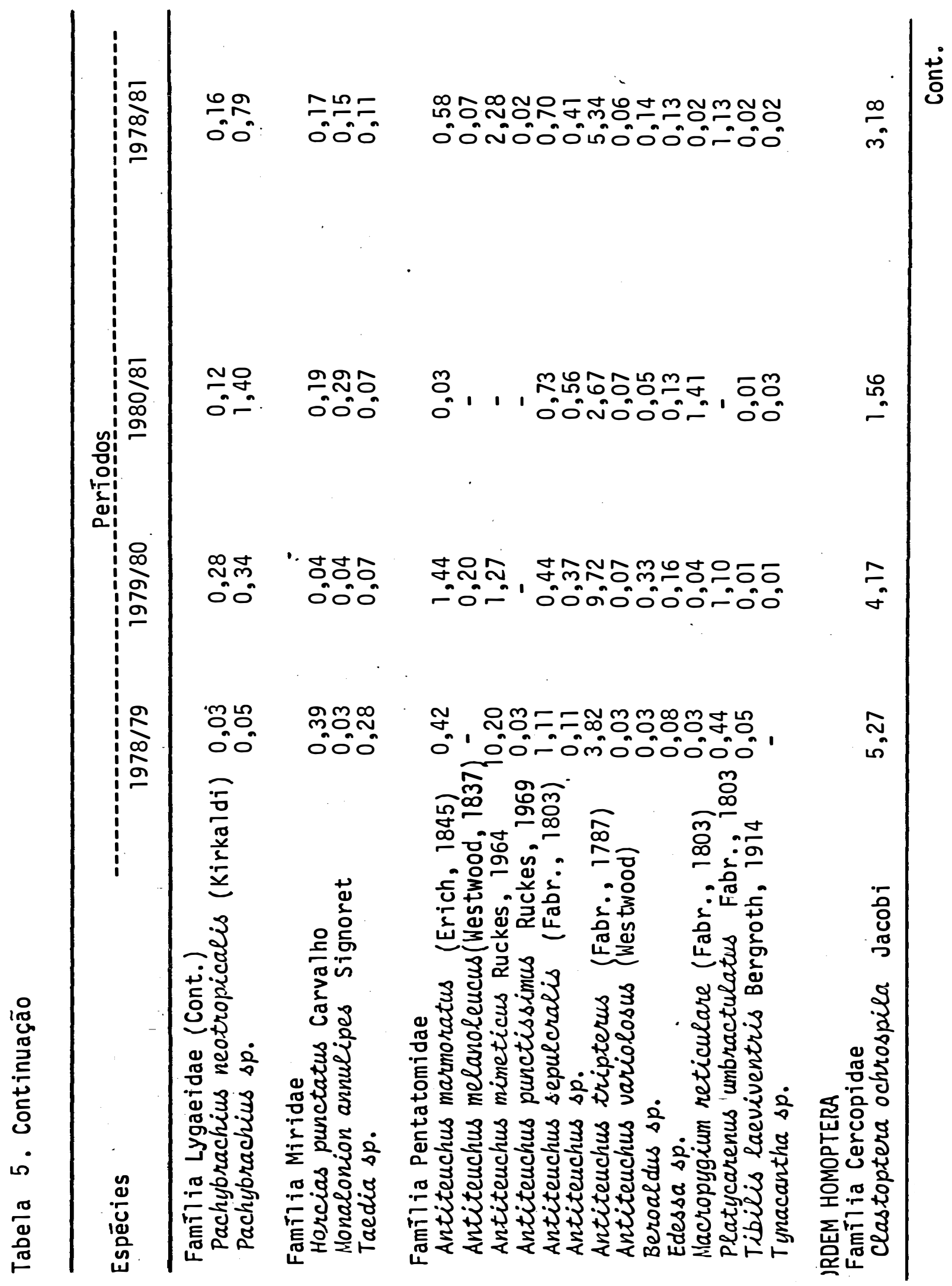




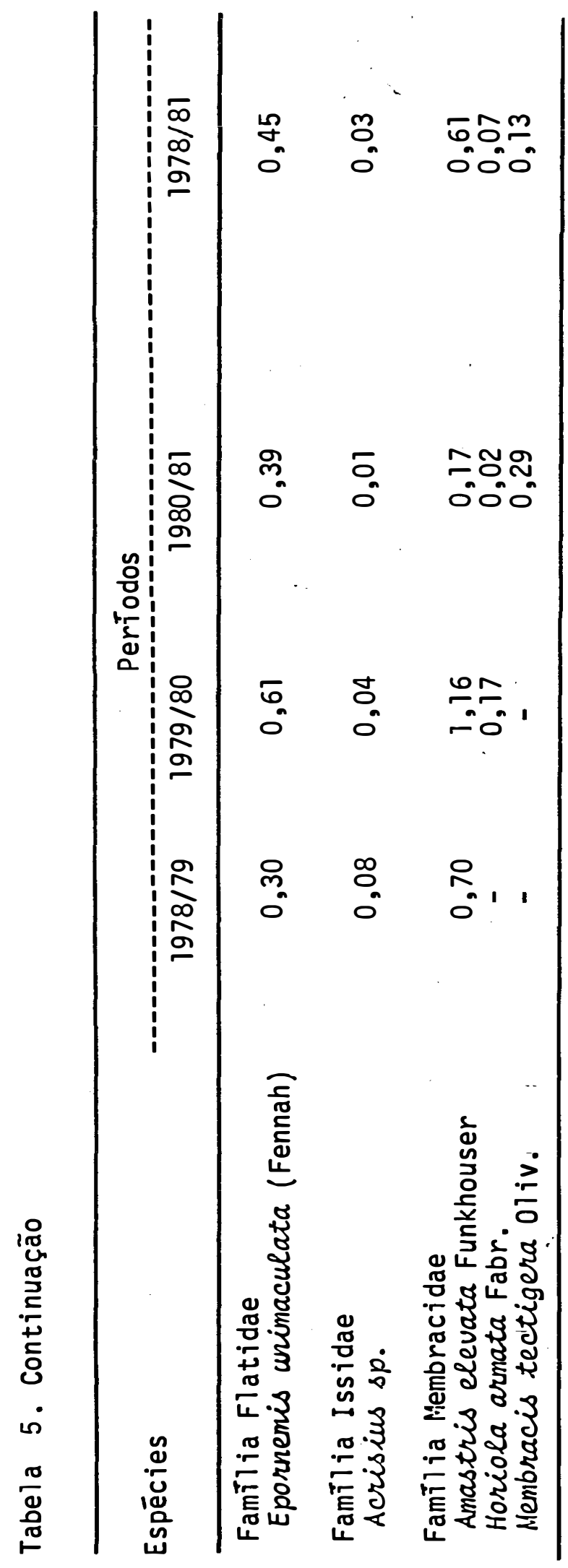


52.

Observa-se a ordem Coleoptera com o maior $n \bar{u}-$ mero de famílias capturadas (Tabela 6), cuja frequiéncia de $46,66 \%$ é superior à das ordens Hemiptera e Homoptera, ambas com $26,67 \%$.

A nīvel de espēcie, a ordem Coleoptera tambēm foi a de maior destaque, apresentando $70,65 \%$ das espécies, se guida das ordens Hemiptera $(22,83 \%)$ e Homoptera $(6,52 \%)$ (Tabela 6$)$.

Ainda com relação ao nūmero de espécies observa-se que na orden Coleoptera (Figura 1), a maior frequéncia diz respeito a família Chrysomelidae $(53,85 \%)$, seguida das familias Curculionidae $(26,15 \%)$ e Cerambycidae $(12,31 \%)$, sendo que as demais apresentam frequièncias de 3,07 e $1,54 \%$. Com uma freqüéncia de $66,67 \%$ a famîlia Pentatomidae foi a de maior destaque na ordem Hemiptera (Figura 2). As famílias Lygaeidae e Miridae vem logo a seguir, ambas com freqüència de $14,28 \%$.

Para a ordem Homoptera, foi registrada uma fre qüēncia de $50 \%$ para a famîlia Membracidae, enquanto todas as demais apresentaram valores de $16,66 \%$ (Figura 3 ). 
53.

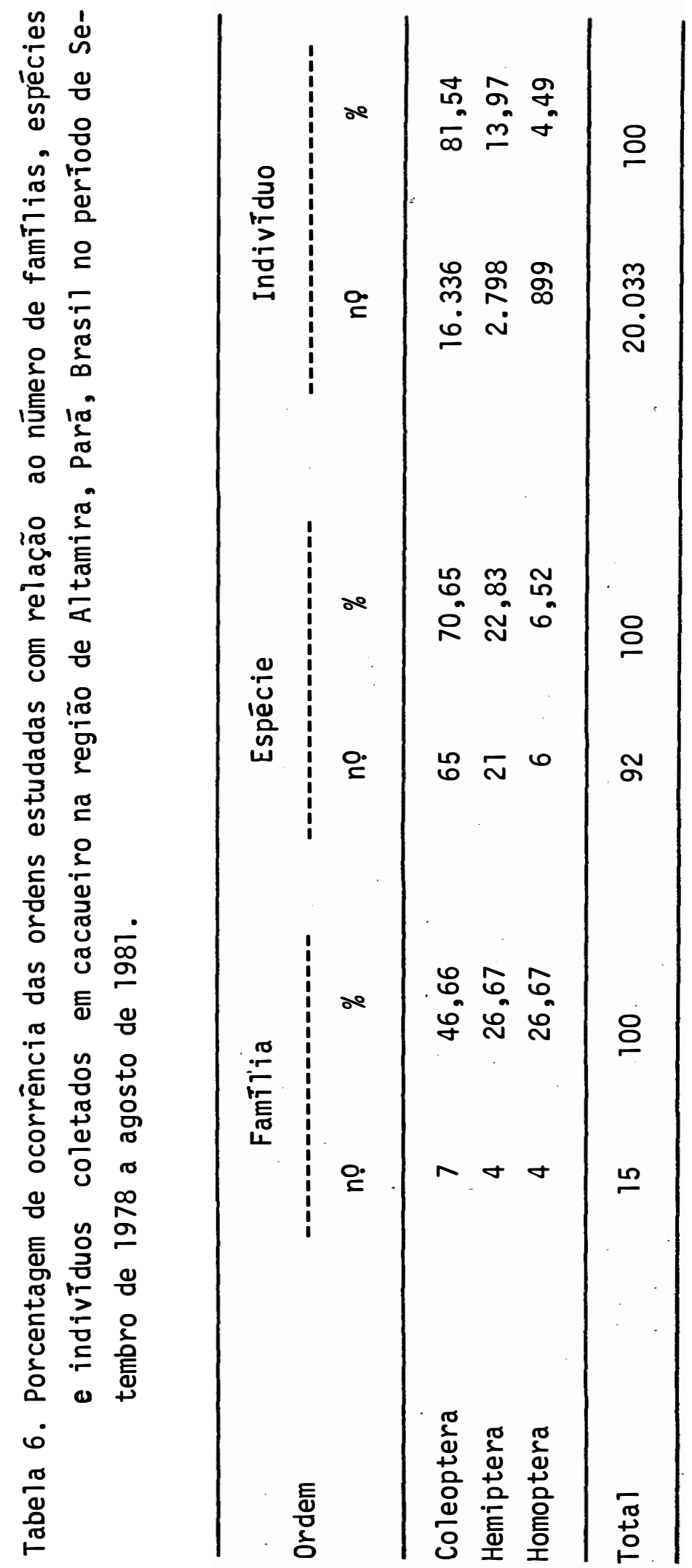



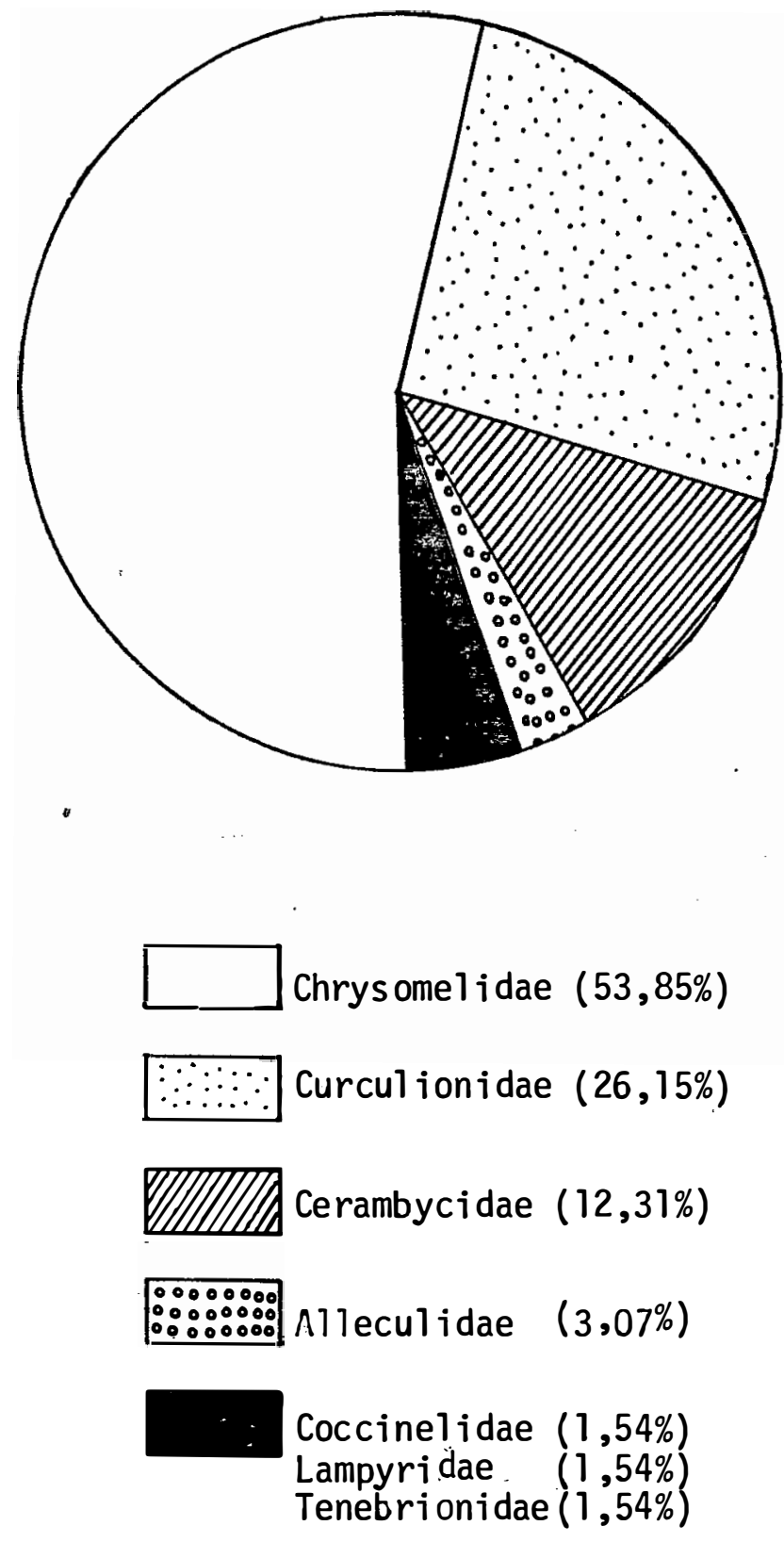

Figura 1. Freqüēncia das famílias da ordem Coleoptera coleta das em cacaueiro no período de setembro de 1978 a agosto de 1981. Altamira, Parā, Brasil. 


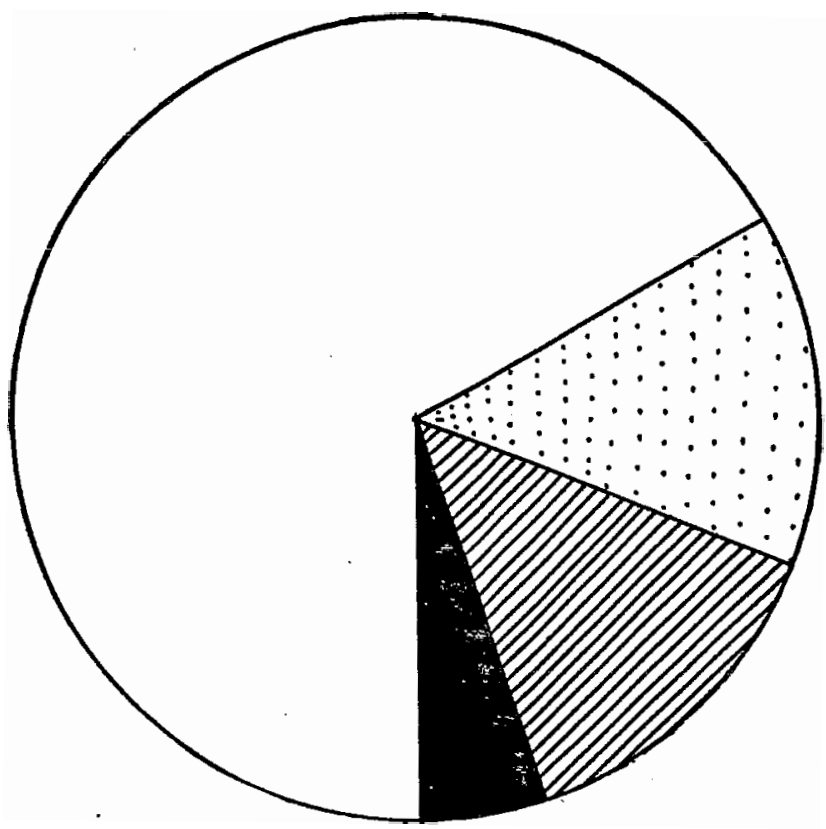

Pentatomidae $(66,67 \%)$

$\left[\begin{array}{ll}0: \vdots \\ \hdashline: \because\end{array}\right]$ Lygaeidae $(14,28 \%)$

QIIAlA Miridae $(14,28 \%)$

Largidae $(4,77 \%)$

Figura 2. Frequência das famīlias da ordem Hemiptera coletadas em cacaueiro no período de setembro de 1978 a agosto de 1981. Altamira, Parā, Brasil. 
56.
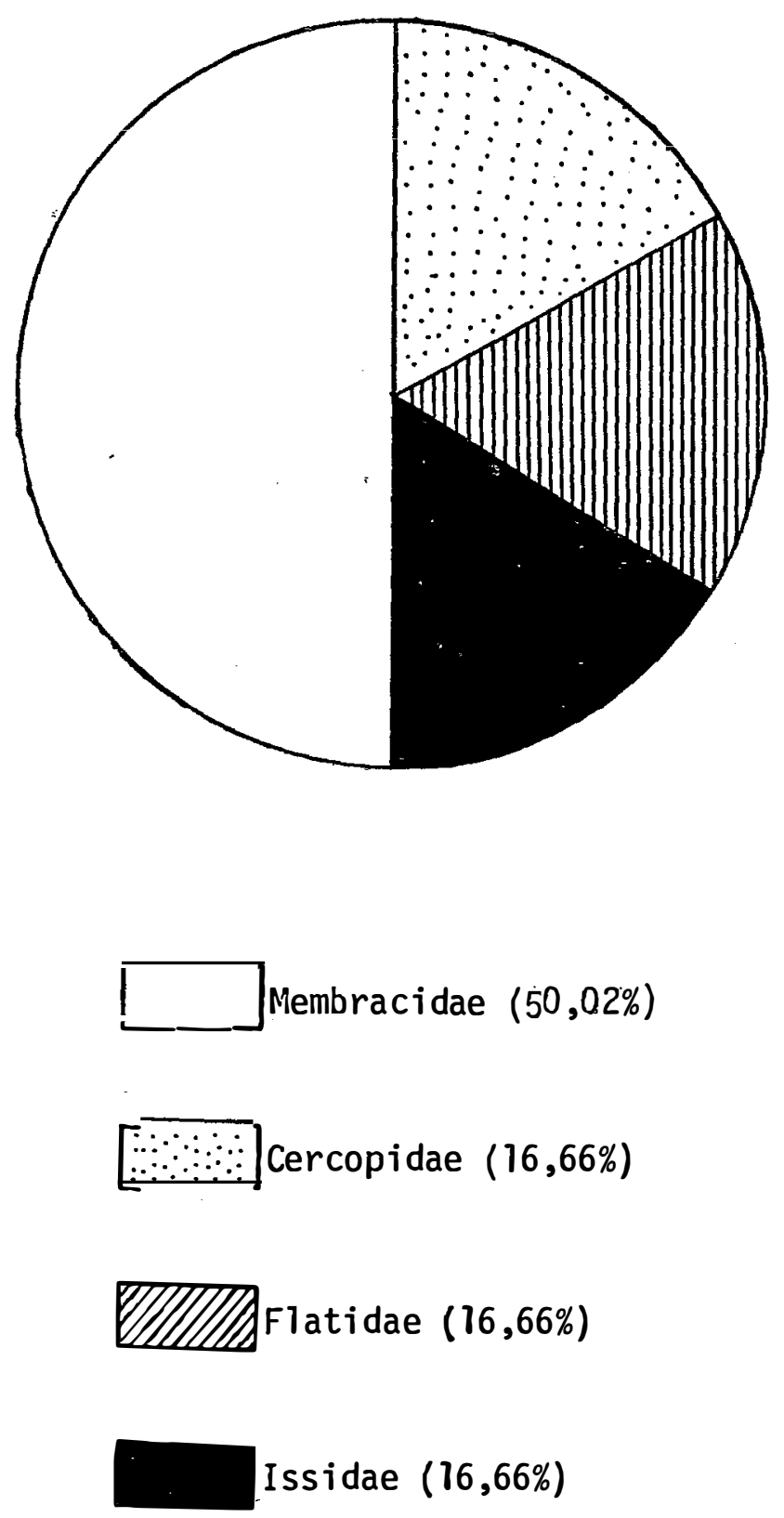

Figura 3. Frequiência das famílias da ordem Homoptera coletadas em cacauei ro no período de setembro de 1978 a agosto de 1981. Altamíra, Parā, Brasil. 
A familia Chrysomelidae destacou-se com a maior frequência (38\%), seguida das famîlias Curculionidade $(18,5 \%)$, Pentatomidae $(15,2 \%)$ e Cerambycidae $(8,7 \%)$, sendo que nas de mais familias a frequēncia variou de $3,26 \%$ a $1,09 \%$ : (figura 4).

\subsubsection{Constāncia}

A separação das espécies de acordo com a constância, está na tabela 7 . Observa-se que para a região em estudo, 13 espécies apresentaram-se como constantes, 20 foram acessórias e 59 acidentais, e que são mostrados na tabela 8, com as respectivas porcentagens.

Isto demonstra que, de todos os insetos estuda dos, as espécies: Colaspis sp., Noriaia sp., Eccoptopsis sp., Rhabdopterus sp., A. tripterus (Fabr., 1787), Antitupona spp. C. ochrospila Jacobi, Hilax sp., P. umbractulatus Fabr.,1803, Compsus sp., Acinocoris lunaris (Gmelin), Amastris elevata Funkhouser e Epormenis unimaculata (Fennah), estão constantemente presentes na cultura do cacaueiro, caracterizando sua perfeita adaptação à esta cultura. Estas espécies represen = tam $14,13 \%$ da fauna estudada na região de Altamira.

E evidente, portanto, o maior número de espécies adaptadas ao cacaueiro nesta região, quando comparadas com os resultados obtidos por GARCIA é SILVEIRA NETO (1980), também no Pará, onde registraram para a região Bragantina so- 
58.
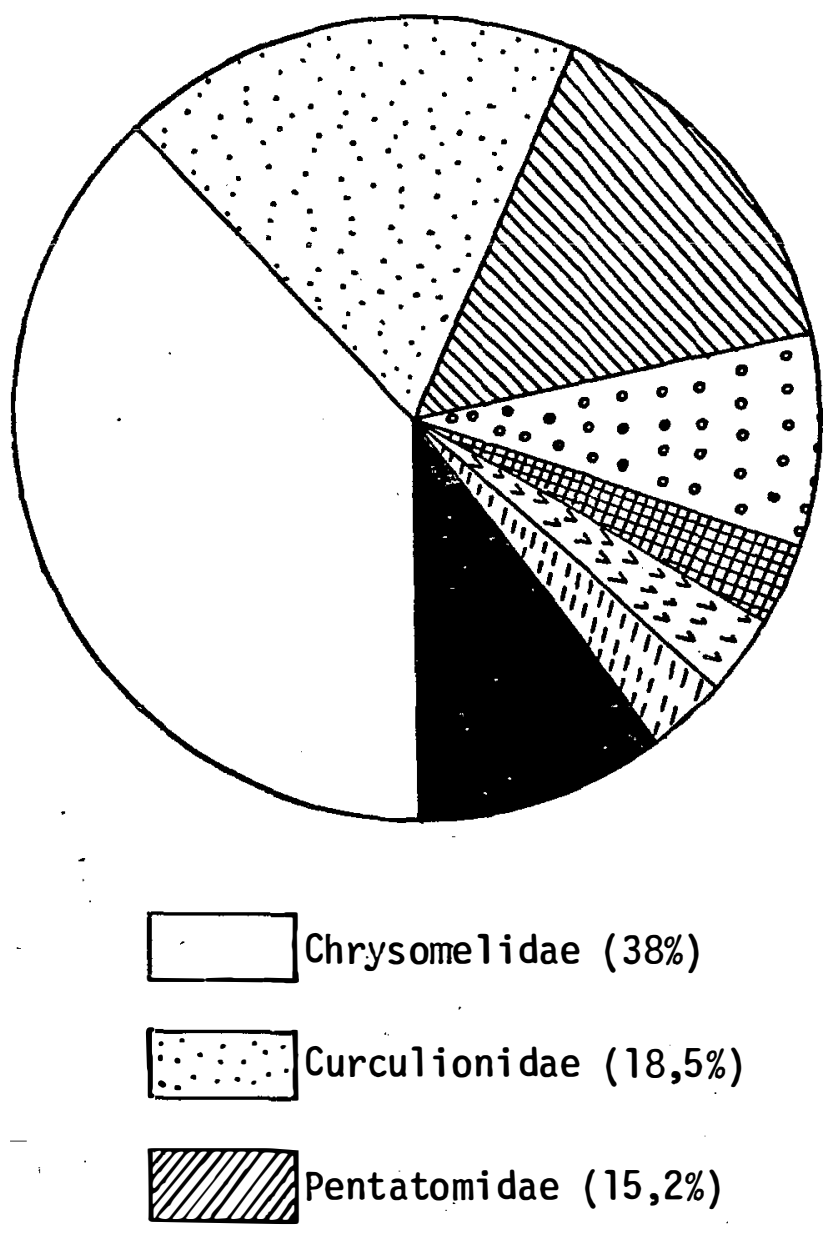

$\because \because \because 0$ Cerambycidae $(8,7 \%)$

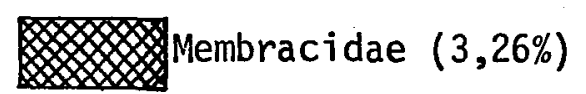

$[\wedge \wedge \wedge \wedge$ Miridae $(3,26 \%)$

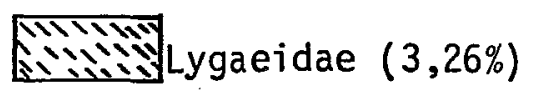

Outras $(2,17 \bar{a} 1,09 \%)$

Figura 4. Frequēencia das famīlias de insetos coletadas em cacaueiro no período de setembro de 1978 a agosto de 1981. Altamira, Pará, Brasil. 


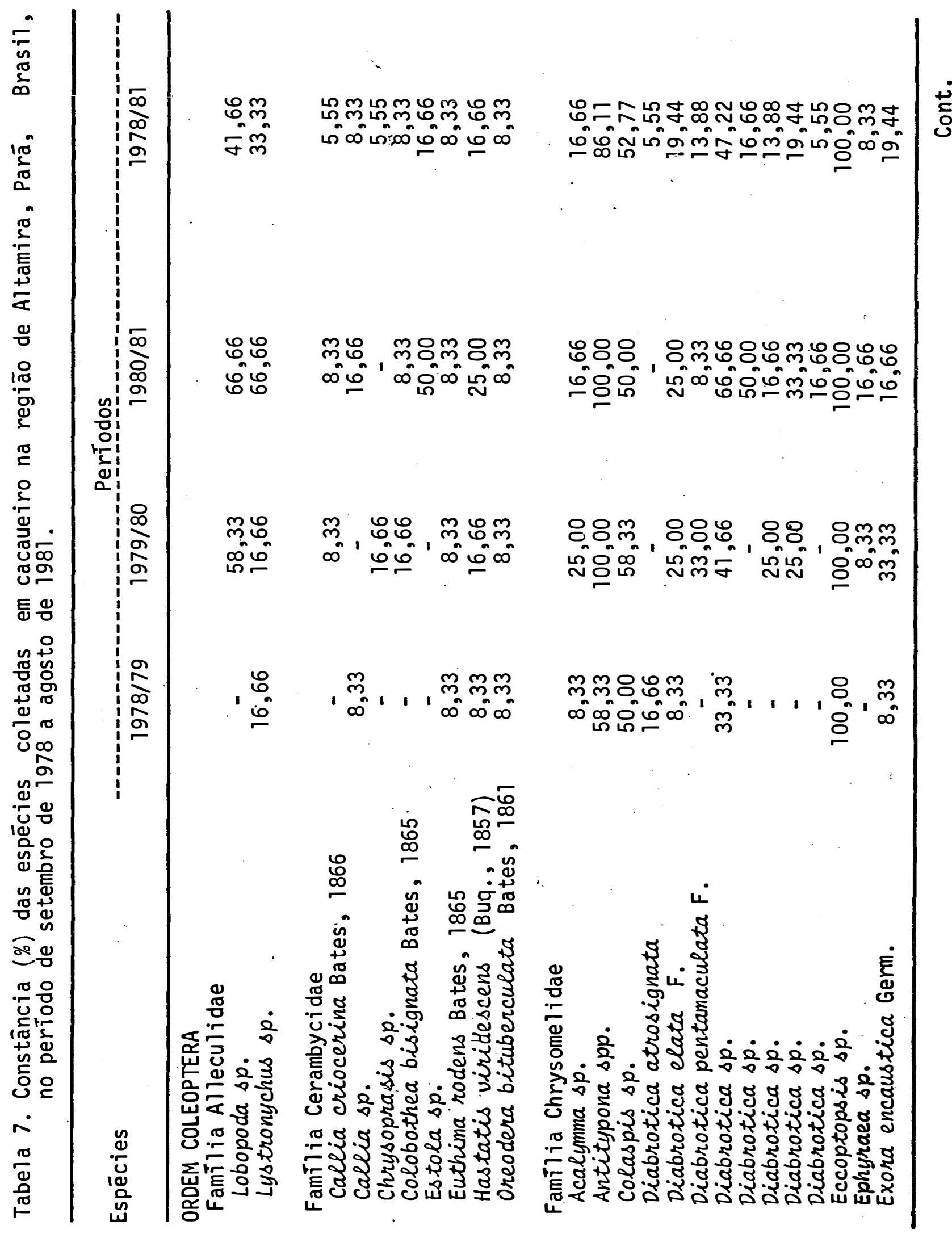




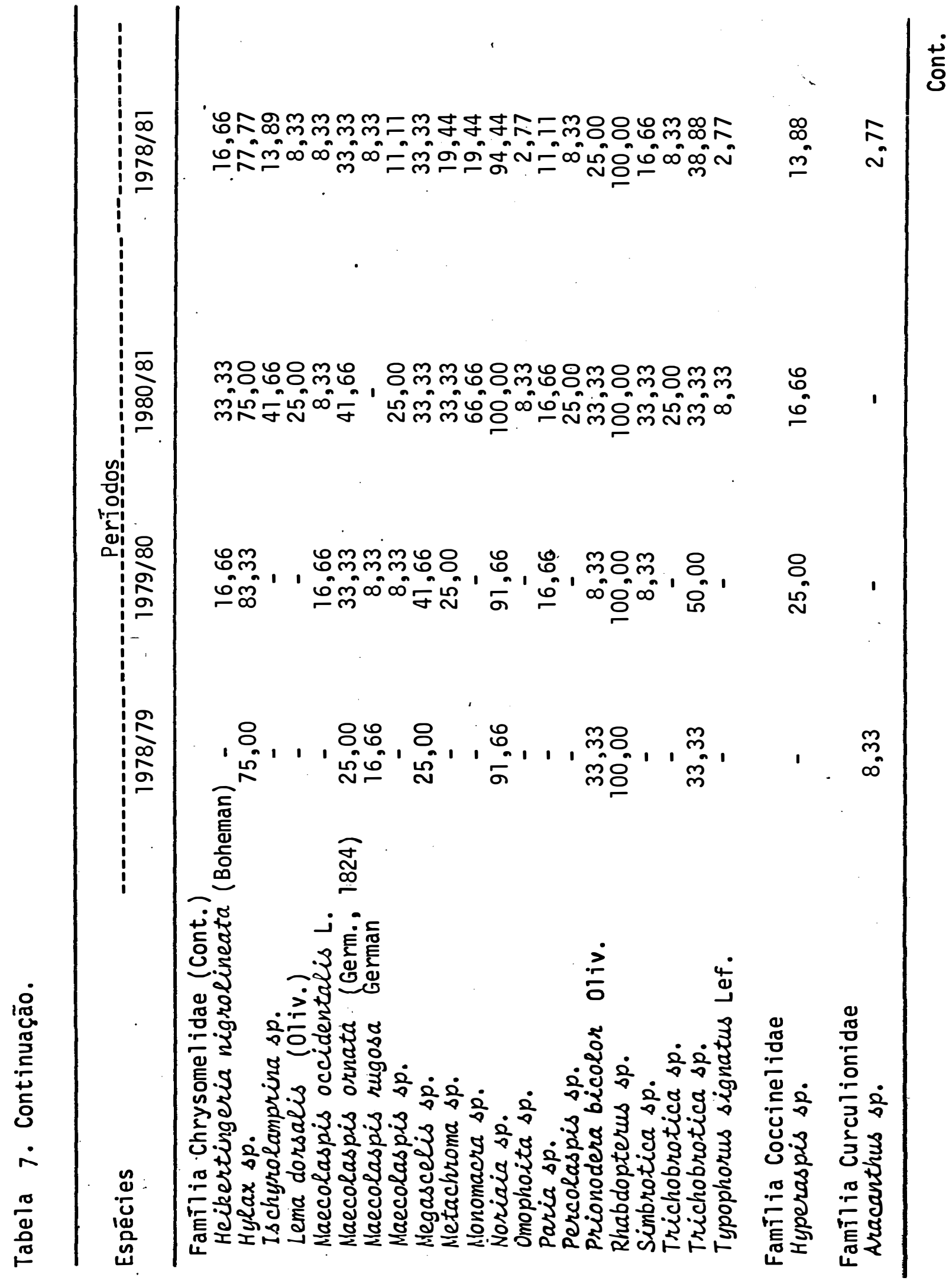




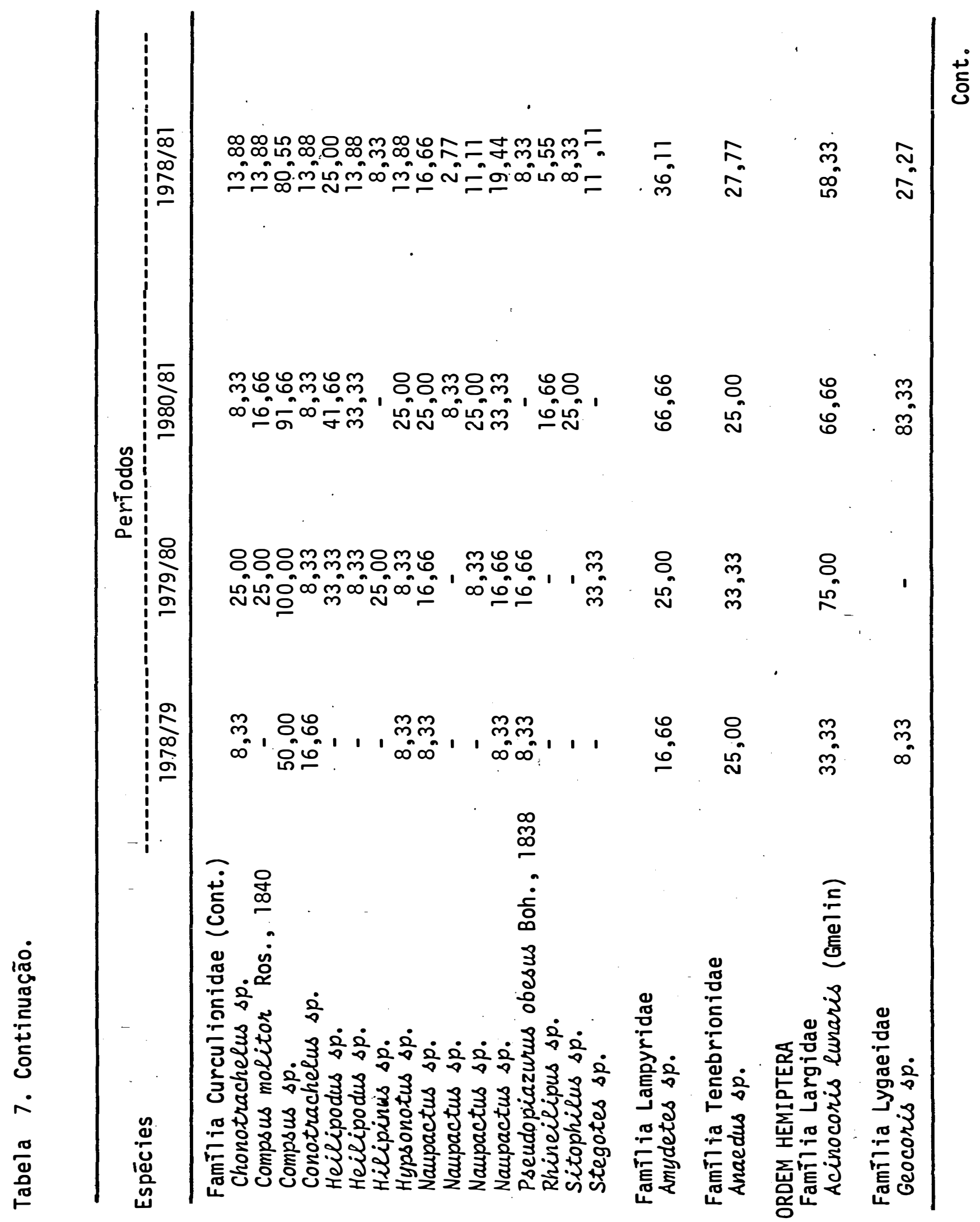




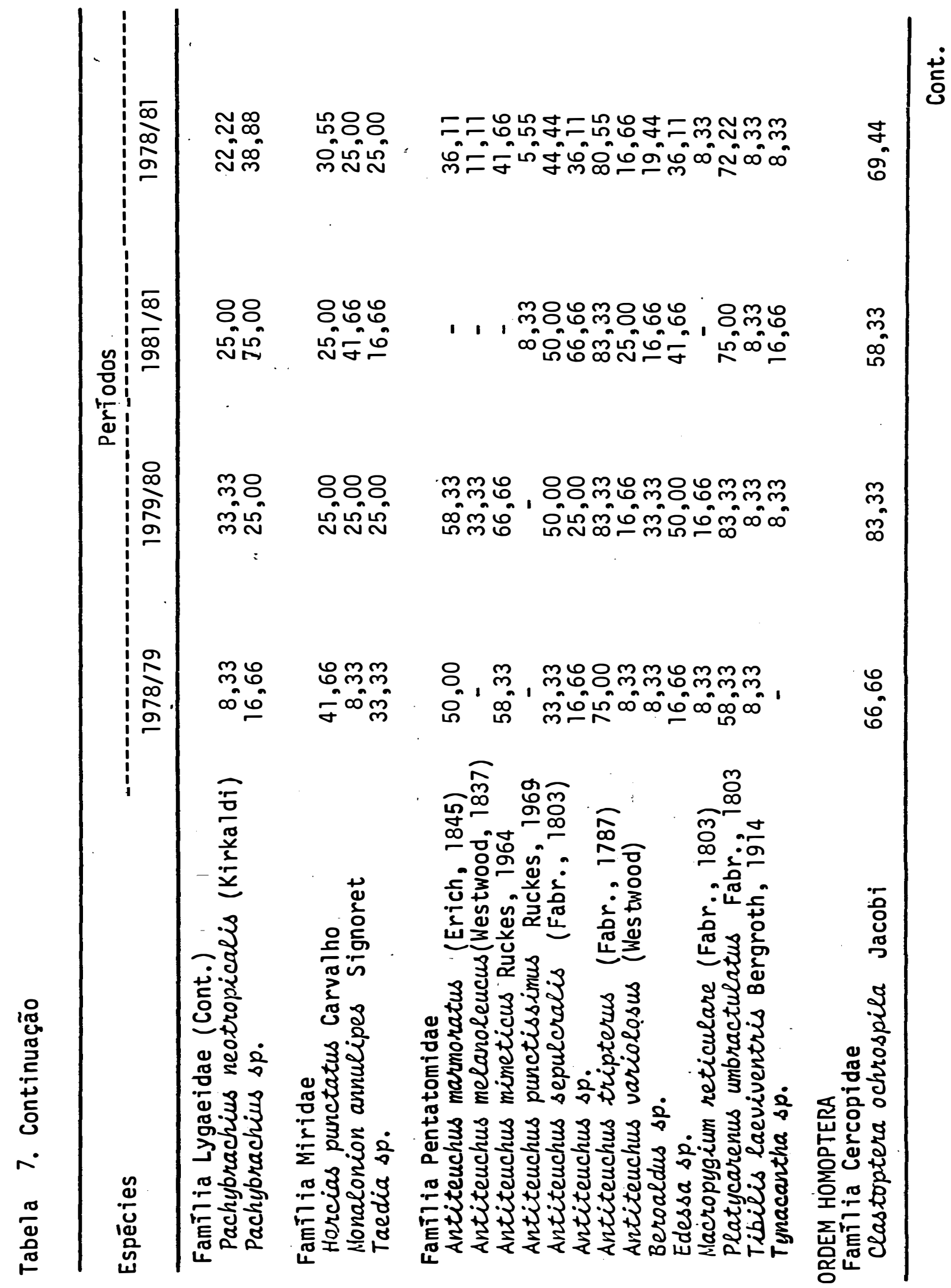


63.

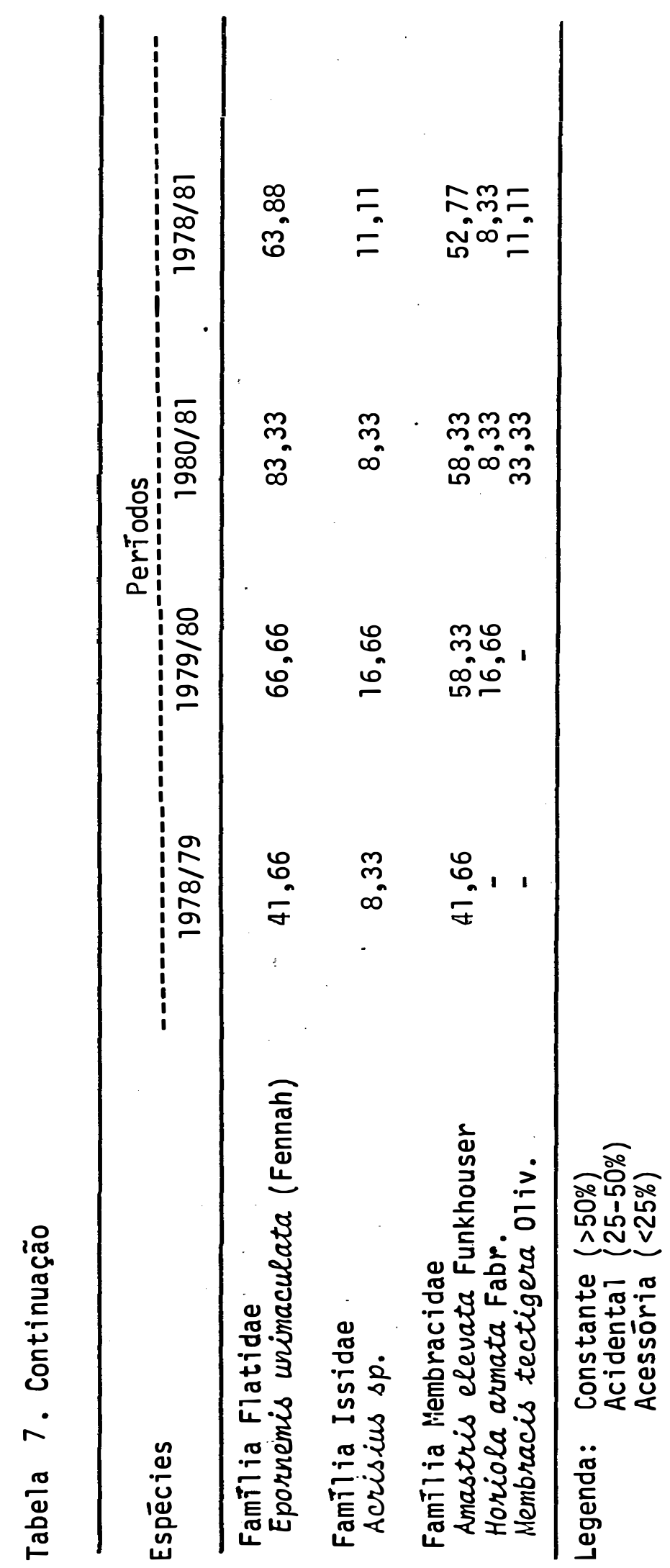


64.

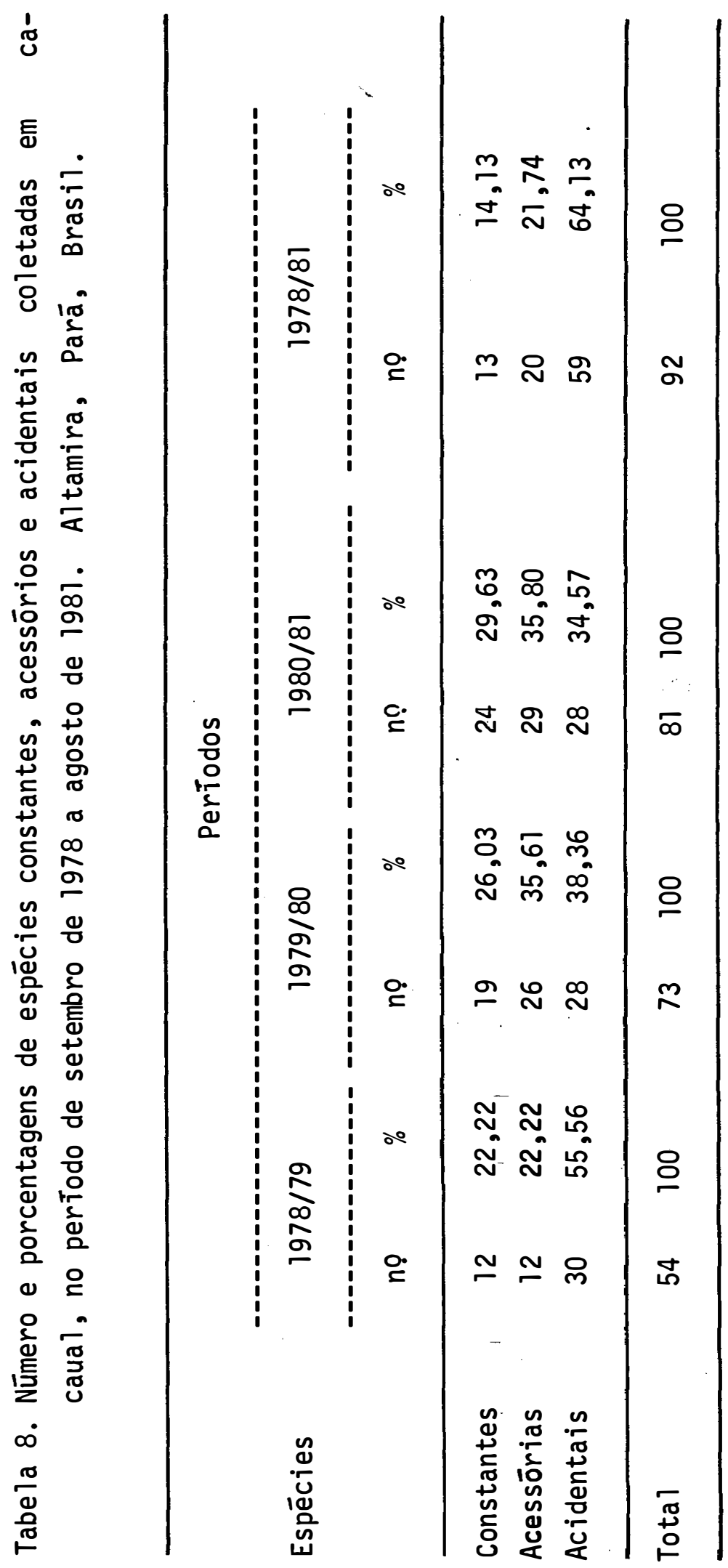


mente três espēcies constante, e na Guajarina apenas duas espécies constantes, que representaram $6,52 \%$ e $5,55 \%$ da fauna estudada nestas duas regiões respectivamente.

Embora muitas espēcies constantes na região de Altamira ocorram também na Bragantina e Guajarina, nenhuma de las no entanto, apresentou-se como constante para aquelas duas regiões. Entretanto, MENDES e ROSARRIO (1980) citaram as especies A. tripterus (Fabr., 1787) e C. ochrospila Jacobi como constantes em Rondōnia, e Rhabdopterus sp. no Amazonas, e que tambēm são conśtantes na região de Altamira.

\subsubsection{Dominância}

A classificação das espēcies de acordo com $\therefore$ a dominância, está contida na tabela 9 .

Para o período de $1978 / 81,-$ pode-se observar que das 92 espécies de insetos : coletadas em cacaueiro na região de Altamira, 73 delas foram dominantes $(79,35 \%)$, enquanto que somente 19 espécies $(20,65 \%)$ constitui ram-se em não dominantes (Tabeị 10).

A comparação dos resultados da dominância das espécies para cada ano de amostragem (tabela 10), mostrou que o número de espécies não dominantes permaneceu Ipraticamente constante, nos três anos de amostragens. Entretanto, percentualmente houve uma redução marcante destas espécies entre o primeiro (50\%) e o ūitimo (21\%) ano de amostragem. Com re- 
lação às espécies dominantes, nota-se um aumento acentuado das mesmas, passando de 27 espécies no período de 1978/79, pa ra 56 espécies no período 1980/81.

observa-se portanto, que em relativamente pouco tempo, um grande número de ocorréncias de espécies tornou - se perfeitamente adaptado ao novo habitat, constituindo-se desse modo, em espécies potencialmente capazes de modificarem o equilíbrio do ecossistema cacaueiro na região.

\subsubsection{Abundāncia}

A abundāncia das espécies é mostrada na Tabe1 a 9 .

De acordo com os resultados obtidos (Tabela 9) pode-se observar que na região de Altamira, ocorreram 10 espécies muito abundantes, 12 espécies comuns, 10 espécies dispersas e 60 espécies raras. Não houve a ocorrência de espécies abun dantes para o total dos anos.

No cómputo geral das amostragens, as espécies muito abundantes foram: Antitypona sp., Colaspis sp., Eccoptopsis sp., Hylax sp., Ischyrolamprina sp., Noriaia sp., Rhab dopterus sp., Antiteuchus mimeticus Ruckes, 1964, A.tripterus (Fabr., 1787) e clastoptera ochrospila Jacobi.

Analisando-se a abundāncia das espécies em relação a cada ano de amostragem, pode-se observar que o crisomelídeo Hylax sp. foi muito abundante apenas no ano de 1978/ 


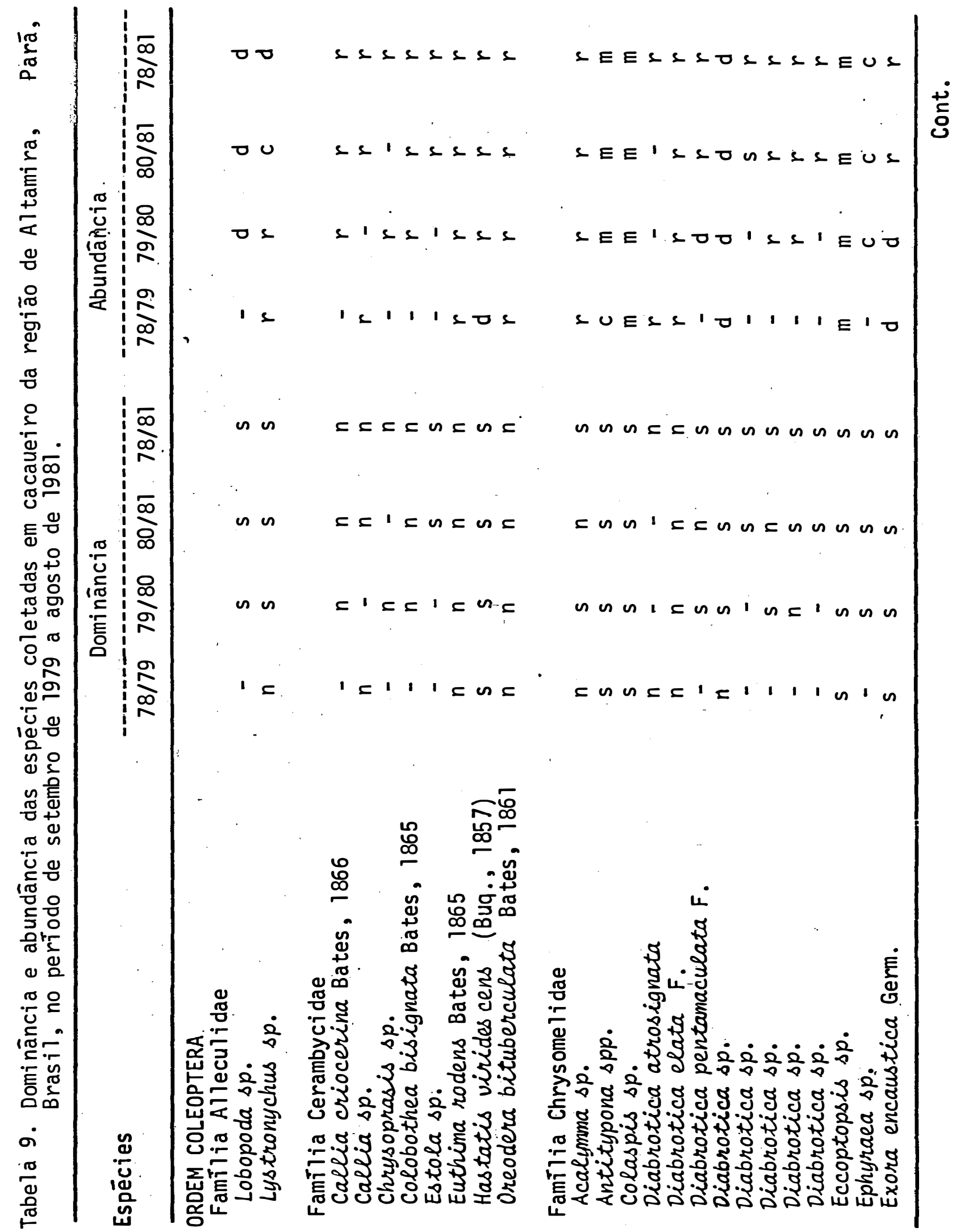


68.

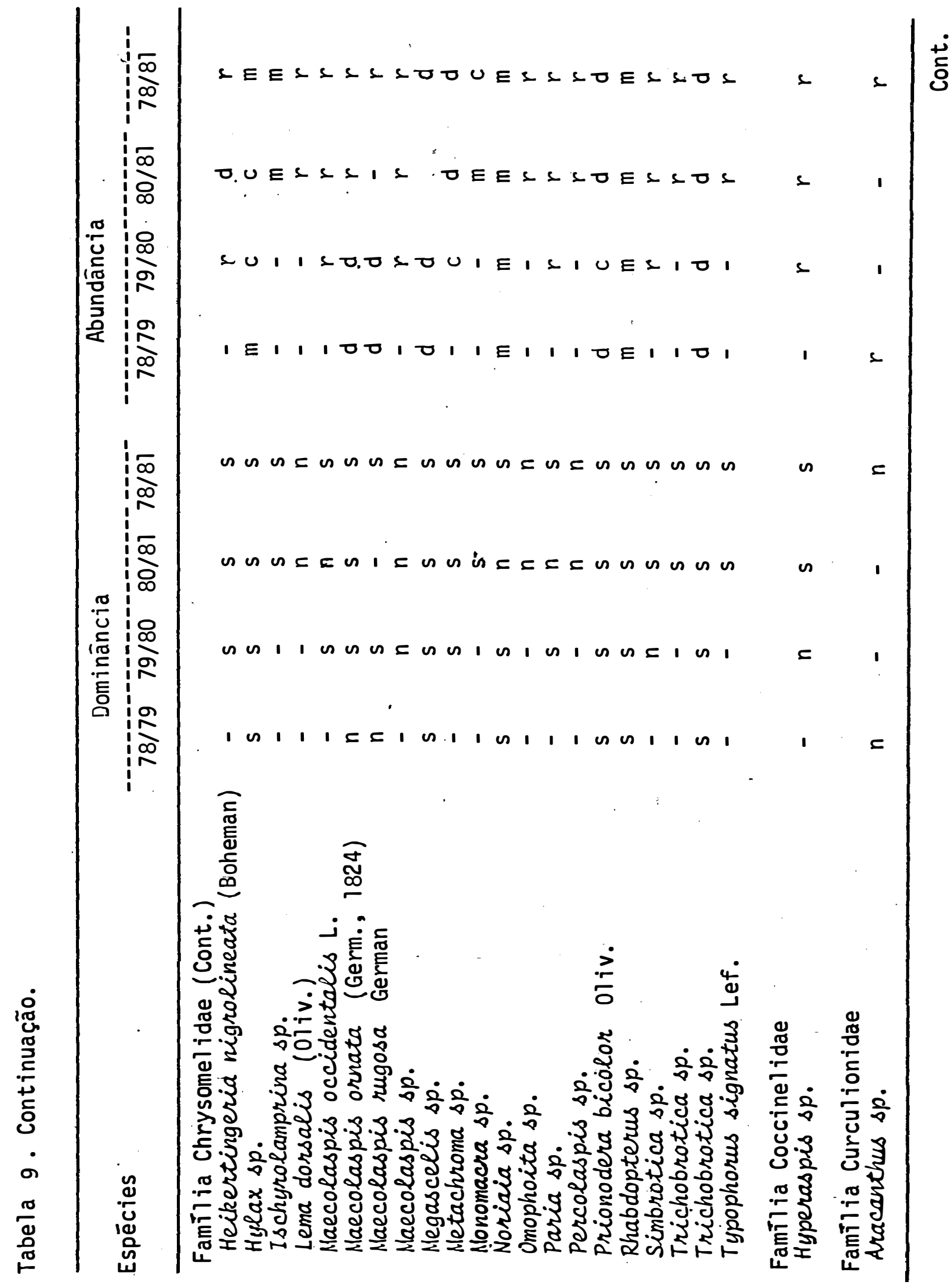


69.

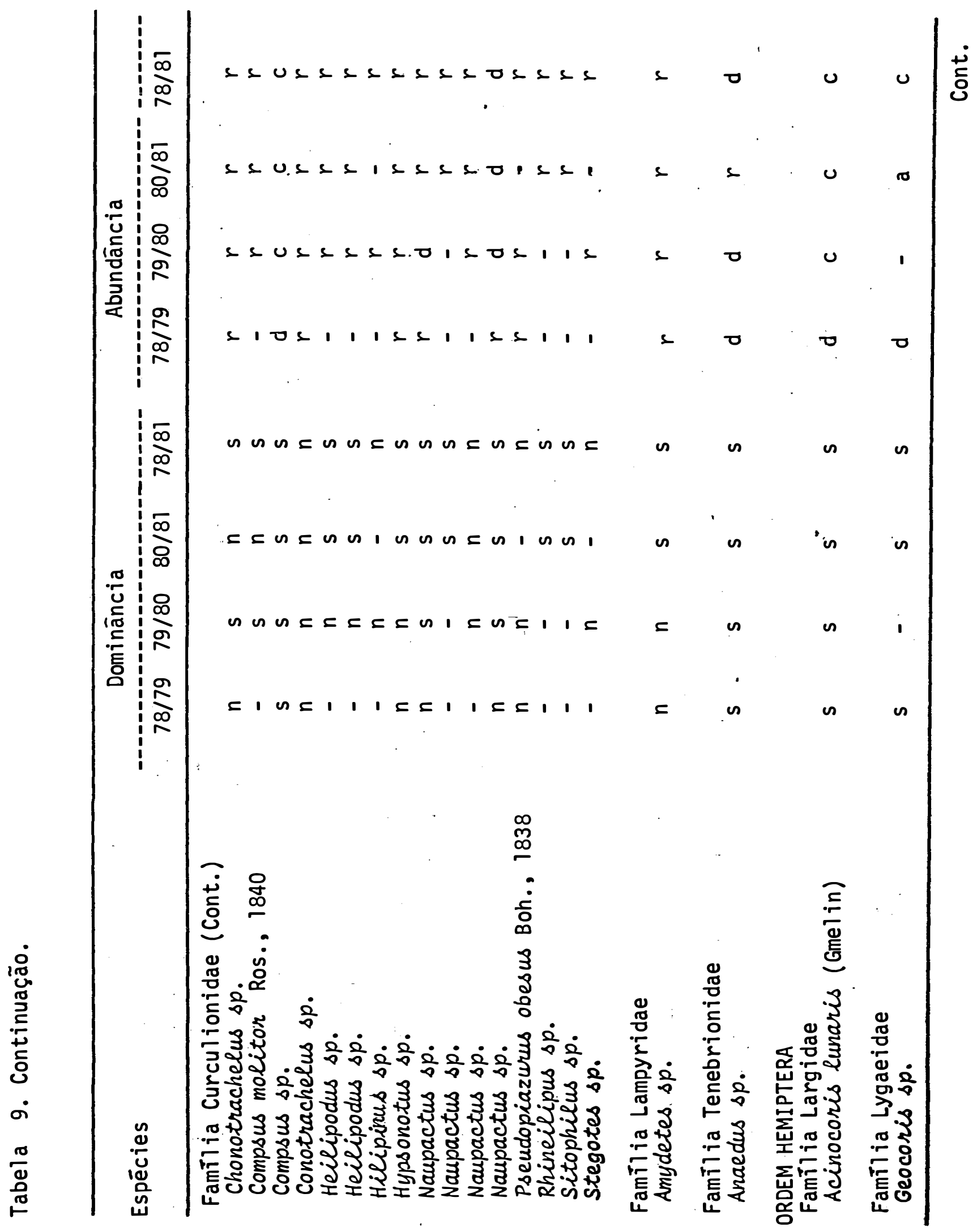


70.

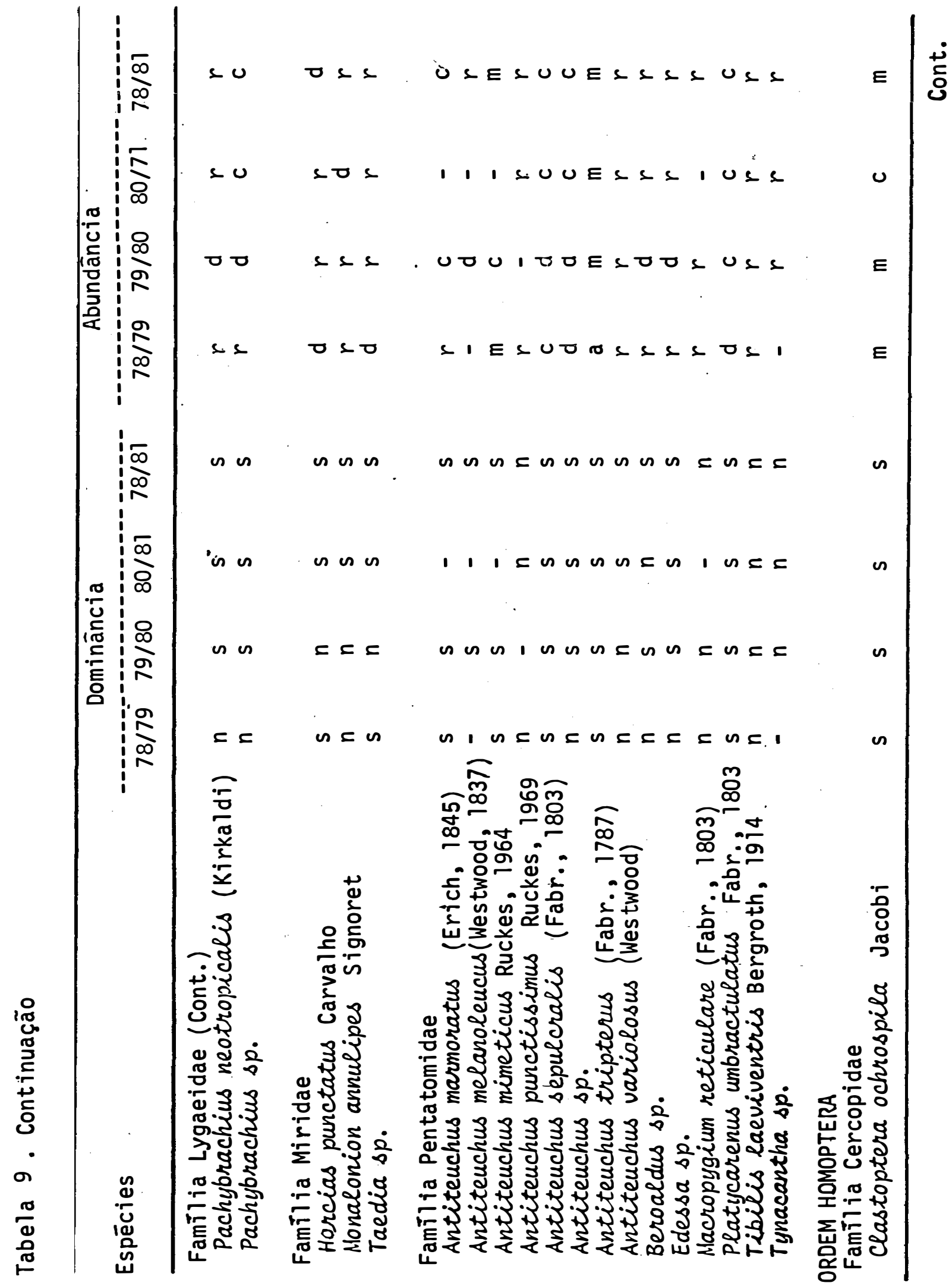


71.

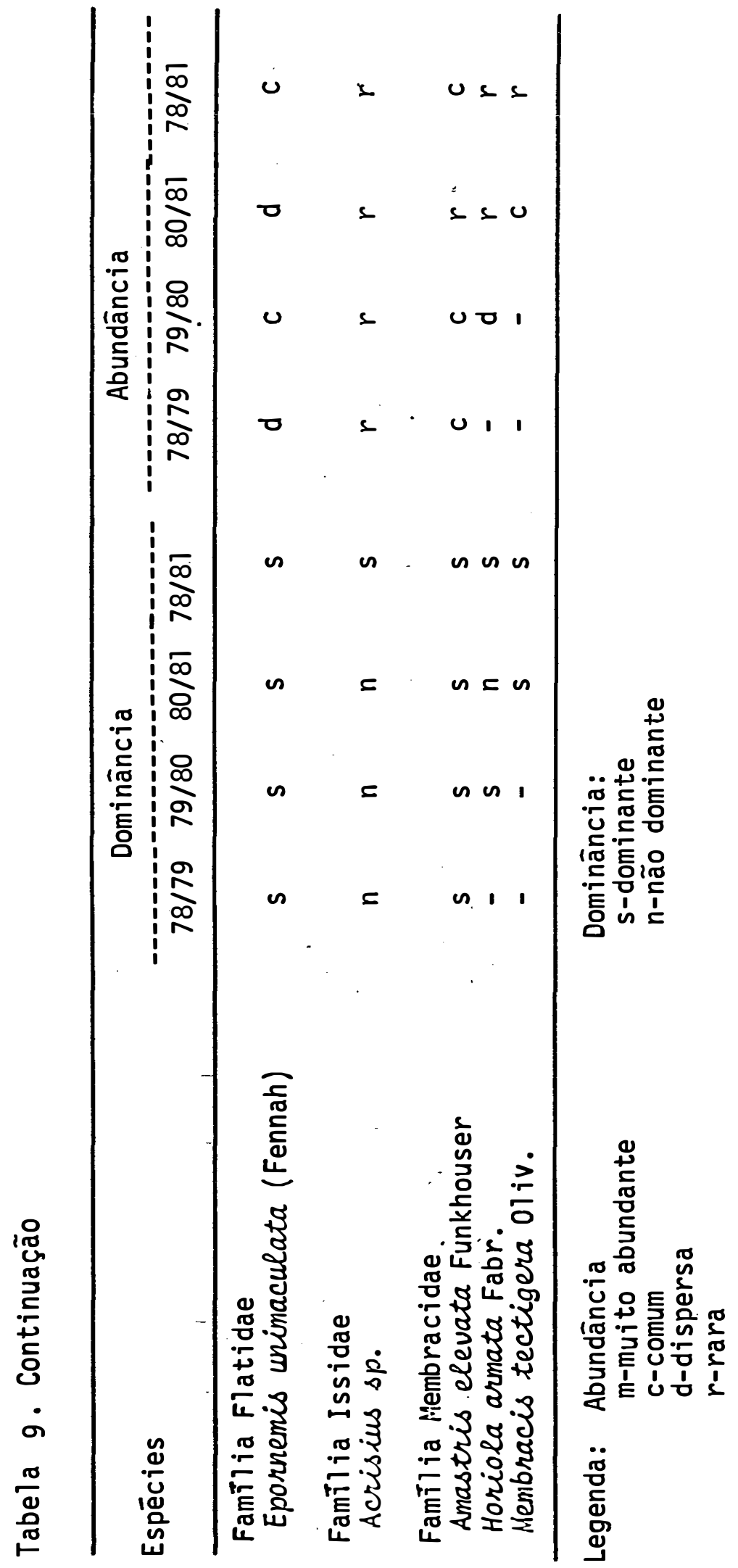




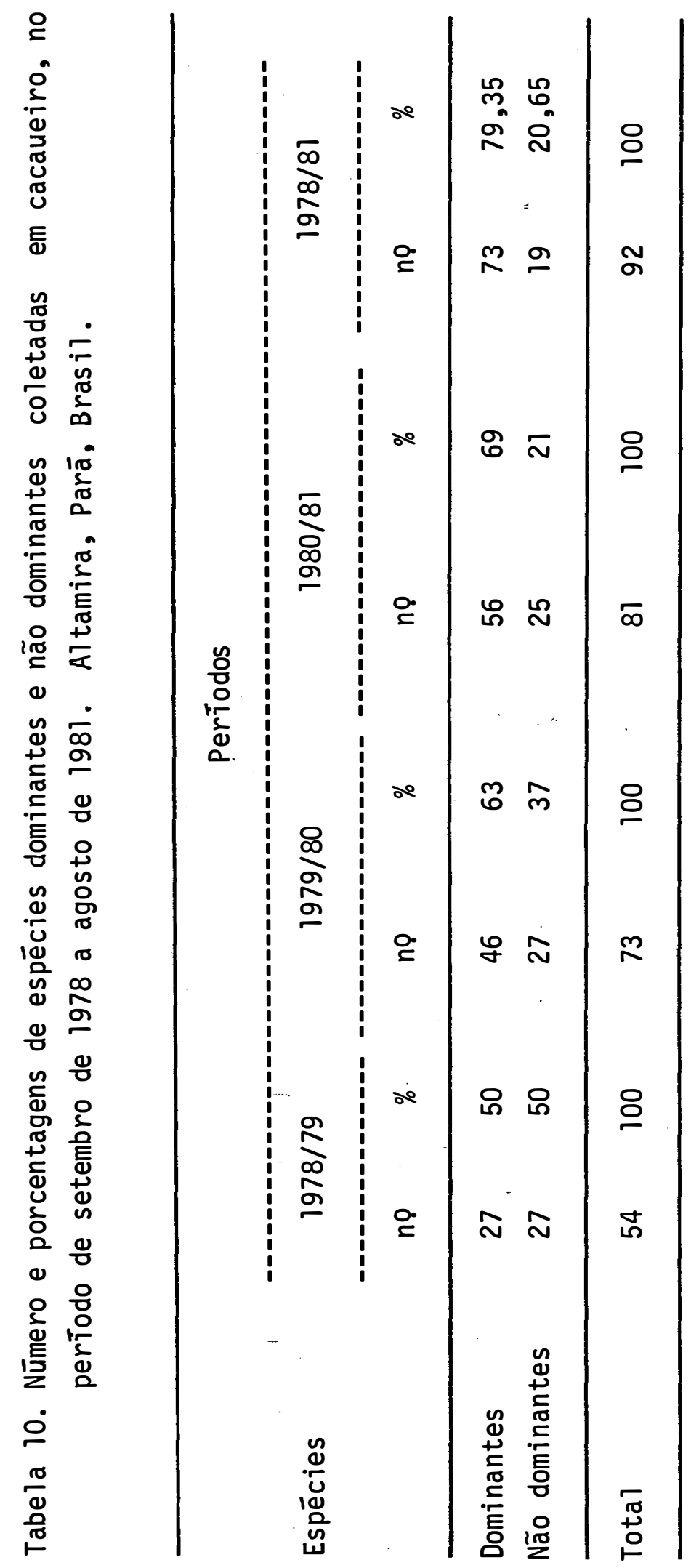


79, enquanto que nos demais caracterizou-se como espécie comum, devido provavelmente a fatores ambientais adversos. Fato semelhante ocorreu com o pentatomídeo A. mimeticus Ruckes, que em 1978/79 mostrou-se como espécie muito abundante, para em 1979/80 caracterizar-se como espécie comum e desaparecerem $1980 / 81$.

Os crisomelideos Ischyrolamprina sp. e Monomacra sp. não estiveram presentes nos anos de $1978 / 79$ e 1979 / 80 , ocorrendo entretanto em $1980 / 81$ como espécies muito abundantes.

Dentre as espécies muito abundantes, destaca ram-se os crisomelideos Colaspis sp., Noriaia sp., Eccoptopsis sp. e Rhabdopterus sp., que além de caracterizarem-se como muito abundantes em todos os anos de amostragens, apresenta ram frequências muito superiores às demais espécies.

\subsubsection{Indice de Diversidade.}

Na tabela 11 são apresentados o nümero total de espécies e de indivíduos capturados anualmente, bem comoos respectivos indices de diversidade, incluindo os do período de $1978 / 81$.

Observa-se pelos resultados obtidos, que os anos de 1979/80 e 1980/81 foram semelhantes, com diversidades de 8,13 e 8,74 respectivamente. No entanto, 0 ano de $1978 / 79$ apresentou um indice de diversidade de 6,47, indicando que 
neste ano de amostragem, houve a ação de fatores limitantes, ocasionando um aumento no número de indivíduos das espécies mais comuns, com uma consequente diminuição de espécies raras.

Para os três anos de amostragens, a diversidade da fauna na região de Altamira foi de 9,18. Comparando-se este resultado com os obtidos por GARCIA e SILVEIRA NETO (1980) pa ra as regiões Bragantina $(6,7)$ e Guajarima $(5,3)$, observa-se que : a fauna de Altamira apresenta-se mais diversificada do que as referidas regiões.

\subsubsection{Indice de Simijaridade}

A separação das comunidades de insetos existen tes em cacaual, no periodo de setembro de 1978 a agosto de 1981 , baseada no indice de similaridade entre os anos de amos tragens, pode ser öbservada nas treliças abaixo e cujá representação grāfica é mostrada pela figura 7 .

\begin{tabular}{lcc}
\hline Anos & $1979 / 80$ & $1980 / 81$ \\
\hline $1978 / 79$ & 0,059 & 0,039 \\
\hline $1979 / 80$ & - & 0,065 \\
\hline $1980 / 81$ & - & - \\
\hline
\end{tabular}


75.

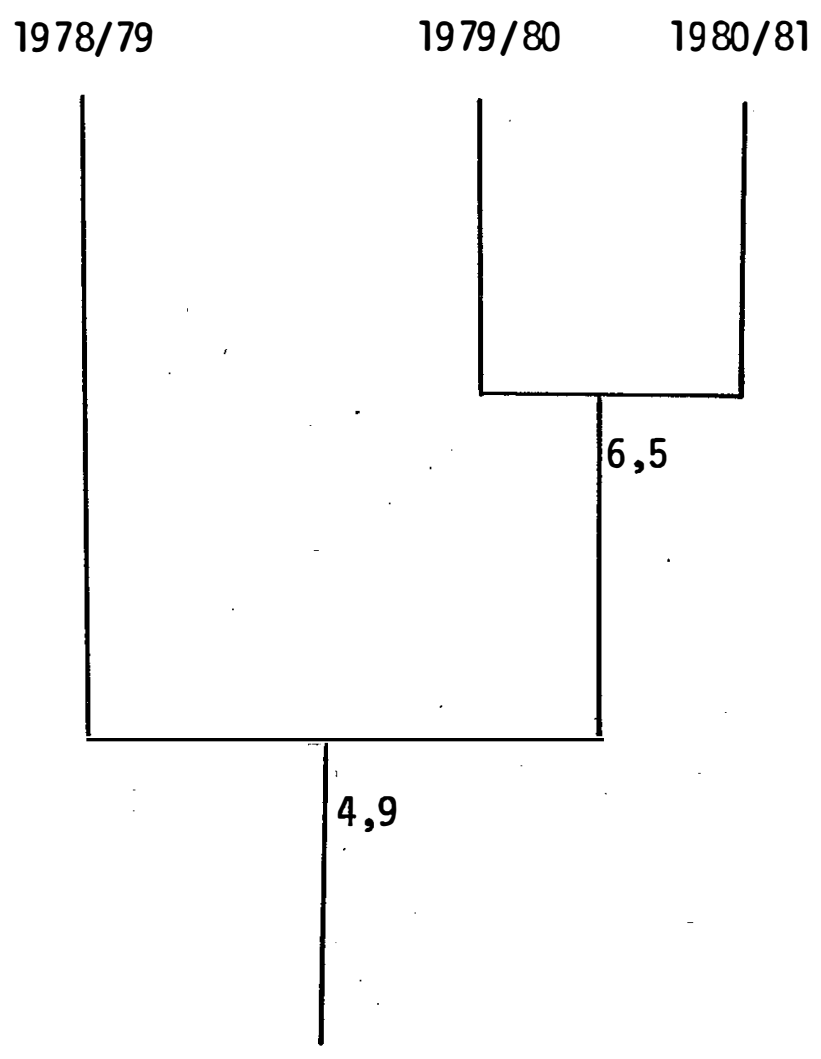

Figura 5. Classificação dos anos de amosträgens quanto ao indice de similaridade (\%). 
76.

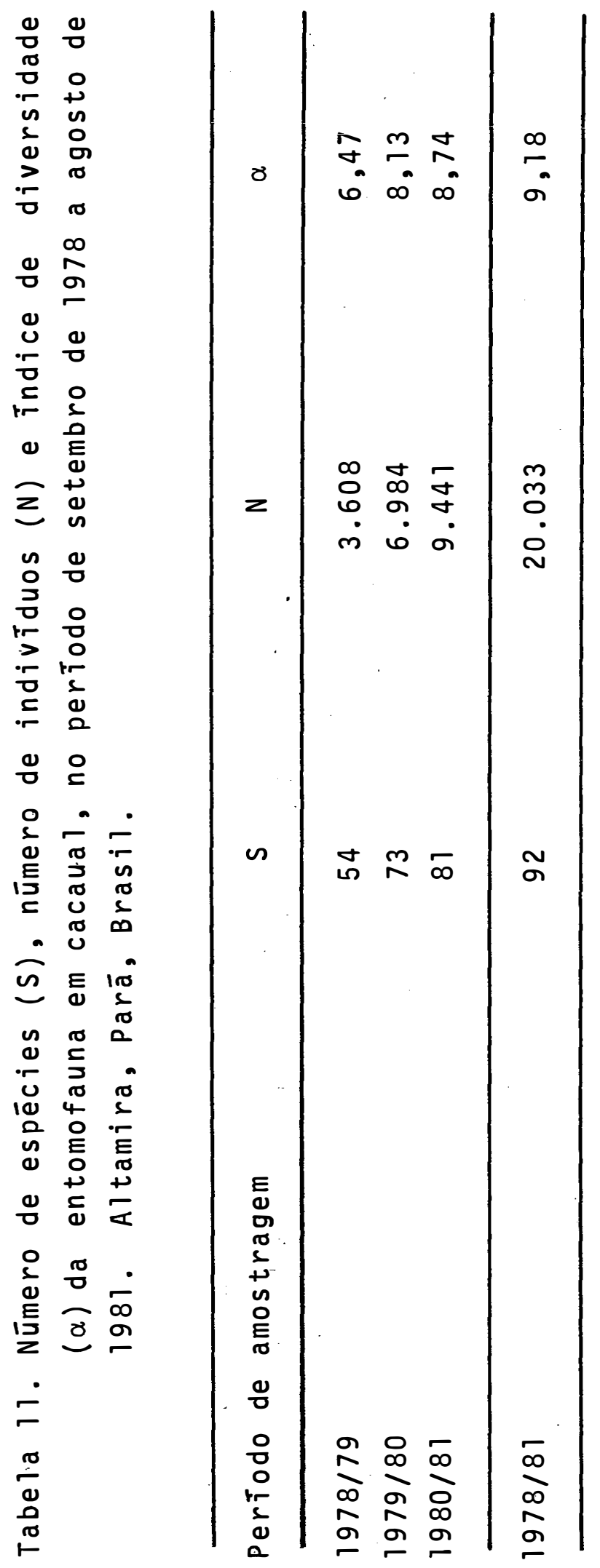


A partir destes resultados observa-se que houve uma maior similaridade entre os períodos de 1979/80 e 1980/ 81, e uma menor similaridade com o período de 1978/79.

Tal resultado indica que os dois ūltimos anos apresentaram um maior número de espécies comuns, o que de cer ta forma deve ser esperado, uma vez que a manutenção do cacau na área favorece a estabilidade da fauna.

\subsubsection{Porcentagem de Similaridade}

Visando a comprovação dos resultados obtidos no cálculo do indice de similaridade, obteve-se os dados de porcentagem de similaridade (Tábela 12).

Pelos dados obtidos notou-se que trabalhando apenas com as espécies comuns aos trés períodos de amostragens, a ordem de similaridade não foi alterada; ou seja, conseguiu - se cerca de $86,58 \%$ de similaridade éntre os períodos de 1979/80 e 1980/81, caindo para 79,71\% entre 1978/79 e 1979/80, o que de monstra, portanto, a maior semelhança entre os dois ültimos períodos de coleta e realça a afirmação da tendēncia à estabilida de da fauna na região. 
TABELA 12. Porcentagens de similaridade (\%S) entre os anos de amostragens de insetos em cacaual, no período de setembro de 1978 a agosto de 1981. Altamira, Pará, Brasil.

Anos comparados $\% \mathrm{~S}$

$\begin{array}{ll}1978 / 79 \times 1979 / 80 & 79,71 \\ 1979 / 80 \times 1980 / 81 & 86,58 \\ 1978 / 79 \times 1980 / 81 & 82,66\end{array}$

4.3. FLUTUAÇAO POPULACIONAL

Os estudos de flutuação populacional das espēcies predominantes (Tabela 13) foram feitos através de representações grāficas (Figuras 6 a 18), obtidas a partir da mēdia mensal do número de indivíduos capturados nos trēs anos de amostragens (Tabela 14).

os dados relativos às variāveis climāticas (umj dade relativa, precipitação pluvial e temperatura), e os referentes às fenológicas (produção, lançamento e floração) estão contidos nas Tabelas 15 e 16 , respectivamente. 


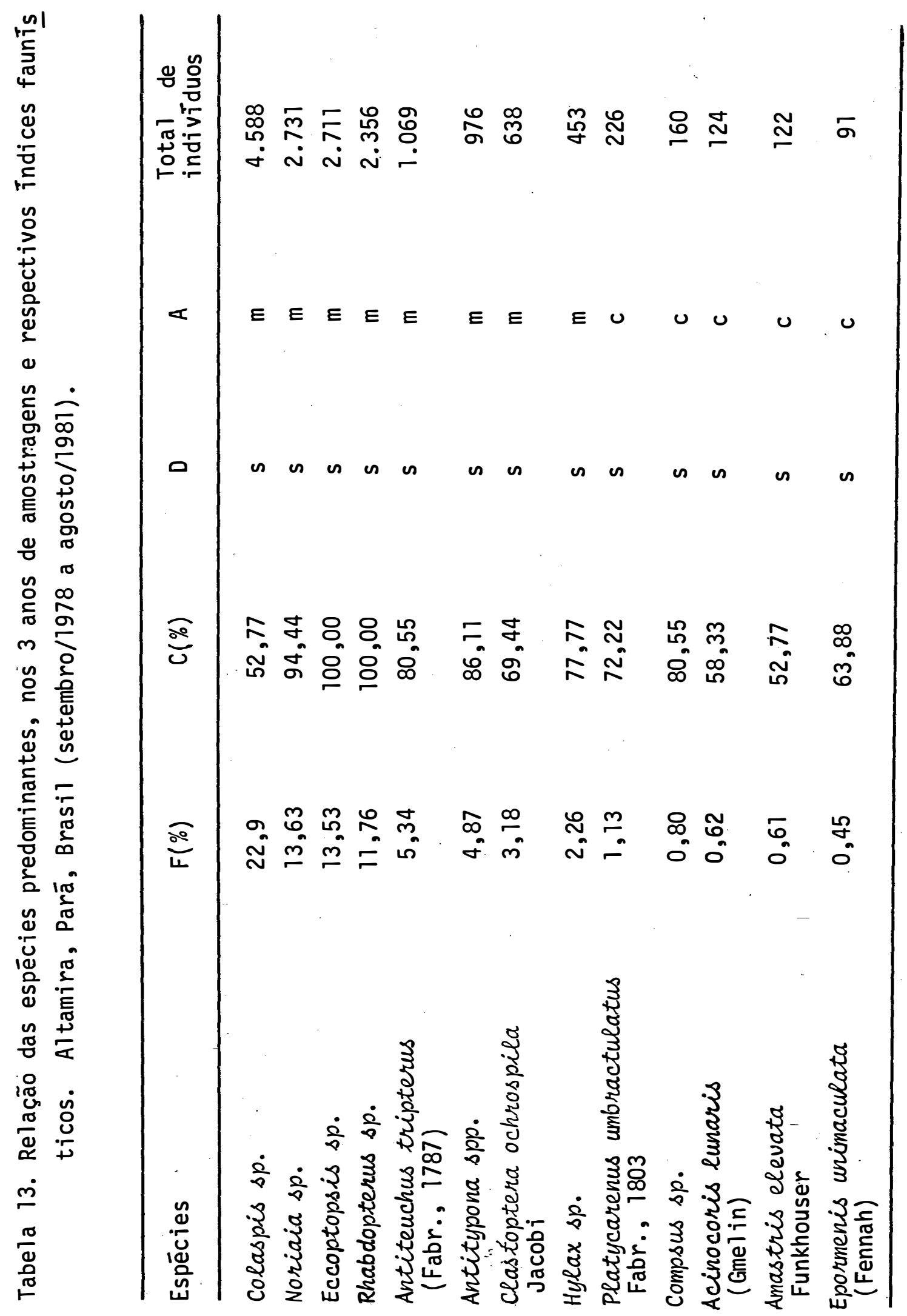




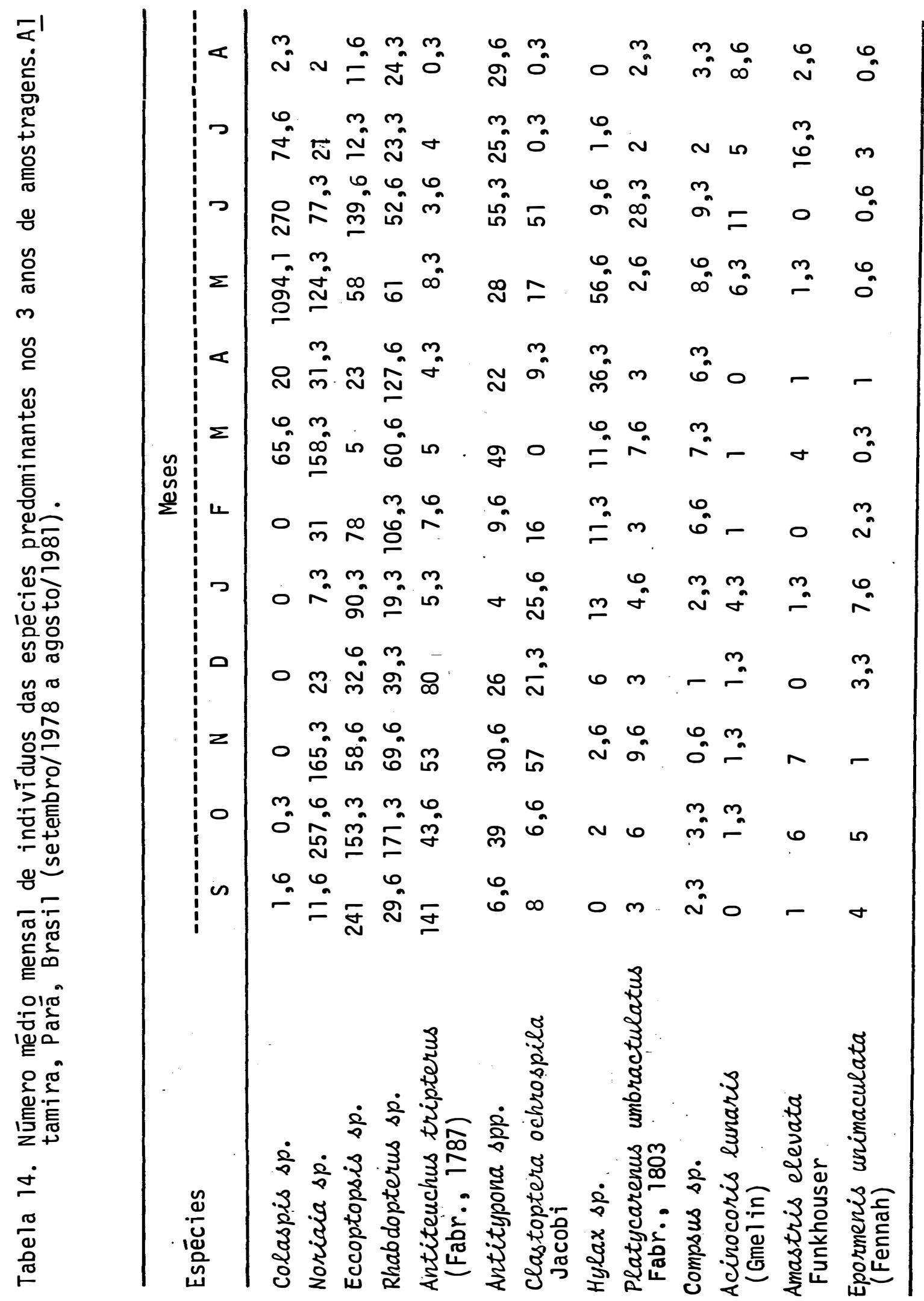


81.

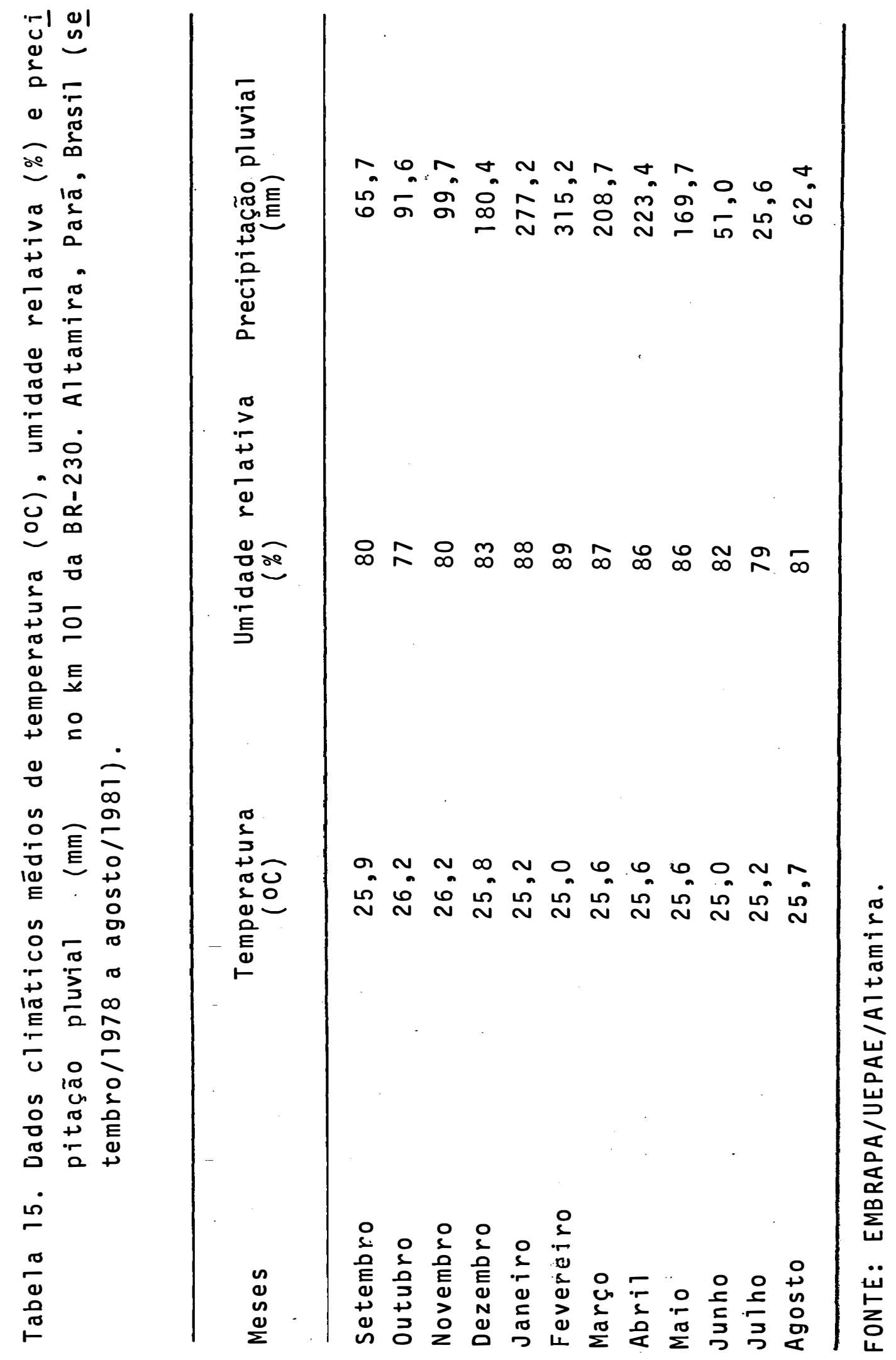


82.

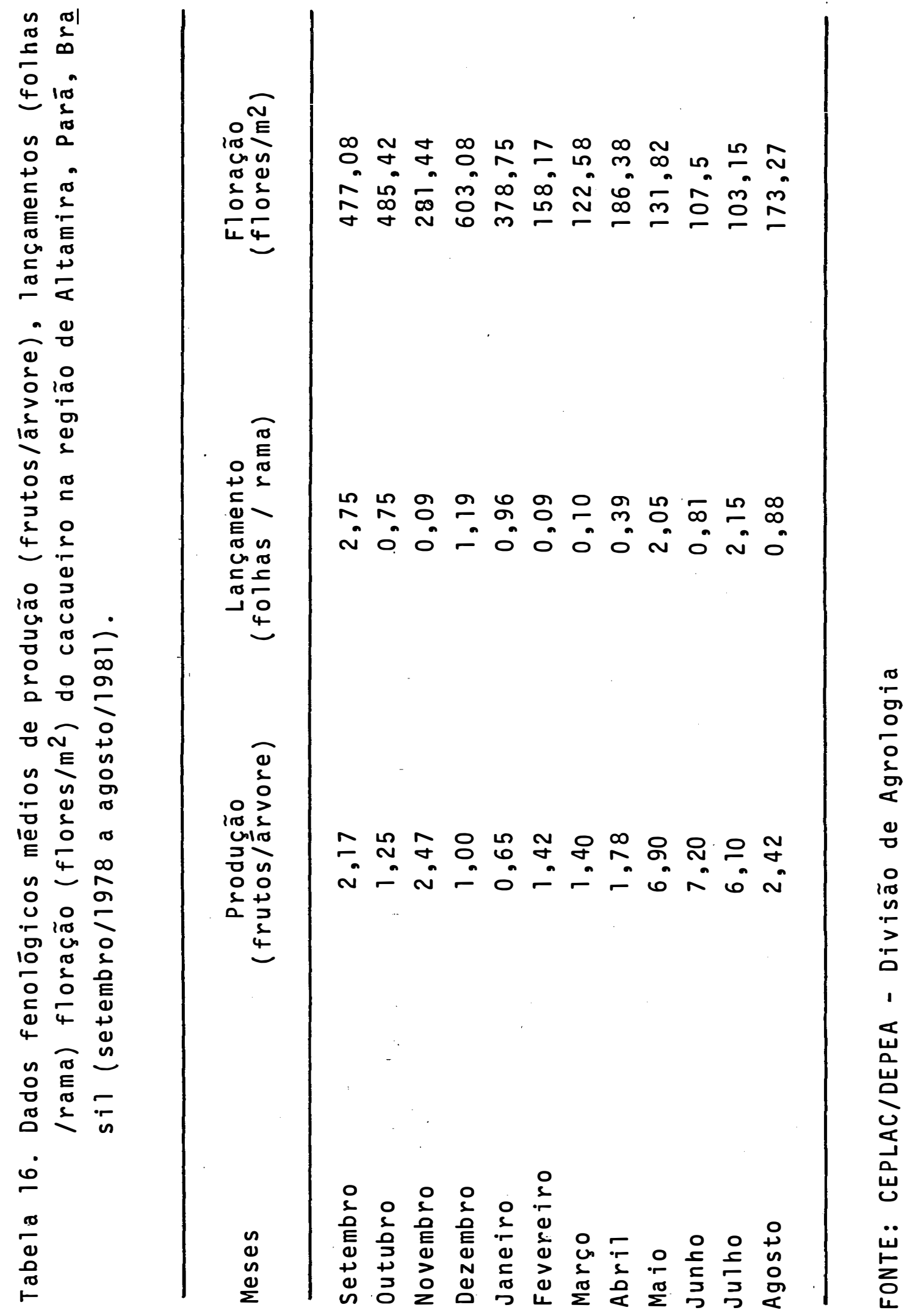


De uma maneira geral, os resultados obtidos nas anālises de regressão mūltipla, demonstram que a popula ção de $70 \%$ das espécies predominantes foi influenciada por fá tores fenológicos do cacaueiro. Entretanto, nos estudos rea lizados por GARCiA e SILVEIRA NeTO (1980) no Estado do Parā, não ficou evidenciada uma influencia significativa destes fatores, sobre a população de insetos associados à cultura do cacaueiro.

Analisando-se a flutuação anual média das espécies, observa-se que:

Colaspis s.p. foi a espécie de mais alta frequência em todos os anos de amostragens, sendo constatada sua presença de março a outubro na lavoura de cacau, não ocor rendo entretanto nos meses de outubro, novembro, dezembro, ja neiro e fevereiro.

Caracterizou-se como espécie dominante, cons tante e muito abundante em cada ano de amostragem. Sua população atinge apenas um pico populacional no més de maio, que representa o fim do período chuvoso na região, conforme pode ser observado na Figura 6.

Através da anālise de regressão mūltipla (Tabela 17), observou-se que a variāvel produção $\left(x_{5}\right)$ apresentou uma contribuição de $4697 \%$ na explicação da variação populacional destes insetos. 


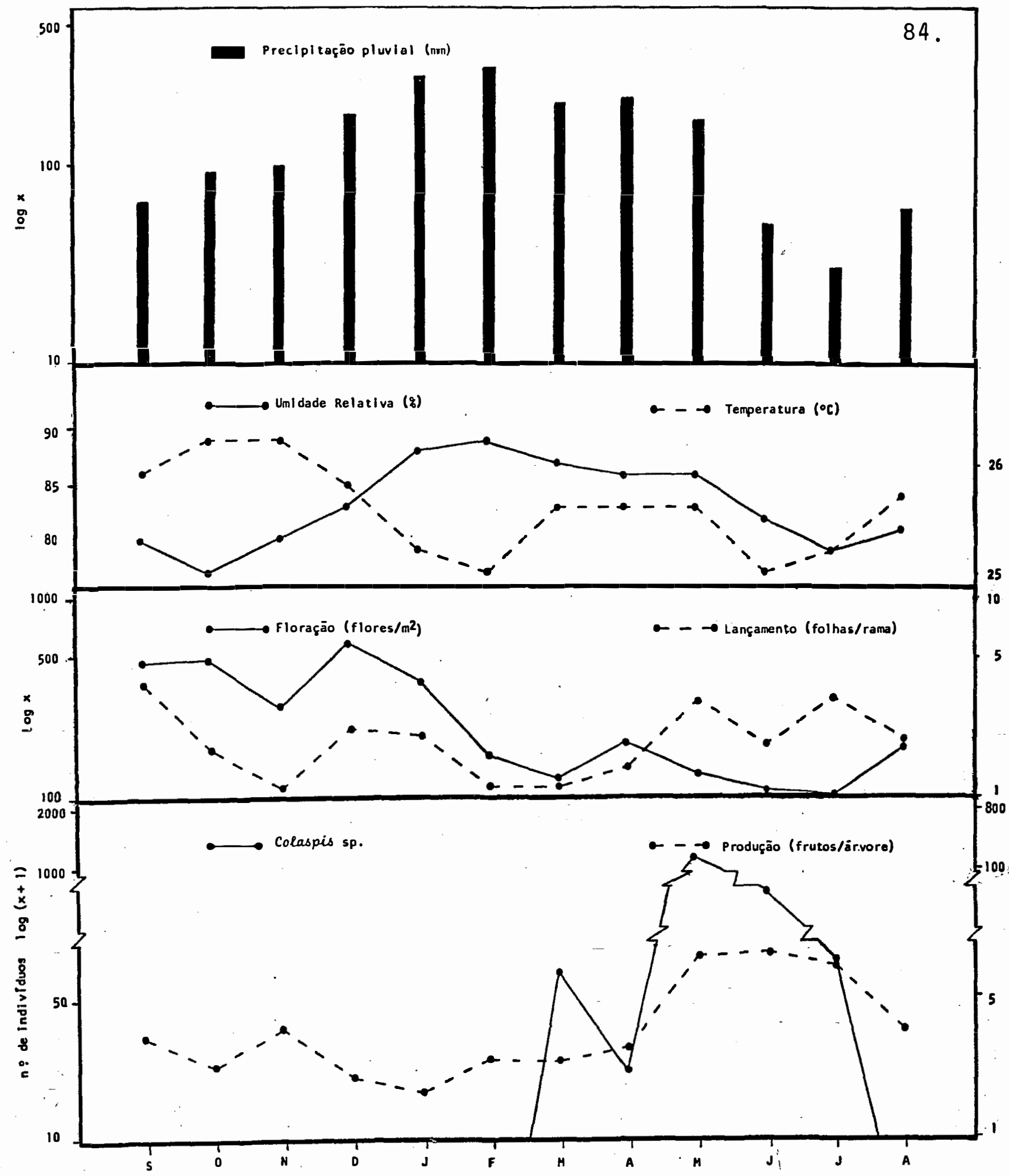

Figura 6. Flutuação populacional mēdia de colaspis sp., correlacionada com dados climáticos e fenológicos do cacaueiro. Altamira, Pará, Brasil (setembro de 1978 a agosto de 1981). 
Tabela 17. Valores do teste "F" e do coeficiente de determinação $\left(R^{2}\right)$ das difecentes variāveis nas equações de regressão para explicação da variação populacional de Colaspis sp., na região de Altami ra, Parā, Brasil (setembro de 1978 a agosto de 1981).

\begin{tabular}{lrl}
\hline Variāveis na regressão & $F$ & $R^{2}(\%)$ \\
\hline$X_{5}^{*}$ & $8,85^{*}$ & 46,97 \\
$X_{2}, X_{5}^{*}$ & $7,37 *$ & 62,12 \\
$X_{2}^{*}, x_{3}^{*}, x_{5}^{*}$ & $16,73^{*}$ & 86,25 \\
$x_{2}^{*}, x_{3}^{*}, x_{4}, x_{5}^{*}$ & $16,71^{*}$ & 90,52 \\
$x_{1}, x_{2}, x_{3}^{*}, x_{4}, x_{5}^{*}$ & $13,76^{*}$ & 91,98 \\
$x_{1}, x_{2}, x_{3}^{*}, x_{4}, x_{5}^{*}, x_{6}$ & $9,65^{*}$ & 92,06
\end{tabular}

* Significativo ao nível de $5 \%$ de probabilidade Variáveis climáticas

$x_{1}$ - umidade relativa (\%)

$x_{2}$ - precipitação pluvial (mm)

$x_{3}$ - temperatura (OC)

Variáveis fenológicas

$x_{4}$ - lançamento (folhas/rama)

$x_{5}$ - produção (frutos/ārvore)

$x_{6}$ - floração (flores $/ m^{2}$ ) 
Por outro lado, a melhor equação é dada pelas variāveis produção $\left(X_{5}\right)$, preçipitação pluvial $\left(X_{2}\right)$ e temperatura $\left(x_{3}\right)$, com $86,25 \%$ de explicação, dada por:

$$
P\left(x_{2}, x_{3}, x_{5}\right)=-13866,97+2,99 x_{2}+508,97 x_{3}+183,50 x_{5}
$$

Noriaia sp., também é encontrada em grandes po pulações, estando presente em todos os meses do ano e apresen ta 3 picos populacionais. Um pico maior no mês de outubro e outros dois menores em março e maio. Sua ocorrēncia verifica -se tanto no período seco como em plena época chuvosa.

A população desta espécie não mostrou correlação com nenhum dos fatores meteorológicos e fenológicos estudados, embora óbserve-se na figura 7 , a existência de uma leve tendēncia de aumento da população, com a elevação da tempe ratura.

Evidenciou-se pelos resultados da anālise de re gressão mūltipla (tabela 18), que não houve efeito das va riāveis estudadas sobre a flutuação populacional desta espēcie.

Mostrou-se como espécie dominante, constante e muito abundante em todos os anos de amostragens, éxceto em 1980/81 onde caracterizou-se como não dominante.

Eccoptopsis sp., fez-se presente durante todo o ano, apresentando 3 picos populacionais correspondentes aos 


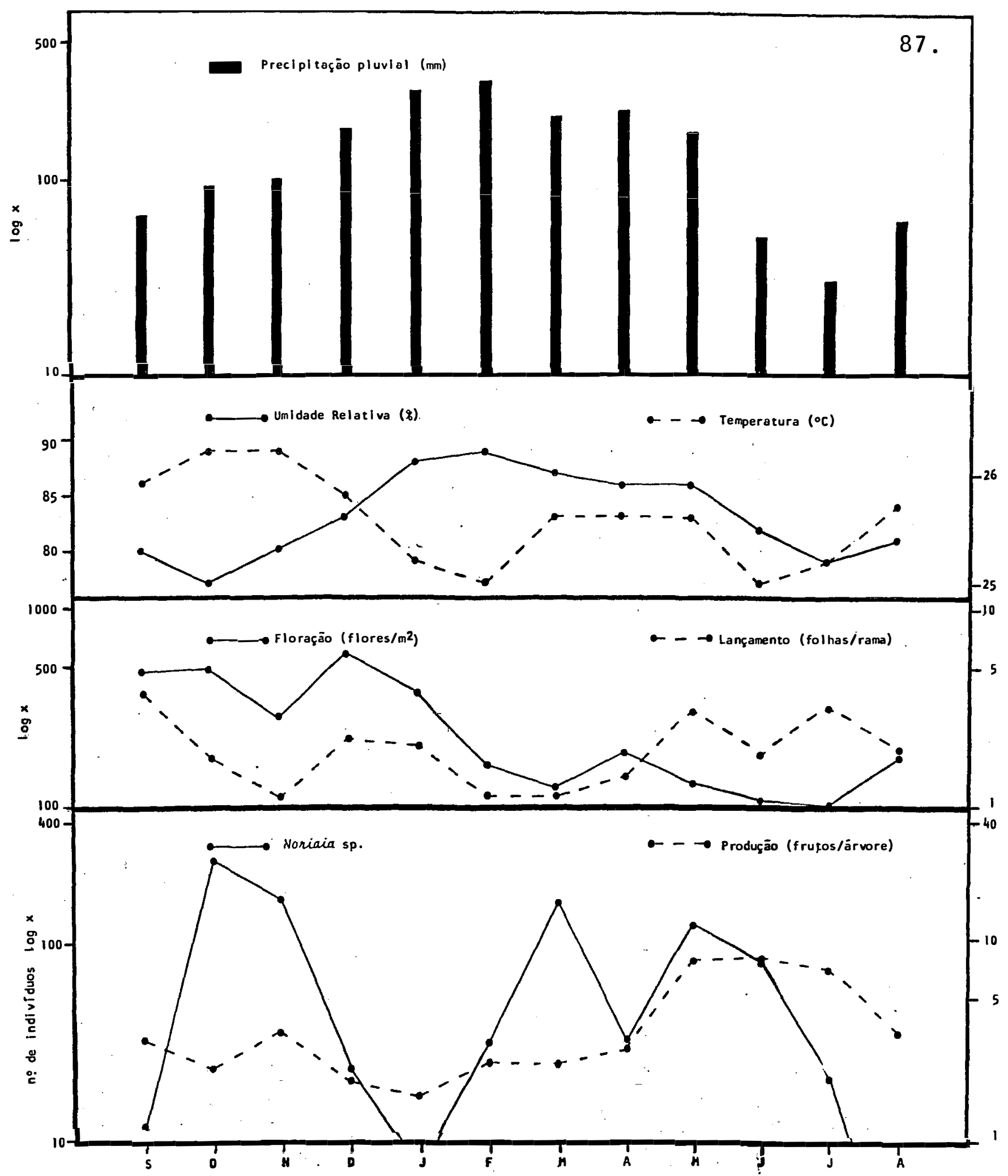

Figura 7. Flutuação populacional média de Noriaia sp., cor relacionada com dadós climáticos e fenológicos do cacaueiro. Altamira, Pará, Brasil (setembro de 1978 a agosto de 1981). 
Tabela 18. Valores do teste "F" e do coeficiente de determinação $\left(R^{2}\right)$ das diferentes variāveis nas equações de regressão para explicação da variação populacio nal de Noriaia sp., na região de Altamira, Pará, Brasil (setembro de 1978 a agosto de 1981).

Variāveis na regressão

F $\quad R^{2}(\%)$

$x_{3}$

$x_{3}, x_{4}^{-}$

$x_{3}^{*}, x_{4}^{-}, x_{5}$

$x_{2}, x_{3}^{*}, x_{4}^{-}, x_{5}$

$x_{1}^{-}, x_{2}, x_{3}, x_{4}^{-}, x_{5}$

$x_{1}^{-}, x_{2}, x_{3}^{-}, x_{4}^{-}, x_{5}, x_{6}^{-}$
4,01

28,65

2,96

39,76

3,56

57,21

2,54

59,21

2,36

66,35

1,66

* Significativo ao nível de $5 \%$ de probabilidade

- Variável correlacionada negativamente com a população

Variāveis climáticas

$x_{1}$ - umidade relativa (\%)

$x_{2}$ - precipitação pluviat (mm)

$x_{3}$ - temperatura (OC)

Variáveis fenológicas

$x_{4}$ - lançamento (folhas/rama)

$x_{5}$ - produção (frutos/ārvore)

$x_{6}$ - floração /flores/m2) 
meses de setembro, janeiro e junho (figura 8 ). Nos meses de março, julho e agosto regi-straram-se os mais baixos niveis populacionais destes insetos.

A flutuação populacional desta éspécie não sofreu influēncia de nenhum dos fatores estudados, o que pode ser observado pelos resultados de análise de regressão apresentados na tabela 19.

Algumas evidências tem mostrado que esta espécie, apesar de ser dominante, constante e muito abundante nas lavouras de cacau, possui preferência às plantas de clitoria racemosa (palheteira), árvore utilizada para o sombreamento definitivo do cacaueiro. Logo, é provável que o aumento populacional destes insetos seja condicionado por fatores intrīnsecos à esta árvore.

Rhabdopterus sp., ocorreu durante todo 0 ano, com densidade populacional relativamente alta. Registrou picos populacionais nos meses de outubro, fevereiro e abril ( $\underline{\mathbf{j}}$ gura 9).

Esta espécie manteve-se constante, dominante e muito abundante em todos os anos de amostragens, mas sua flutuação populacional não sof̣reu influência significativa dos fatores meteorológicos e fenológicos estudados, conforme mostram os resultados de análise de regressão múltipla (tabela 20). 


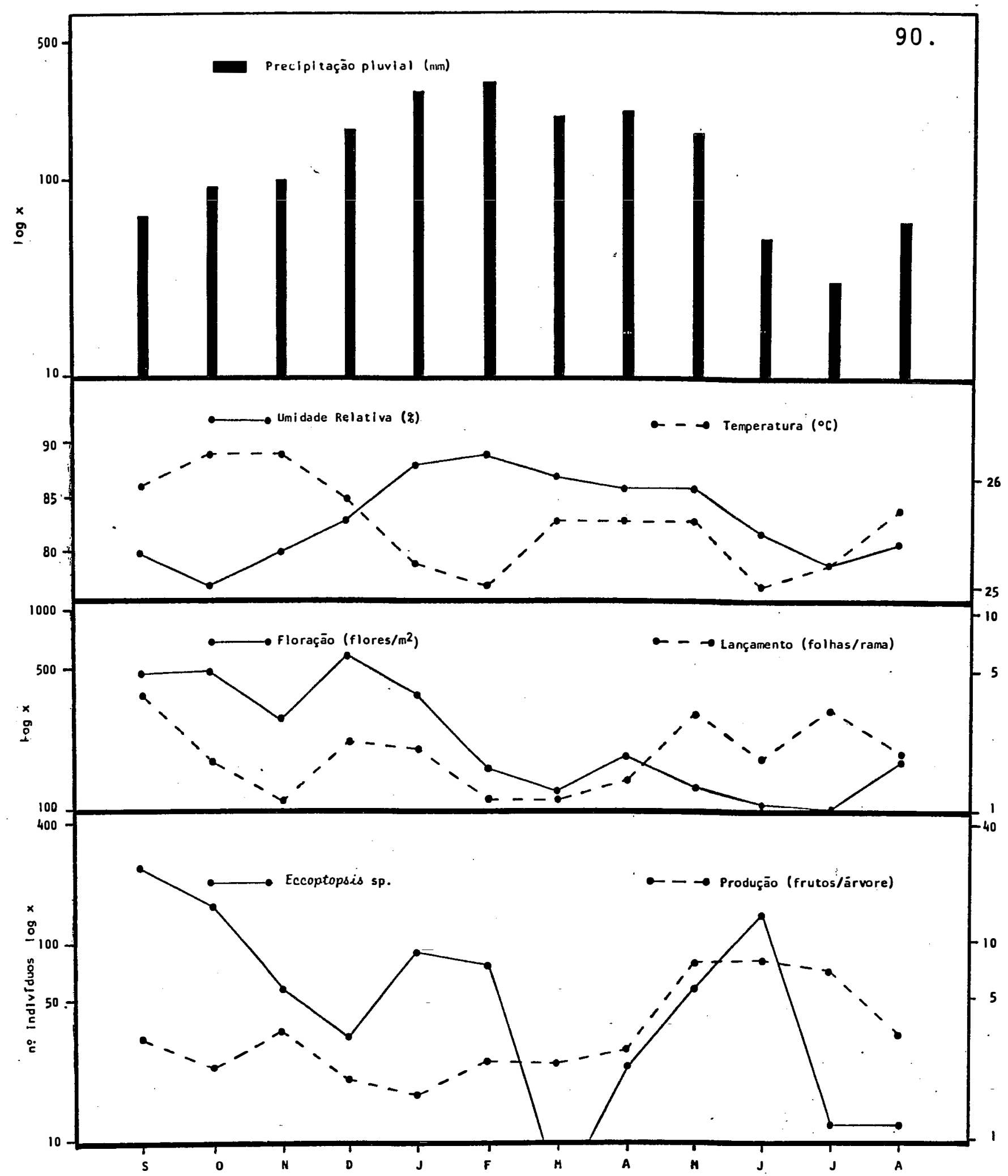

Figura 8. Flutuação populacional média de Eccoptopsis sp., correlacionada com dados climáticos e fenológicos do cacaueiro. Altamira, Pará, Brasil (setembro de 1978 a agosto de 1981). 
Tabela 19. Valores do teste "F" e do coeficiente de determina ção $\left(R^{2}\right)$ das diferentes variáveis nas equações de regressão para explicação da variação populacional de Eccoptopsis sp., na região de Altamira, Pará, Brasil. (setembro de 1978 a agosto de 1981).

\begin{tabular}{lll}
\hline Variāveis na regressão & $F$ & $R^{2}(\%)$ \\
\hline$x_{6}$ & 2,50 & 20,02 \\
$x_{5}, x_{6}$ & 1,93 & 30,03 \\
$x_{4}, x_{5}, x_{6}$ & 1,24 & 31,82 \\
$x_{3}^{-}, x_{4}, x_{5}, x_{6}$ & 0,83 & 32,43 \\
$x_{1}^{-}, x_{3}^{-}, x_{4}, x_{5}, x_{6}$ & 0,61 & 33,99 \\
$x_{1}^{-}, x_{2}, x_{3}^{-}, x_{4}, x_{5}, x_{6}$ & 0,42 & 34,00 \\
\hline
\end{tabular}

- Variável correlacionada negativamente com a população Variáveis climáticas

$x_{1}$ - umidade relativa (\%)

$x_{2}$ - precipitação pluvial (mm)

$x_{3}$ - temperatura $(O C)$

Variáveis fenológicas

$x_{4}$ - lançamento (folhas/rama)

$x_{5}$ - produção (frutos/ārvore)

$x_{6}-f l o r a c ̧ a ̃ o\left(f l o r e s / m^{2}\right)$ 


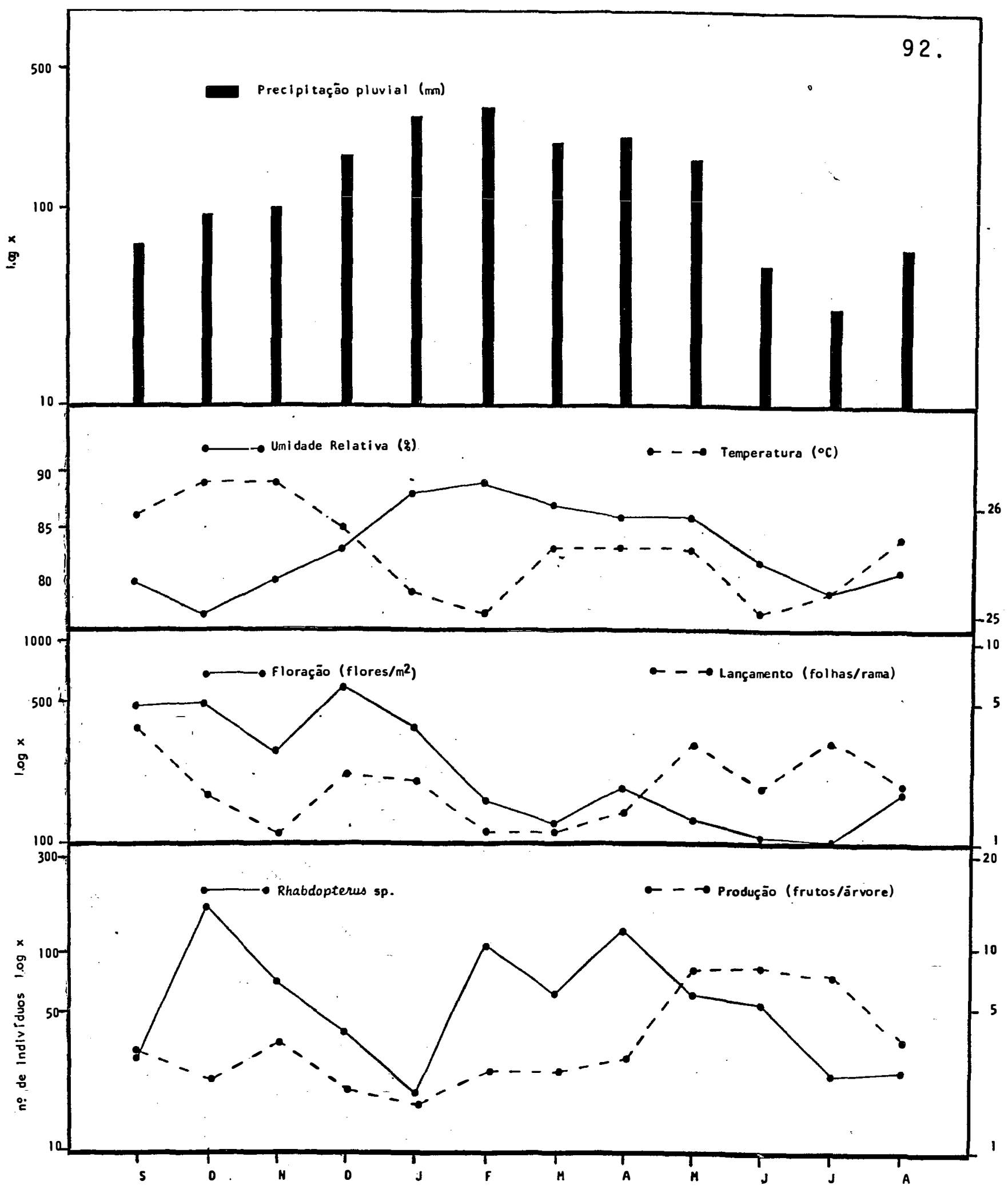

Figura 9 Flutuação populacional média de Rhabdopterus sp. correlacio nada com dados climáticos e fenológicos do cacaueiro. Altamira, Parā, Brasil (setembro de 1978 a agosto de 1981). 
Tabela 20. Valores do teste "F" e do coeficiente de determina ção $\left(R^{2}\right)$ das diferentes variāveis nas equações de regressão para explicação da variação populacional de Rhabdopterus sp., na região de Altamira, Pará, Brasil (setembro de 1978 a agosto de 1981).

\begin{tabular}{lll}
\hline Variáveis na regressão & $F$ & $R^{2}(\%)$ \\
\hline$x_{4}^{-}$ & 2,77 & 21,74 \\
$x_{3}, x_{4}^{-}$ & 2,03 & 31,19 \\
$x_{2}, x_{3}, x_{4}^{-}$ & 1,28 & 32,60 \\
$x_{1}^{-}, x_{2}, x_{3}, x_{4}^{-}$ & 1,53 & 46,70 \\
$x_{1}^{-}, x_{2}, x_{3}, x_{4}^{-}, x_{5}$ & 2,04 & 63,07 \\
$x_{1}^{-}, x_{2}, x_{3}, x_{4}^{-}, x_{5}, x_{6}^{-}$ & 1,75 & 67,80 \\
\hline
\end{tabular}

- Variável correlacionada negativamente com a população

Variāveis climáticas

$x_{1}$ - umidade relativa (\%)

$x_{2}$ - precipitação pluvial (mm)

$x_{3}$ - temperatura (OC)

Variāveis fenológicas

$x_{4}$ - lançamento (fol has/rama)

$x_{5}$ - produção (frutos/árvore)

$x_{6}-$ floração (flores/m²) 
Antiteuchus tripterus, apresentou grande parte de sua população concentrada no período de setembro a janeiro. Nos outros meses, sua população mostrou-se bastante baixa, em bora estivesse presente em todos os meses do ano (Figura 10). E considerada espécie dominante, constante e muito abundante em todos os anos emostrados.

Foram registrados dois picos populacionais des ta espécie. Um grande pico no mês de setembro e um outro me nor em dezembro.

Pelo exame da Figura 10 , verifica-se a tendēncia da população destes insetos de concentrar-se na faixa de maior temperatura, menores umidades relativa e precipitação pluvial. Estes resultados assemelham-se aos obtidos por GARCiA e Silveira neto (1980), para as espécies deste gēnero na região Bragantina.

De acordo com os resultados da anālise de regressão mûltipla contidos na Tabela 21 , a floração $\left(X_{6}\right)$ foi a variāvel que mais influenciou a flutuação da população, com um coeficiente de determinação de 57,13\%. A melhor explicação é dada pela variāvel floração $\left(x_{6}\right)$, cuja equaçao de regressão é:

$$
P\left(x_{6}\right)=-20,44+0,19
$$




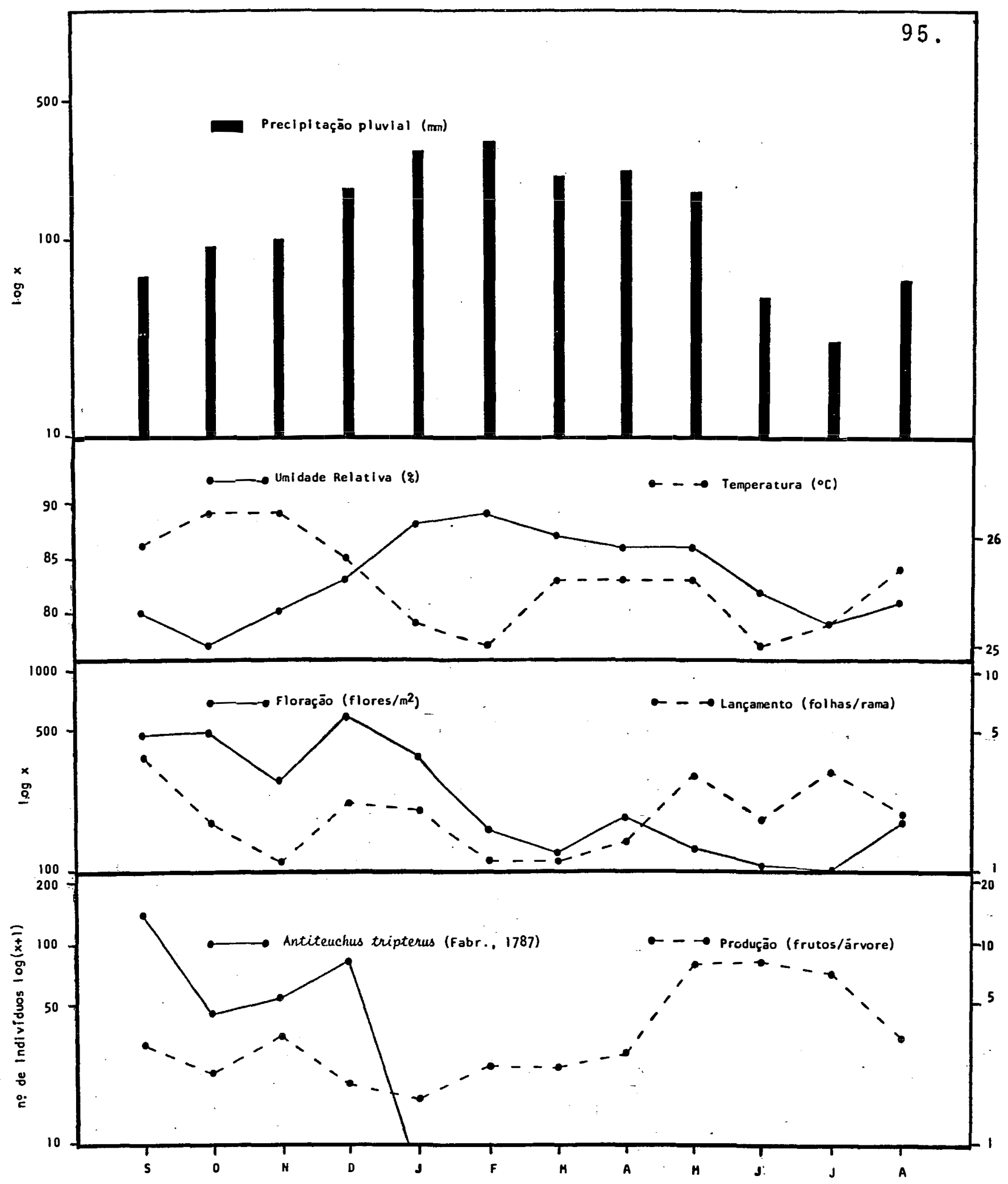

Figura 10. Flutuação populacional média de Antiteuchus tripterus (Fabr., 1787), correlacionada com dados climāticos e fenológicos doca caueiro. Altamira, Parā, Brasil (setembro de 1978 a agosto de 1981). 
Tabela 21. Valores do teste "F" e do coeficiente de determina ção $\left(R^{2}\right)$ das diferentes variáveis nas equações de regressão para explicação da variação populacional de Antiteuchus tripterus Fabr., 1787, na região de Altamira, Pará, Brasil (setembro de 1978 a agosto de 1981).

\begin{tabular}{lrl}
\hline Variáveis na regressão & $F$ & $R^{2}(\%)$ \\
\hline$x_{6}^{*}$ & $13,32^{*}$ & 57,13 \\
$x_{4}, x_{6}^{*}$ & $9,20^{*}$ & 67,16 \\
$x_{3}, x_{4}, x_{6}^{*}$ & $6,76^{*}$ & 71,74 \\
$x_{3}, x_{4}, x_{5}^{-}, x_{6}$ & $4,48^{*}$ & 71,92 \\
$x_{2}^{-}, x_{3}, x_{4}, x_{5}^{-}, x_{6}$ & 3,14 & 72,41 \\
$x_{1}, x_{2}, x_{3}, x_{4}, x_{5}^{-}, x_{6}$ & 2,38 & 74,07 \\
\hline
\end{tabular}

* Significativo ao nível de $5 \%$ de probabilidade

- Variável correlacionada negativamente com a população

Variāveis climáticas

$x_{1}$ - umidade relativa (\%)

$x_{2}$ - precipitação pluvial (mm)

$x_{3}$ - temperatura $(O C)$

Variāveis fenológicas

$x_{4}$ - lançamento (folhas/rama)

$x_{5}$ - produção (frutos/ārvore)

$x_{6}-$ floração (flores/m²) 
Antitypona snp., foram encontradas durante todo o ano, embora com populações muito baixas nos meses de setembro e janeiro. Apresentaram-se como dominantes, constantes e muito abundantes em todos os anos de amostragens. Os picos populacionais registraram-se nos meses de março, junho e outubro (Figura 11).

As populações destes insetos não mostraram cor relação significativa com a precipitação pluvial $\left(X_{2}\right)$, entretanto, através dos resultados da anālise de regressão apresen tados na Tabela 22, observa-se que a ação conjunta das variāveis precipitação pluvial $\left(\underline{X}_{2}\right)$, lançamento $\left(x_{4}\right)$ mostrou ser estatisticamente significativa e cuja equação de regressão E mostrada a seguir:

$$
P_{\left(x_{2}, x_{4}\right)}=56,69-0,12 x_{2}-11,78 x_{4}
$$

Clastoptera ochrospila Jacobi, não ocorreu nos meses de março, julho e agosto, estando presente em todos os demais. A população desta espécie apresentou dois picos popu lacionais bem definidos, sendo um em junho e outro em novembro (Figura 12). Estes dois meses representam respectivamente, o inīcio e 0 final do período seco na região de Altamira. 


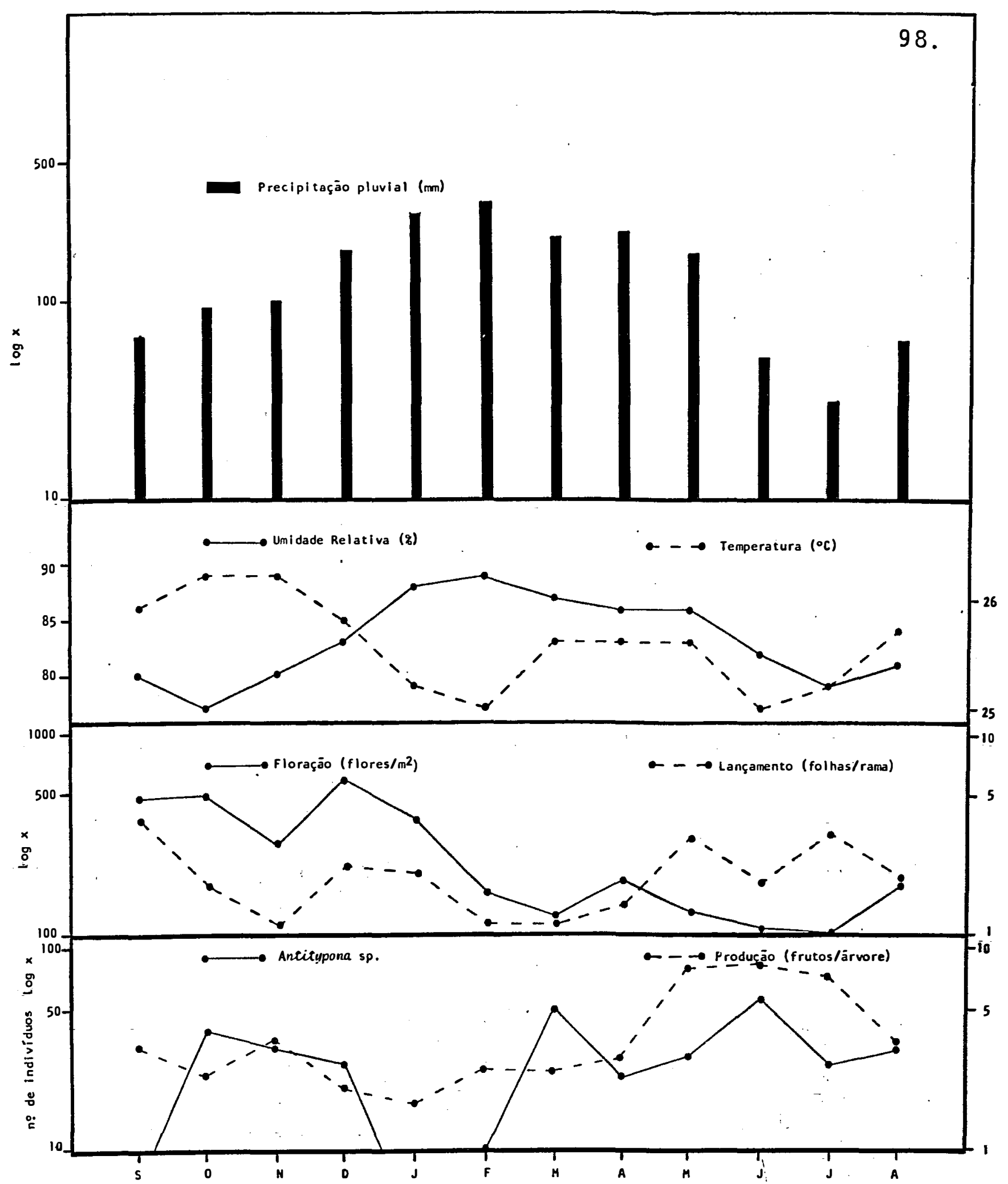

Figura 11. Flutuação populacional média de Antitypona spp. corre łacionada com dados climáticos efenológicos do cacaueiro. Altamira, $\mathrm{Pa}-$ rá, Brasil (setembro de 1978 a agosto de 1981). 
Tabela 22. Valores do teste "F" e do coeficiente de determina ção $\left(R^{2}\right)$ das diferentes variāveis nas equações de regressão para explicação da variação populacional de Antitypona spp., na região de Altamira, Pará, Brasil (setembro de 1978 a agosto de 1981).

\begin{tabular}{|c|c|c|}
\hline Variāveis na regressão & $F$ & $R^{2}(\%)$ \\
\hline$x_{2}^{-}$ & 2,10 & 17,37 \\
\hline$x \frac{*}{2}, x_{4}^{\star *}$ & $4,71 *$ & 51,15 \\
\hline$x_{2}^{-}, x_{4}^{\star}, x_{5}$ & $4 ; 86$ * & 64,58 \\
\hline$x_{2}^{-}, x_{4}^{\frac{*}{4}}, x_{5}, x_{6}$ & 3,48 & 66,56 \\
\hline$x_{1}, x_{2}^{-}, x_{4}^{\star}, x_{5}, x_{6}$ & 2,84 & 70,36 \\
\hline$x_{1}, x_{2}^{-}, x_{3}, x_{4}^{*}, x_{5}, x_{6}$ & 2,17 & 72,33 \\
\hline
\end{tabular}

* Significativo ao nível de $5 \%$ de probabilidade

- Variável correlacionada negativamente com a população

Variáveis climáticas

$x_{1}$ - umidade relativa (\%)

$x_{2}$ - precipitação pluvial (mm)

$x_{3}$ - temperatura (OC)

Variāveis fenológicas

$x_{4}$ - lançamento (folhas/rama)

$x_{5}$ - produção (frutos/ārvore)

$x_{6}-$ floração (flores/m²) 


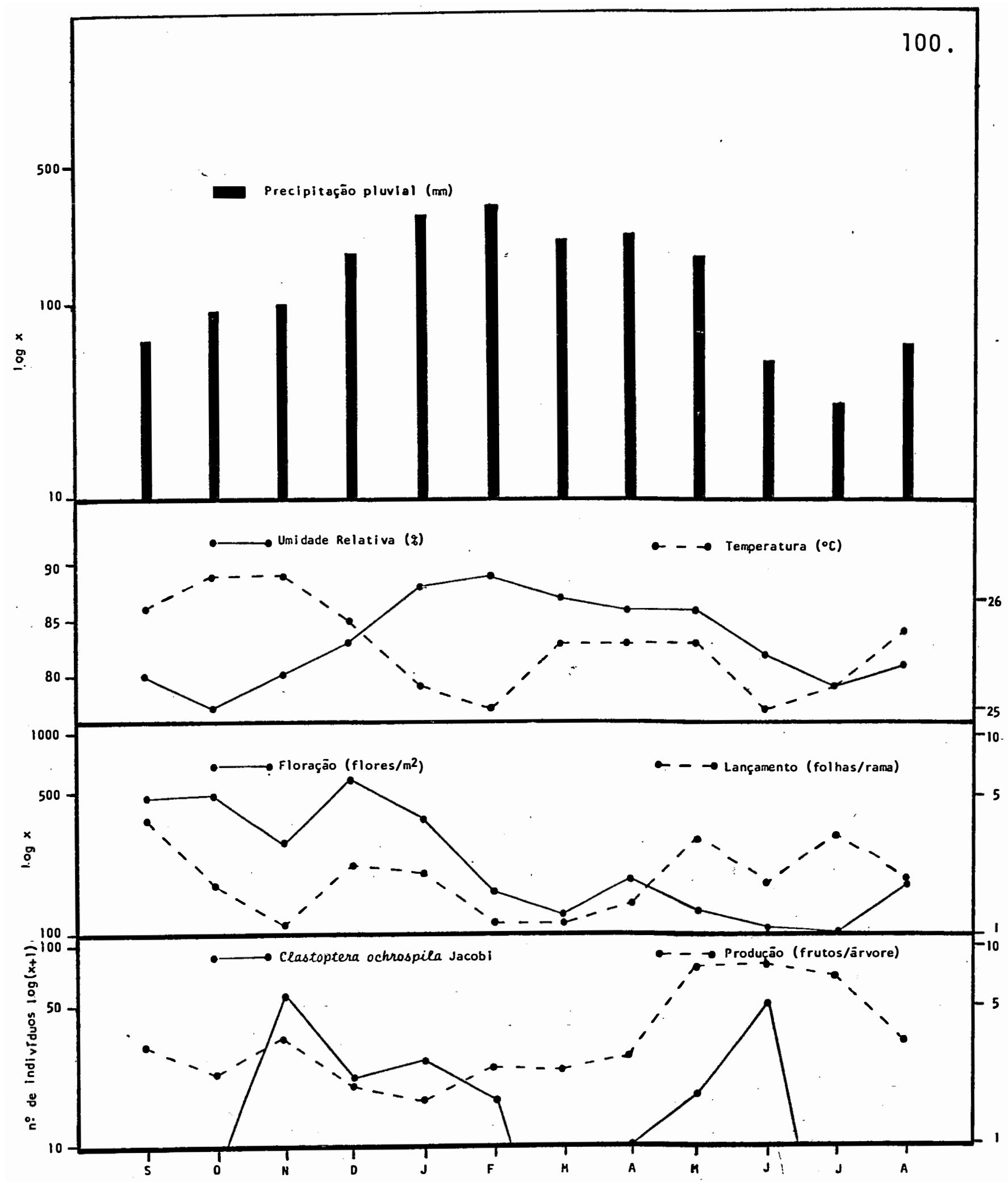

Figura 12. Flutuação populacional média de Clastoptera ochrospila Jacobi, correlacionada com dados climāticos e fenológicos do cacaueiro. Altamira, Parā, Brasil (setembro de 1978 a agosto de 1981). 
Os resuitados das anālises de regressão mūltipla mostraram haver significāncia para regressão, conforme pode-se observar na Tabela 23.

Entretanto, atravēs da Figura 12 , é possível verificar que os períodos de baixa densidade populacional coin cidem com o período de maiores umidade relativa e precipita ção pluvial.

Hylax sp., foi constante e dominante em todos os anos de amonstragens mostrando-se muito abundante somente no primeiro ano de amostragem (1978/79), enquanto que em 1979/80 e 1980/81 caracterizou-se como espécie comum

Apresentou grande densidade populacional no perīodo de janeiro a junho, com populações baixas nos demais meses e não ocorrendo em agosto e setembro.

Durante o período de ocorréncia, esta espécie registrou apenas um pico populacional em maio (Figura 13).

os resultados da anālise de regressão (Tabela 24) mostraram que as variáveis umidade relativa $\left(x_{1}\right)$, tempera tura $\left(x_{3}\right)$ e produção $\left(x_{5}\right)$ estão significativamente correlacio nadas com a flutuação populacional, cuja equação de regressão è a seguinte:

$$
P_{\left(x_{1}, x_{3}, x_{5}\right)}=-1233,07+4,92 x_{1}+32 x_{3}-6,05 x_{5}
$$


Tabela 23. Valores do teste "F" e do coeficiente de determina ção $\left(R^{2}\right)$ das diferentes variāveis nas equações dé regressão para explicação da variação populacional de Clastoptera ochrospila Jacobi, na região de Altamira, Pará, Brásil (setembro de 1978 a agosto de $1981)$.

\begin{tabular}{lll}
\hline Variāveis ria regressão & $F$ & $R^{2}(\%)$ \\
\hline$x_{4}^{-}$ & 0,88 & 8,10 \\
$x_{4}^{-}, x_{5}$ & 1,36 & 23,23 \\
$x_{4}^{*}, x_{5}^{*}, x_{6}^{*}$ & 3,32 & 55,46 \\
$x_{1}, x_{4}^{*}, x_{5}^{*}, x_{6}^{*}$ & 2,43 & 58,14 \\
$x_{1}, x_{2}^{-}, x_{4}^{*}, x_{5}, x_{6}$ & 1,83 & 60,44 \\
$x_{1}, x_{2}^{-}, x_{3}^{-}, x_{4}^{-}, x_{5}, x_{6}$ & 1,27 & 60,44 \\
\hline
\end{tabular}

* Significativo ao nivel de $5 \%$ de probabilidade

- Variável correlacionada negativamente com a população

Variáveis climáticas

$x_{1}$ - umidade relativa $(\%)$

$x_{2}$ - precipitação pluvial (mm)

$x_{3}$ - temperatura $(O C)$

Variáveis fenológicas

$x_{4}$ - lançamento (folhas/rama)

$x_{5}$ - produção (frutos/rama)

$x_{6}$ - floração (flores/m²) 


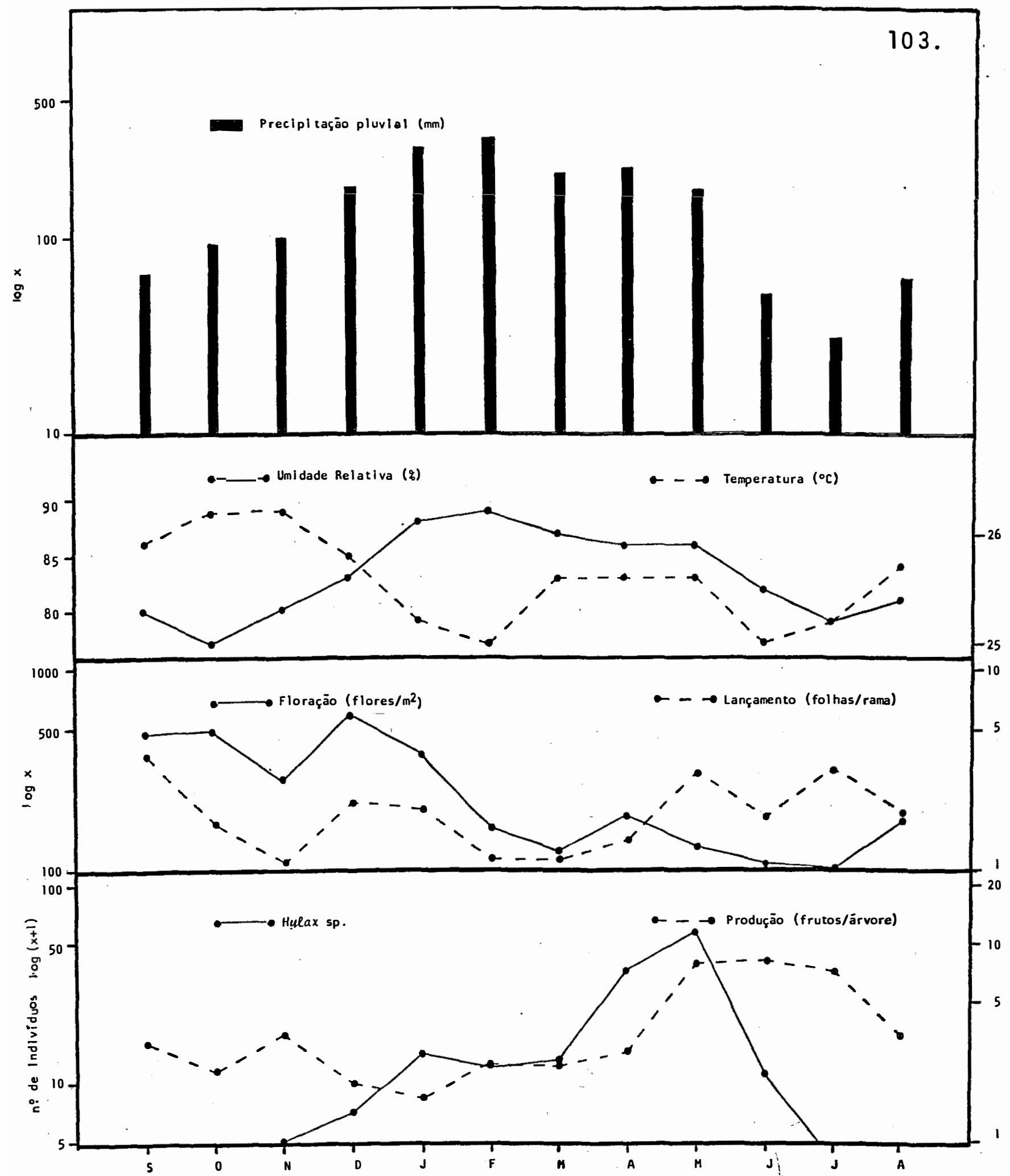

Figura 13. Flutuação populacional média de Hylax sp., correlacionada com dados climáticos e fenológicos do cacaueiro. Altamira, Pará, Brasil (setembro de 1978 a agosto de 1981) 
Tabela 24. Valores do teste "F" e do coeficiente de determina ção $\left(R^{2}\right)$ das diferentes variāveis nas equações de regressão para explicação da variação populacional de Hylax sp., na região de Altamira, Pará, Brasil (setembro de 1978 a agosto de 1981).

Variāveis na regressão

$\mathrm{F}$

$R^{2}(\%)$

\begin{tabular}{lll}
\hline$x_{1}$ & 4,08 & 28,99 \\
$x_{1}^{*}, x_{5}$ & 4,47 & 49,85 \\
$x_{1}^{*}, x_{3}^{*}, x_{5}^{*}$ & $9,51^{*}$ & 78,11 \\
$x_{1}, x_{2}, x_{3}^{*}, x_{5}^{*}$ & $8,49 *$ & 82,93 \\
$x_{1}, x_{2}, x_{3}^{*}, x_{4}, x_{5}^{*}$ & $6,64 *$ & 84,70 \\
$x_{1}, x_{2}, x_{3}^{*}, x_{4}, x_{5}^{*}, x_{6}^{-}$ & 4,92 & 85,53 \\
\hline
\end{tabular}

* Significativo ao nível de $5 \%$ de probabilidade

- Variável correlacionada negativamente com a população

Variāveis climāticas

$x_{1}$ - umidade relativa $(\%)$

$x_{2}$ - precipitação pluvial (mm)

$x_{3}$ - temperatura (OC)

Variāveis fenológicas

$x_{4}$ - lançamento (folhas/rama)

$x_{5}$ - produção (frutos/ārvore)

$x_{6}-$ floração (flores $\left./ m^{2}\right)$ 
Platycarenus umbractulatus, caracterizou-se co mo espécie constante, dominante, dispersa no primeiro ano de amostragem e comum nos demais.

De ocorréncia em todos os meses do ano, esta espécie apresentou um pico populacional bem definido, registrado no més de junho, conforme pode ser observado na Figura 14.

Embora não tenha apresentado correlação significativa com qualquer dos fatores meteorológicos e fenológicos estudados (Tabela 25), a população desta espécie mostra a maior densidade populacional na época de maior produção do cacaueiro e de baixas precipitação pluvial e umidade relativa (Figura 14).

Compsus sp., presente em todos os meses do ano, não possui um pico populacional bem definido, mas sim uma fai xa correspondente aos meses de fevereiro a junho, onde se con centra quase que a totalidade da população destes insetos. (Figura 15). E considerada espécie constante e dominante em todos os anos de amostragens, surgindo contudo, como dispersa em 1978/79 e comum nos demais anos.

A população desta espécie está bastante correlacionada com a floração do cacaueiro, conforme mostram os resultados da anālise de regressão mūltipla (Tabela 26) que definem a referida variável como a de maior coeficiente de ex 


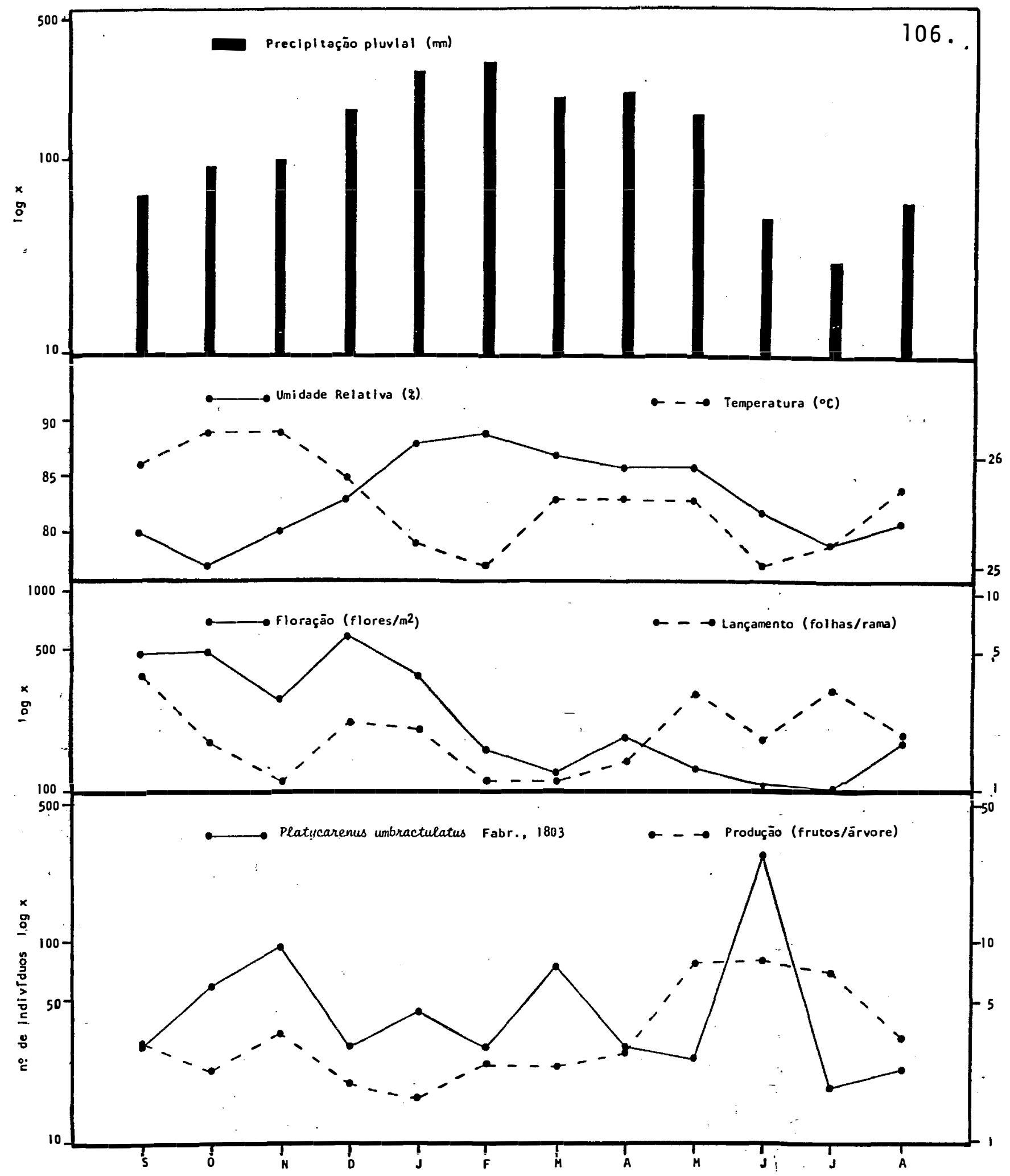

Figura 14. Flutuação populacional mēdia de Platycarenus umbractulatus Fabr., 1803, correlacionada com dados climāticos e fenológicos do cacau eiro. Altamira, Parā, Brasil (setembro de 1978 a agosto de 1981). 
Tabela 25. Valores do teste "F" e do coeficiente de determina ção $\left(R^{2}\right)$ das diferentes variáveis nas equações de regressão para explicação da variação populacional de Platycarenus umbractulatus Fabr., 1803, na região de Altamira, Pară, Brasil (setembro de 1978 a agosto de 1981).

Variāveis na regressão

F $\quad R^{2}(\%)$

\begin{tabular}{lll}
$x_{5}$ & 2,50 & 20,00 \\
$x_{4}^{-}, x_{5}^{*}$ & 3,51 & 43,87 \\
$x_{4}^{\frac{*}{4}}, x_{5}, x_{6}$ & 3,83 & 59,02 \\
$x_{3}^{-}, x_{4}^{*}, x_{5}^{*}, x_{6}$ & 2,98 & 63,03 \\
$x_{2}^{-}, x_{3}^{-}, x_{4}^{*}, x_{5}, x_{6}$ & 3,13 & 72,33 \\
$x_{1}, x_{2}^{-}, x_{3}^{-}, x_{4}^{*}, x_{5}, x_{6}^{*}$ & 3,61 & 81,26 \\
\hline
\end{tabular}

* Significativo ao nivel de $5 \%$ de probabilidade

- Variável correlacionada negativamente com a população

Variāveis climáticas

$x_{1}$ - umidade relativa (\%)

$x_{2}$ - precipitação pluvial $(\mathrm{mm})$

$x_{3}$ - temperatura (OC)

Variáveis fenológicas

$x_{4}$ - lançamento (fol has/rama)

$x_{5}$ - produção (frutos/ārvore)

$x_{6}$ - floração (flores $/ m^{2}$ ) 


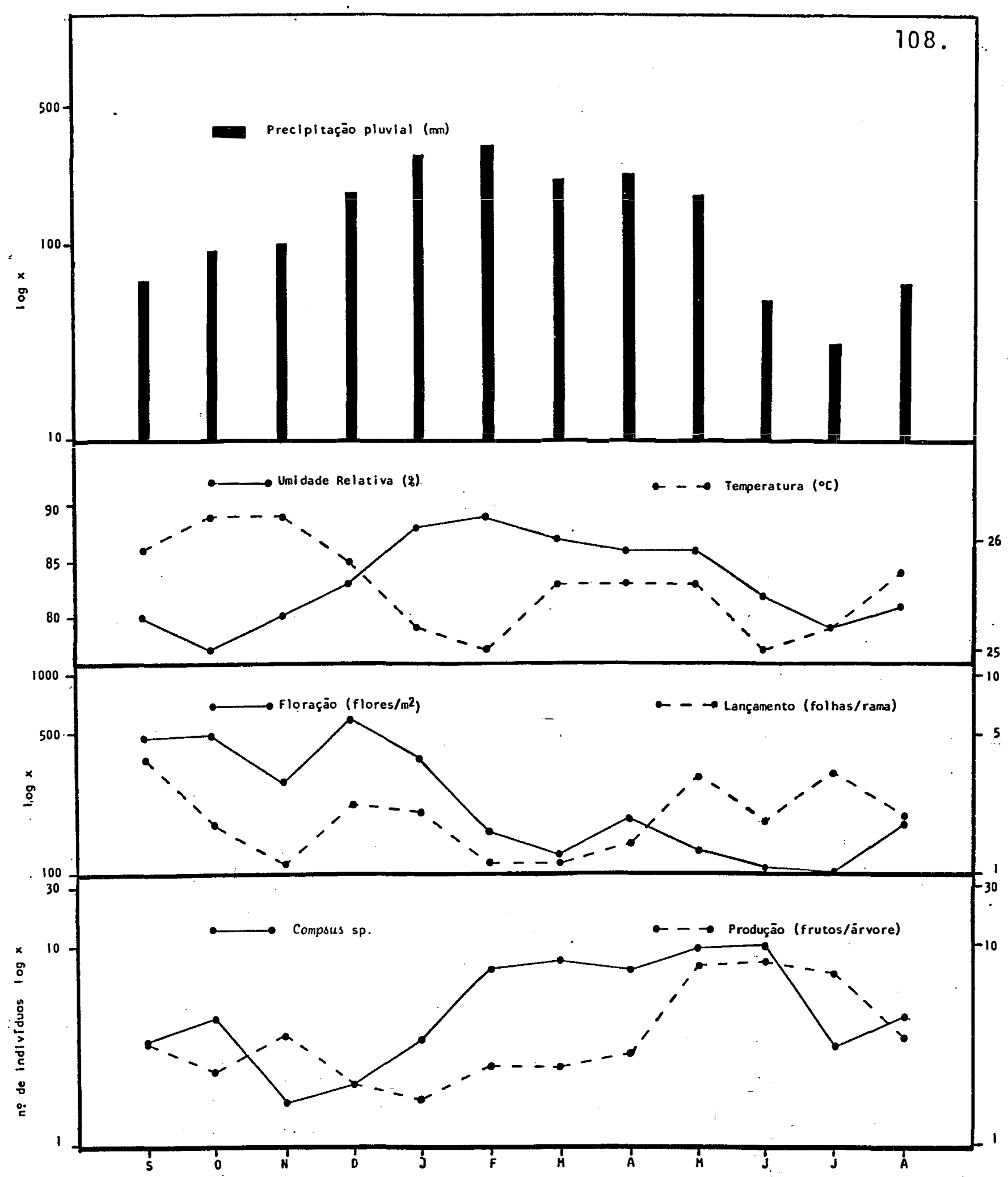

Figura 15. Flutuação populacional média de Compsus sp., correlacionada com dados climáticos e fenológicos do cacaueiro. Altamira, Pará Brasil (setembro de 1978 a agosto de 1981). 
Tabela 26. Valores do teste "F" e do coeficiente de determina ção $\left(R^{2}\right)$ das diferentes variāveis nas equações dé regressão para explicação da variação populacional de Compsus sp., na região de Altamira, Parā, Bra sil (setembro de 1978 a agosto de 1981).

\begin{tabular}{lll}
\hline Variāveis na regressão & $F$ & $R^{2}(\%)$ \\
\hline$x_{6}^{\frac{*}{6}}$ & $7,19 *$ & 41,85 \\
$x_{1}, x_{6}^{-}$ & $4,69 *$ & 51,04 \\
$x_{1}, x_{5}, x_{6}^{-}$ & 3,94 & 59,68 \\
$x_{1}, x_{4}^{-}, x_{5}, x_{6}^{-}$ & 3,00 & 63,21 \\
$x_{1}, x_{3}, x_{4}^{-}, x_{5}, x_{6}^{-}$ & 2,12 & 53,95 \\
$x_{1}, x_{2}^{-}, x_{3}, x_{4}^{-}, x_{5}, x_{6}^{-}$ & 1,49 & 64,13 \\
\hline
\end{tabular}

* Significativo ao nível de $5 \%$ de probabilidade

- Variável correlacionada negativamente com a população

Variāveis climáticas

$x_{1}$ - umidade relativa (\%)

$x_{2}$ - precipitação pluvial (mm)

$x_{3}$ - temperatura $(O C)$

Variáveis fenológicas

$x_{4}$ - lançamento (folhas/rama)

$x_{5}$ - produção (frutos/árvore)

$x_{6}$ - floração (flores/m²) 
plicação do evento, e cuja representação matemātica ē dada por:

$$
P_{\left(x_{6}\right)}=7,41-0,01 x_{6}
$$

A Figura 15 evidencia que a maior densidade po pulacional destes insetos ocorre na época de maior umidade re lativa e baixa floração do cacaueiro.

Acinocoris lunaris, ocorreu em densidades populacionais relativamente baixas, sendo que em setembro e abril não foi constatada sua ocorrēncia. Considerada espécie constante e dominanté em cacaual, apresentou-se como especie dispersa em 1978/79 para caracterizar-se como comum nos anos de 1979/80 e 1980/81 (Figura 16).

Percebe-se pelos resultados da análise de regressão mūltipla (Tabela 27), que produção $\left(X_{5}\right)$ é a variāvel mais relacionada com a população desta espécie, contribuindo com uma porcentagem de explicação de $49,04 \%$, expressa pela seguinte equação de regressão:

$$
P_{\left(x_{5}\right)}=0,35+1,06 x_{5}
$$




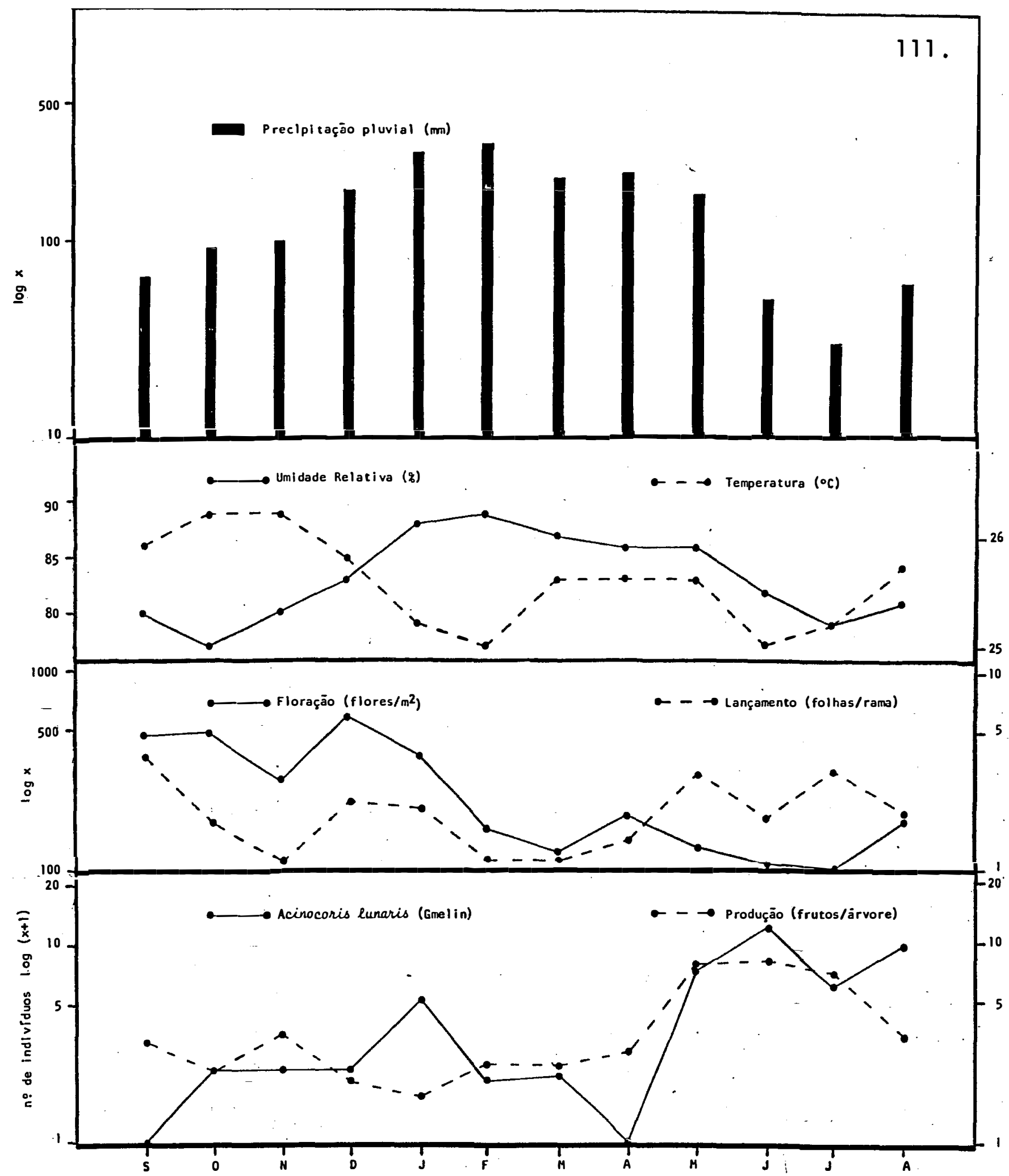

Figura 16. Flutuação populacional média de Acinocoris lunaris (Gmelin), cor relacionada com dados c] imáticos e fenológicos do cacaueiro. Al tamira, Pará, Brasil (setembro de 1978 a agosto de 1981). 
Tabela 27. Valores do teste "F" e do coeficiente de determina ção $\left(R^{2}\right)$ das diferentes variāveis nas equações dé regressão para explicação da variação populacional de Acinocoris lunaris (Gmelin), na região de Altamira, Pará, Brasil (setembro de 1978 a agosto de 1981).

\begin{tabular}{lll}
\hline Variāveis na regressão & $F$ & $R^{2}(\%)$ \\
\hline$x_{5}^{*}$ & $9,62 *$ & 49,04 \\
$x_{3}, x_{5}^{*}$ & $5,22^{*}$ & 53,73 \\
$x_{2}^{-}, x_{3}^{-}, x_{5}$ & 4,02 & 60,13 \\
$x_{2}^{-}, x_{3}^{-}, x_{4}^{-}, x_{5}$ & 3,06 & 63,66 \\
$x_{1}, x_{2}^{-}, x_{3}^{-}, x_{4}^{-}, x_{5}$ & 2,40 & 66,73 \\
$x_{1}, x_{2}^{-}, x_{3}^{-}, x_{4}^{-}, x_{5}, x_{6}$ & 2,09 & 71,53 \\
\hline
\end{tabular}

* Significativo ao nível de $5 \%$ de probabilidade

- Variável correlacionada negativamente com a população

Variāveis climáticas

$x_{1}$ - umidade relativa (\%)

$x_{2}$ - precipitação pluvial (mm)

$x_{3}$ - temperatura $(O C)$

Variāveis fenolōgicas

$x_{4}$ - lançamento (folhas/rama)

$x_{5}$ - produção (frutos/árvore)

$x_{6}$ - floração (flores/m²) 
Amastris elevata Funkhouser, ocorreu em baixas densidades populacionais e deixando de ocorrer nos meses de dezembro, fevereiro e junho. Nos meses de novembro, maio e julho foram registrados os picos populacionais desta espécie, sendo que o pico de maio pode ser considerado menor e in termediário aos outros dois (Figura 17).

Embora os resultados da anālise de regressão mūltipla (Tabela 28) não tenham mostrado nenhuma significān cia dos fatores meteorológicos e fenológicos, observa-se na Figura 17 que a época de menor densidade populacional deste inseto, ocorre no período de umidade relativa e precipitação altas.

Esta espécie caracteriza-se como dominante e constante em todos os anos, sendo porém, espécie comum nos dois primeiros anos de amonstragens (1978/79 e 1979/80) e rara em $1980 / 81$.

Epormenis unimaculata, mesmo ocorrendo em baixas densidades populacionais, mostrou-se presente em todos os meses do ano e apresentou apenas um pico populacional registrado no mès de janeiro (Figura 18).

Caracterizando-se como espécie constante e dominante na cultura do cacau, mostrou-se dispersa no periodo de 1989/79, comum em 1979/80 e novamente dispersa em 1980/ 81 . 


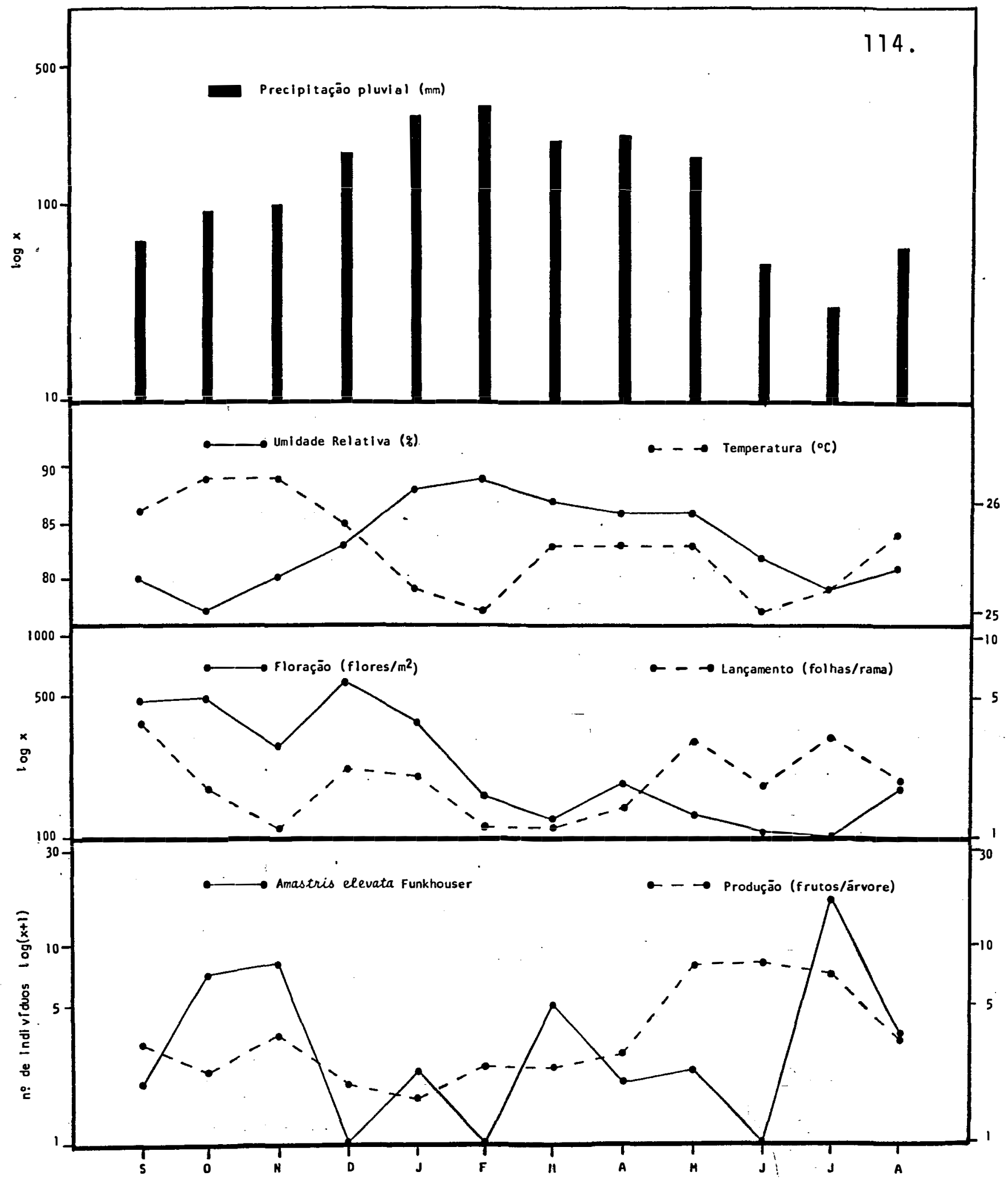

Figura 17. Flutuação populacional média de Amastris elevata Funkhouser, correlacionada com dados climáticos e fenológicos do cacaueiro. Altamira, Parā, Brasil (setembro de 1978 a agosto de 1981). 
Tabela 28. Valores do teste "F" e do coeficiente de determina ção $\left(R^{2}\right)$ das diferentes variāveis nas equações de regressão para explicação da variação populacional de Amastris elevata Funkhouser, na região de Altamira, Pará, Brasil. (setembro de 1978 a agosto de $1981)$.

\begin{tabular}{lll}
\hline Variāveis na regressão & $F$ & $R^{2}(\%)$ \\
\hline$x_{1}^{-}$ & 3,93 & 28,26 \\
$x_{1}^{-}, x_{6}^{-}$ & 3,60 & 44,47 \\
$x_{1}^{-}, x_{2}, x_{6}^{-}$ & 3,03 & 53,19 \\
$x_{1}^{*}, x_{2}, x_{4}, x_{\frac{6}{6}}^{*}$ & 2,80 & 61,56 \\
$x_{1}^{-}, x_{2}, x_{4}, x_{5}^{-}, x_{6}^{-}$ & 2,04 & 63,05 \\
$x_{1}^{-}, x_{2}, x_{3}, x_{4}, x_{5}^{-}, x_{6}^{-}$ & 1,47 & 63,96 \\
\hline
\end{tabular}

* Significativo ao nível de $5 \%$ de probabilidade

- Variável correlacionada negativamente com a população

Variāveis climáticas

$x_{1}$ - umidade relativa (\%)

$x_{2}$ - precipitação pluvial (mm)

$x_{3}$ - temperatura $(O C)$

Variáveis fenológicas

$x_{4}$ - lançamento (folhas/rama)

$x_{5}$ - produção (frutos / árvore)

$x_{6}$ - floração (flores/m²) 


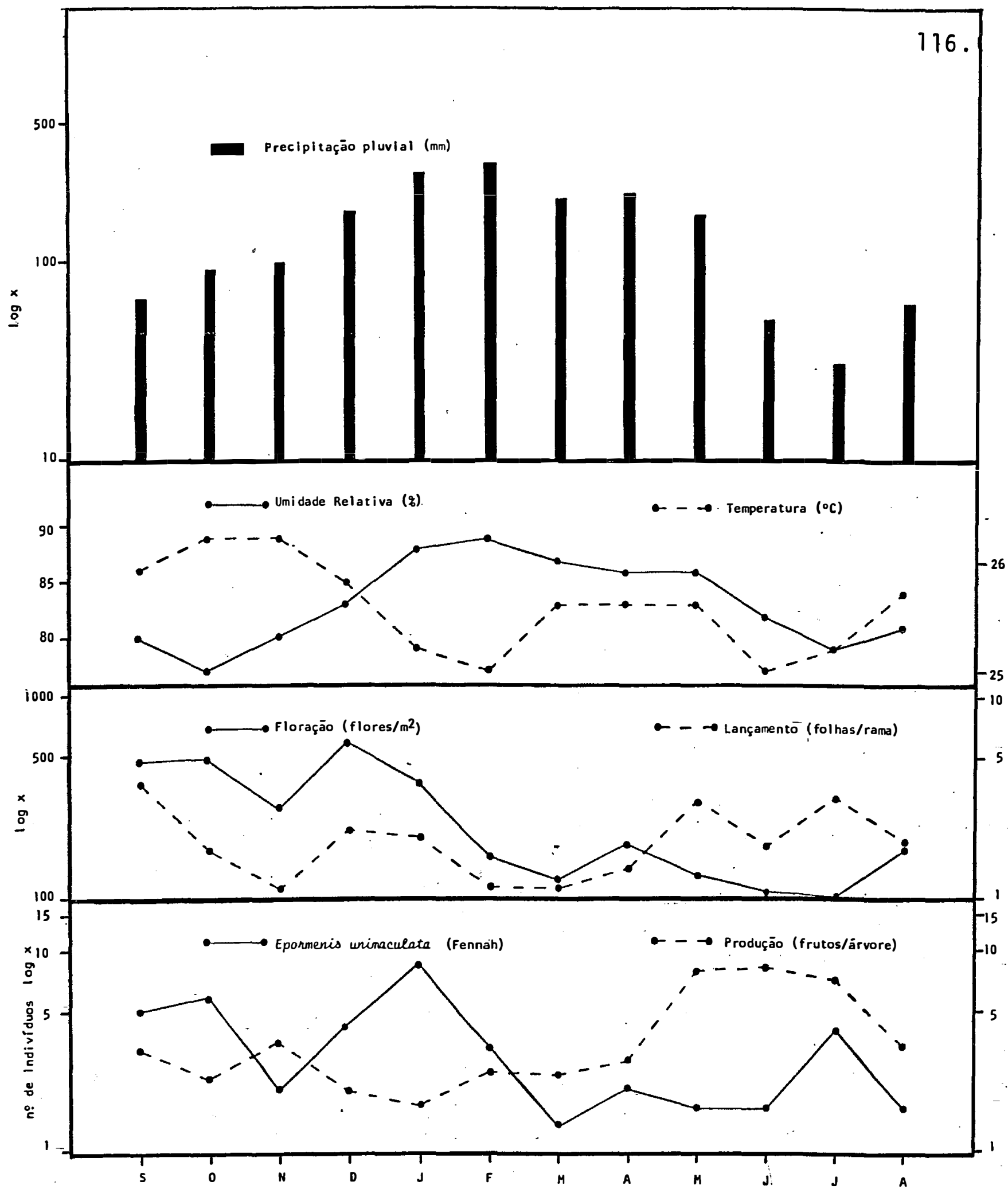

Figurā 18. Flutuação populacional média de Epormenis unimaculata (Fennah), correlacionada com dados climáticos e fenológicos do cacaueiro. Altamira, Pará, Brasil (setembro de 1978 a agosto de 1981). 
A variāvel floração $\left(x_{6}\right)$ do cacaueiro, foi entre todas a de maior influência na variação da população destes insetos, com uma porcentagem de explicação de $41,84 \%$ ( $T a-$ bela 29) e cúja equação de regressão é:

$$
P_{\left(x_{6}\right)}=0,22+0,01 x_{6} .
$$


Tabela 29. Valores do teste "F" e do coeficiente de determina ção $\left(R^{2}\right)$ das diferentes variāveis nas equações de regressão para explicação da variação populacional de Epormenis unimaculata (Fennah), na região de Al tamira, Pará, Brasil (setembro de 1978 a agosto de 1981 ).

\begin{tabular}{lll}
\hline Variáveis na regressão & $F$ & $R^{2}(\%)$ \\
\hline$X_{6}^{*}$ & $7,19 *$ & 41,84 \\
$X_{3}^{-}, x_{6}^{*}$ & $6,77^{*}$ & 60,11 \\
$X_{3}^{-}, x_{5}^{-}, x_{6}^{*}$ & $4,19 *$ & 61,12 \\
$X_{3}^{-}, x_{4}, x_{5}^{-}, x_{6}$ & 3,24 & 64,98 \\
$X_{1}^{-}, x_{3}^{-}, x_{4}, x_{5}^{-}, x_{6}$ & 2,46 & 67,30 \\
$X_{1}^{-}, x_{2}, x_{3}^{-}, x_{4}, x_{5}^{-}, x_{6}$ & 2,56 & 75,51 \\
\hline
\end{tabular}

* Significativo ao nível de $5 \%$ de probabilidade

- Variável correlacionada negativamente com a população

Variāveis climáticas

$x_{1}$ - umidade relativa (\%)

$x_{2}$ - precipitação pluvial (mm)

$x_{3}$ - temperatura (OC)

Variāveis fenológicas

$x_{4}$ - lançamento (folhas/rama)

$x_{5}$ - produção (frutos/árvore)

$x_{6}$ - floração (flores $/ \mathrm{m}^{2}$ ) 
119.

\section{CONCLUSOES}

Pelos resultados obtidos no presente trabalho, pode-se tirar as seguintes conclusões:

a - Das ordens estudadas, Coleoptera é predominante na cultura do cacau, tanto em nūmero de espécies como de indịĩduos.

b - Dentre as famīilas encontradas, as mais fre quientes em cacaueiros na região de Altamira são; Chrysomelidae, Curculionidae, Pentatomidae e Cerambycidae, em ordem de crescente de freqüēncia.

c - Com base nos îndices faunísticos-apresenta dos, verifica-se que as espécies predominantes em plantações de cacau na região de Altamira são: Colaspis sp., Noriaia sp., Eccoptopsis sp., Rhabdopterus sp., Antiteuchus tripterus (Fabr., 1787). Antitypona spp., Clastoptera ochrospila Jacobi, Hylax sp., Platycarenus umbractulatus Fabr., 1803, Compsus sp., 
Acinocoris lunaris (Gmelin), Amastris elevata Funkhouser e Epormenis unimaculata (Fennah).

$$
\text { d - A espécie colaspis sp. é entre todas, a }
$$

mais frequiente nos cacauais de Altamira.

$$
\text { e - Colaspis sp., Noriaia sp., Eccoptopsis sp. }
$$

e Rhabdopterus sp. são as espēcies mais frequientes na região de Altamira, cujos acmes populacionais ocorrem nos meses de maio, outubro, setembro e outubro, respectivamente.

$f$ - As populações das espécies predominantes em cacauais na região de Altamira, sofrem maior influēncia de fatores fenológicos do cacaueiro do que de fatores climáticos, como nos mostram as anālises de regressão, sendo as variáveis floração e produção as de maior destaque dentre os fatores fenológicos estudados. 


\section{LITERATURA CITADA}

ABREU, J.M., 1971. Fenologia de alguns coleópteros nocivos ao cacaueiro no Espírito Santo. Piracicaba. ESALQ/USP, 54 p. (Dissertação de Mestrado).

BIGGER, M., 1981. The relative abundance of the mealybug vectors (Hemiptera: Coccidae ard Pseudococcidae) of cocoa swollen shoot disease in Ghana. Bull. Ent. Res., London, 71: $435-448$.

BRINEAU de MIRE, 1970. Observations sur les' fluctuations saisonniēres d'une population de sahlbergella singularis au Cameroun. Café Cacao Thé, Nogent-Sur-Marne, 14(3): 202 208.

CALDEIRA, E.S. e J.T. VIEIRA, 1938. Primeiro catálogo dos in setos que vivem nas plantas do Estado do Pará. Diretoriage ral da Agricultura e Pecuária do Estado do Pará, Belém, 17 pāginas.

COMISSAOO EXECUTIVA DO PLANO DA LAYOURA CACAUEIRA - PROCACAU, 1978. O Brasil em primeiro lugar. Itabuna, Bahia, Brasil. $27 \mathrm{p}$. 
CONDURU, J.M.P., 1966. Culturas principais da Amazōnia. Servi ço de informação, agrīcola. Ministério da Agricultura, Rio de Janeiro, Brasil, pp. 13-14.

COSTA, A. da S., 1977. Principais pragas do cacaueiro no Esta do do Parā. Cacau Atualidades, Itabuna, 14(4): 13-22.

ENTWISTLE, P.E., 1964. Cocoa mirids in Nigeria: a riview of present know-ledge. In: Procedings of Cacao Mirid Control Conference, Tafo, Ghana, $6^{\text {th }}$ and $7^{\text {th }}$ August, 1963. pp. 5561.

FALESI, I.C., 1972. Solos da Rodovia Transamazōnica. Belém, Pará, Brasil. IPEAN. Boletim Técnico nọ 55, 196 p.

GARCIA, J.J. da S. e S. SILVEIRA NETO, 1980. Estudo faunistico de Coleópteros e Hemípteros associados ao cacaueiro no Estado do Pará. Revista Theobroma, Itabuna, 10(1): 15-23.

GIBBS, D.G. e D. LESTON, 1970. Insect phenology in a forest cocoa farm locality in West Africa. J. Appl. Ecol., Oxford, 7: $519-548$.

GIBBS, D.G.; A.D. PICKETT e D. LESTON, 1968. Seasonal population changes in cocoa capsids (Hemiptera: Miridae) in Ghana. Bull. Ent. Res., London, 58(2): 279-293.

LAROCA, S. O.H.H. MIELKE, 1975. Ensaios sobre ecologia de comunidade em Sphingidae na Serra do Mar, Paraná, Brasil (Lepidoptera). Rev. Bras. Biol., Rio de Janeiro, 35(1): 119. 
LAVABRE, E.M.; J. DECELLE e P. DEBORD, 1962. Recherches sur les variations des populations de mirids (capsides) en Cōte D'Ivoire. Café Cacao Thēe, Nogent-Sur-Marne, $\underline{6}(4): 287$ -295 .

LAVABRE, E.M.; J. DECELLE e P. DEBORD, 1963. Etude de l'évolu tion régionale et saisonniēre des populations de mirides (capside) en Cōte D'Ivoire. Café Cacao Thé, Nogente - SurMarne, $\underline{7}(3)$ : 267-289.

LESTON, D., 1970. Entomology of the cocoa farm. Annual Review of Entomology, Palo Alto, 15: 273-294.

LESTON, D. e D.G. GIBBS, 1969. Phenology of cocoa and some associated insects in ghana. In: Documentos apresentados na III Conferência Internacional de Pesquisas en Cacau, Accra, Ghana, 23-29 novembro. (mimeografado).

MARGALEF, R., 1951. Diversidade de espécies en 1 as comunidades naturales. Publnes. Inst. Biol. apl., Barcelona, 6: 59-72.

MENDES, A.C. de B., 1979. Ocorrēncia de Clastoptera sp. em cacaueiros na Amazónia Brasileira. Anais da Sociedade Entomológica do Brasil, Jaboticabal, $\underline{8}(2): 367-368$.

MENDES, A.C. de B. e. A.F. da S. ROSARIO, 1980. Levantamento faunistico de coleópteros, hemīpteros e homópteros associa dos ao cacaueiro nos polos de Rondonia e Amazonas. In: VI Congresso Brasileiro de Entomologia. Campinas, Fevereiro, 1980 .

MENDES, A.C. de B. e J.J. da S. GARCIA, 1981. Flutuações popuilacio= na is de coleópteros nocivos ao cacaueiro em Rondōnia e suas correlações com fatores fenológicos e meteorológicos. In: VII Congresso Brasị leirode Entomologia. Fortaleza, julho de 1981. 
MENDES, A.C. de B.; J.J. da S. GARCIA e A.F. da S. ROSARIO, 1979. Insetos nocivos ao cacaueiro na Amazónia Brasileira. Comuniciado Técnico Especial no 1, CEPLAC/DEPEA, Belém, 34 páginas.

MORALES, M.E.; A.A. MATARRITA; P.O. VARGAS; M.I. SOLIS; M.R. MURILLO e P.R. VAN-DYCK, 1963. Flutuaciones de algunas poblaciones insectiles del cacao en el Atlantico. Ministério de Agricultura y Ganadeira. Boletim Técnico, Costa Ri$\mathrm{ca}, \underline{\mathrm{n} 9} 45,19 \mathrm{p}$.

NASCIMENTO, J.C.; A. MOREIRA FILHO; A.M. de GOMES e M.R. de A. JUNQUEIRA, 1975. Situação atual do cultivo do cacau no Amazonas. Cacau Atualidades. Itabuna, 12(4): 103-116.

OWOSU-MANU, E., 1977. Distribution and abundance of the cocoa shield bug, Bathycoelia thalassina (Hemiptera: Pentatomi dae) in Ghana. J.Appl. Ecol., Oxford, 14: 331-341.

PEREIRA, F.B. e J. de S. RODRIGUES, 1971. Possibilidades Agro climáticas do Municīpio de Altamira (Pará). Belém, Pará, Brasil. Escola de Agronomia da Amazōnia. Boletim no 1, 48 pāginas.

REYNE, A., 1921. De Cacaothrips (Heliothrips rubrocinctus Giard). Department Van Den Landbouw in Suriname. Bull. ng 44, $214 \mathrm{p}$.

R00M, P.M., 1975. Relative distributions of ant species in cocoa plantations in Papua New Guines. J. Appl. Ecol., 0xford, $12(1): 47-61$. 
ROOM, P.M. e E.S.C. SMITH, 1975. Relative abundance and distribution of insect pests, ants and other components of the cocoa ecosystem in Papua New Guinea. J. Appl. Ecol., $0 x$ ford, 12(1): $31-46$.

SEFER, E., 1961. Catālogo dos insetos que atacam as plantas cultivadas na Amazónia. Boletim Técnico do Instituto Agronōmico do Norte. Belém, 43: 23-53.

SILVA, P. e A. da S. COSTA, 1973. Nova praga do cacaueiro no Brasil. Revista Theobroma, Itabuna, $\underline{3}(i): 42-43$.

SILVA, P.; J.A. VENTOCILLA; G.E. SMITH e J.M. de ABREU, 1969. Estudos recentes sobre a entomologia do cacaueiro na Bahia e Espîrito Santo. In: memórias da Segunda Conferēncia Internacional de Pesquisas em Cacau, 19 a 26 de Novembro de 1967, Salvador/Itabuna, Bahia, Brasil. pp. 253-258.

SILVEIRA NETO, S.; 0. NAKANO; D. BARBIN e N.A. VILLA NOVA, 1976. Manual de Ecologia dos Insetos. São Paulo, Editora $\underline{A}$ gronōmica Ceres. $419 \mathrm{p}$.

SMITH, F.G.E., 1973. Dināmica populacional do Sêlenothrips rubrocinctus (Giard, 1901) (Thysanoptera: Thripidae), na Região Cacaueira do Espírito Santo, Brasil. Piracicaba, ESALQ/USP, 65 p. (Dissertação de Mestrado).

SORIA, V.S. de J. e P.F.N., CRUZ, 1977. Relatōrio técnico de visita à região Amazōnica. CEPLAC/CEPEC, Itabuna. 6 p. (não publicado).

SOUTHWOOD, T.R.E., 1971. Ecological Methods. Chapman and Hall Ltda., $391 \mathrm{p}$. 
URICH, W.F., 1911. The cacao Thrips (Heliothrips rubrocinctus Giard). Board of Agr. Trinidad, 12: 3-10.

VENTOCILLA, J.A., 1967. Flutuação da população de insetos em cacauais do CEPEC (Luz negra). In: Informe Técnico 1967, CEPEC-CEPLAC, Itabuna, Bahia. pp. 60-61.

VENTOCILLA, J.A., 1970. Flutuação de população de insetos em cacauais do CEPEC (Luz negra). In: Informe Técnico 1969. CEPEC CEPLAC, Itabuna, Bahia. 208 p.

VENTOCILLA, J.A., 1975. Relatōrio de viagem ao Territōrio Federal de Rondónia - Núcleo Colonial do INCRA. Dizol, CEPEC, Itabuna, 3 p. (não publicado).

VILLACORTA, A., 1977. Fluctuacion Anual de:la Poblaciones de Monalonion annulipes Sig. y su relacion com la "li.uerte Descendente de Theobroma cacao" em Costa Rica. Anais da Sociedade Entomológica do Brasil, 6(2): 215-223.

WILLIAMS, G., 1954. Field observations on the cacao mirids Sahlbergella singularis Hagl. and Distantiella theobromae (Dist.), in the Gold Coast. Part III: Population Fluctua tions. Bull. Ent. Res., London, 45: 723-744. 